Working Papers in Linguistics

No. 28

\title{
COMMON DISCOURSE PARTICLES IN ENGLISH CONVERSATION
}

\author{
By \\ Lawrence C. Schourup
}

May 1983

The Ohio State University

DEPARTMENT OF LINGUISTICS 
Copyright by

Lawrence Clifford Schourup

1982 


\section{COMMON DISCOURSE PARTICLES IN ENGLISH CONVERSATION}

\section{DISSERTATION}

\section{Presented in Partial Fulfillment of the Requirements for the Degree Doctor of Philosophy in the Graduate School of The Ohio State University}

By

Lawrence Clifford Schourup, B.A., M.A.

$$
* * * *
$$

The Ohio State University

1982

Reading Committee:

Approved by

Robert A. Fox

Michael L. Geis

Brian D. Joseph

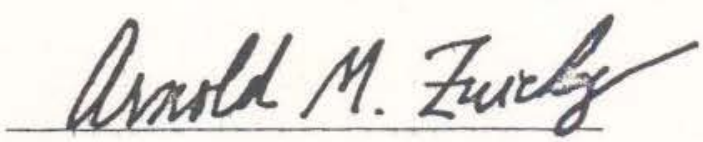

Arnold M. Zwicky

Adviser

Department of Linguistics 


\section{ACKNOWLEDGMENTS}

I am first deeply grateful to my academic adviser, Arnold Zwicky. His penetrating comments at every stage of this research have caused me to think more deeply about many of the topics discussed here and, more than once, to broaden my perspective. I have benefited greatly from his friendship, and from the encouragement I have found in his scholarly example.

My sincere thanks to Robert Fox, Michael Geis, and Brian Joseph for reading this dissertation and making many valuable suggestions.

Several people have helped by discussing specific issues with me; thanks particularly to William Boslego, Douglas Fuller, Richard Garner, Carol Jean Godby, John Nerbonne, Deborah Schaffer, and Rachel Schaffer. Thanks also to Joseph Pettigrew for responding to early sketches, and to the numerous people who provided examples and references.

I would like to thank Francisco Varela of Naropa Institute for first pointing out to me the great inherent fascination of conversation studies.

Several other people, through their patient friendship, have also supported this work. Special thanks to Deborah Andersen, Chester Drake, Carolyn Kurtz, Jacquelyn McKee, Karen Shockey, Helen Thiry, Jeffrey Thomas, and Richard Weiner; and to Marlene Payha, Linguistics Department Secretary, for her seemingly inexhaustible helpfulness and good cheer.

My personal debt to Stephen D. Miller is very great; no one could be a righter, truer friend.

Last--far from least--I thank my father, William Schourup, for his love and trust. 
TABLE OF CONTINTS

ACKNOWLEDGMENTS . . . . . . . . . . . . . . . .

LIST OF TABLES . . . . . . . . . . . . . . . . . . . .

LIST OF SYMBOLS . . . . . . . . . . . . . . . . v1 v

Chapter

1 INTRODUCTION . . . . . . . . . . . . . . . 1

1.1 General Remarks . . . . . . . . . . . 1

1.2 Covert Thinking in Convertiation..... . 3

1.3 Three 'Worlds' of the Speaker. . . . . 5

1.4 Rout inization . . . . . . . . . . 7

1.5 Use of Speech Materfals . . . . . . . 8

1.6 Outline of Remaining Chapters...... 10

Footnotes -- Chapter 1........ 11

2 EVINCIVES ..........

2.1 Interjections as Evincives ....... 13

2.2 Evincives in Quotations........ 16

2.2.1 Well and Oh in Quotations .... 16

2.3 Enquoting............. 21

2.4 Quotation............. . . . 22

2.5 Summary ............... . . . . 25

Footnotes -- Chapter 2........ 26

3 LIKE

3.1 Like in Conversation ........... 28

3.2 Like Introducing Direct Discourse..... 32

3.3 Like After Questions .......... 35

3.4 The 'For Example' Reading . . . . . . . . 36

3.5 Like as an Interjection ........ 39

3.6 It's Like............ . . . . 44

3.7 Conclusion ............. . . 45

Footnotes -- Chapter 3 ........ 47

4 WELL

4.1 Introduction ........... . . 48 
1.. W.1l B.forr. Fixclamations ......... . . . .

14.3 Woll Int roducing Direct Dilicourse ..... 5l

1.4 rople :ihlfeing........... 53

A.' W.ll Bofore Answers ............ 54

1.6 Weli Br.fore Questions ........... 55

4.l W.ll and Self-Repair ........... 56

1.8 W.1l and ot her-Repair ........... 59

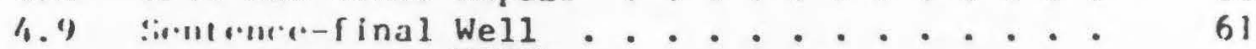

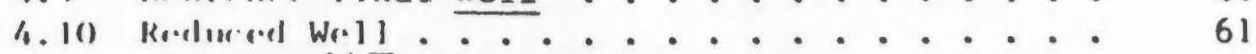

4.11 W.11 and Narrative Elision ......... 62

4.1\% We1! and 'Intension'........... 63

4.13 cimluston .............. 64

Fool noll:t -- Chapter 4.......... . 67

$5 \quad Y^{\prime} K N O W$

5.1 Prollminary Rernarks . . . . . . . . . 68

5.2 YK at: a Truth Parenthetical . . . . . . 69

5.2.1 YK and Propertes of Truth Paren-

thet leals ........... 70

5.3 kividence for TWe Types of YK . . . . . . 71

5.4 The Usc of YKb ............... 73

5.5 Goldberg's YK JII . . . . . . . . . . 76

5.6 Discourse Funclions of $\mathrm{YKb}$. . . . . . . . 77

5.6.1 Toplc Int roduction . . . . . . . 77

5.6.2 Toplc Tracking . . . . . . . . 80

5.6.3 YKb and Repalr ........... 86

5.7 YKb as a 'Sympathetic. Circularity Sequence' . 90

5.8 Interrogative $Y K$. . . . . . . . . . 92

5.9 YK and Turn Taking ............ 93

5.10 Distributional Properties of YK: Quantitative Results ............... 97

5.11 Conclusion ............... 98

Footnotes -- Chapter 5........ 10r,

6 THE ROLE OF DISCOURSE PARTICLES IN CONVERSATIO:

6.1 General Remarks on L1ke, Well, and Y'know . . 102

6.2 Now ............. 10

6.3 I Mean ............... 106

6.4 Mind You ................ 10:

$6.5 \frac{\text { Sort of }}{\text { And so on, kind of }}$. And everything. And stuff,

6.6 Interjections .............. ... 108

6.7 A Taxonomy .............. 10\%

6.8 Conclusion ................ 111

Footnotes -- Chapter 6......... 113

LIST OF REFERENCES ................. . . 11: 


\section{LIST OF TABLES}

Table

Page

1. Turn and Quote Initial Well and $\mathrm{Oh}$ in a Conversation of 336 Turns Including 62 Turn Internal

Quotations ............... 17

2. 111 Quote Initial Interjections in a Corpus of 328

Conversational Quotations .......... 17

3. Quote Allegiance of Well and $\underline{\mathrm{Oh}}$. . . . . . . . 24

4. Disclosure Relationships and Discourse Particles . . 110 


\section{LIST OF SYMBOLS}

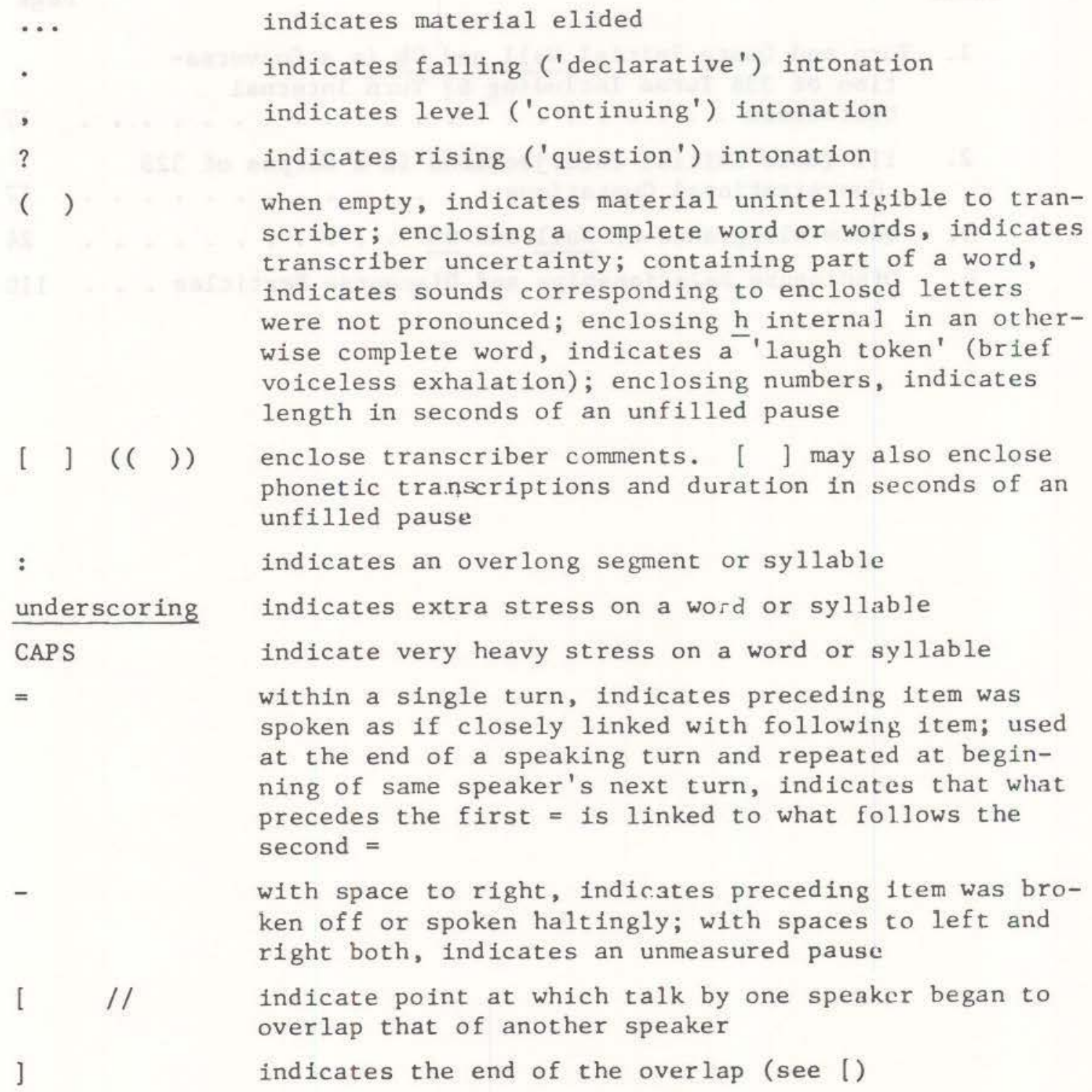


CHAPTER ONE

INTRODUCTION

\subsection{General Remarks}

This is a study of several common items in English conversation known variously as 'discourse particles', 'interjections', 'discourse' markers', and less respectfully as 'hesitations' or 'fillers'. Primary attention will be to analyses of like, well and $\mathrm{y}^{\prime} \mathrm{know}$, but the larger concern of this study is the entire set of items of which these are members, and some attention will therefore also be given to related items, including I mean, now, oh, hey and aha. The term discourse particles is used throughout the study to refer to the forms and short phrases under discussion. The term is intended as a neutral label for these items that avoids a priori judgments on their function or grammatical affiliations but does suggest that they are primarily discourse phenomena. The general program of the study is to examine several such particles in detail and propose a theoretical framework in which their uses individually make sense and in which revealing comparisons can be made between them. A correct understanding of these particles will be shown to considerably widen the usual purview of conversation studies.

The need for work on discourse particles is apparent on examining almost any transcript of ordinary English conversation. The repertoire of favored items may differ from speaker to speaker, but in general instances of like, well, y'know and similar items abound in conversation. Despite their great frequency of occurrence, however, unt 11 recently on1y crude attempts had been made to characterize the role of these 1 tems in conversation. By many researchers they were dismissed as meaningless and presumed to lack interesting distributional features; others offered tentative analyses applicable only to a narrow range of the items' occurrence; and in the popular view such items have tended to be stigmatized as verbal 'crutches' used by those deficient in speaking ability. Reviews of these early treatments are found in James (1974) and Goldberg (1980).

The former neglect of these items seems to have been largely due to the fact that their appearance is for the most part limited to conversation, a use of language itself neglected until fairly recently (despite widespread availability of tape recorders since the 1950's). But the difficulties discourse particles can present when examined by introspection have no doubt also been an obstacle to research. Questions to informants concerning the use or meaning of well, for example, are apt to provoke only puzzlement or a list of examples. It will be

$$
-1-
$$


suggested below that there may be a deeper reason for these introspective difficulties than the commonly noted tendency for such items to be spoken more or less unconsciously.

During the last decade, in which interest in the structure of conversation has increased enormously, the sheer frequency of these items in talk and the lack of an adequate account of their function have led to several serious investigations. All this recent work begins from the no longer disputed observation that such items differ from each other in distribution and use and so cannot be simply regarded as 'fillers'. The studies now available can be divided into two broad categories, according to the type of data used. Studies of the first type are based almost entirely on intuitive evidential statements (e.g. James 1972, 1973, 1974, 1978; R. Lakoff 1973; Hines 1977; Murray 1979). The most ambitious work of this kind is that of James, who has described the semantic and distributional properties of such items as oh, ah and say in some detail (referring to them as 'interjections'--the traditional categorization for forms resisting inclusion in the 'sentential' word classes). Another group of studies attempts to isolate the conventional functions of discourse particles by examining their use in tapes and transcripts of natural conversation. Important studies of this kind have been carried out by Crystal and Davy (1975), Goldberg (1980), Svartvik (1980) and Schiffrin (1981b). Each of the studies mentioned so far will be discussed in more detail in following chapters.

The present study will use both recorded conversations and introspective data in an attempt to identify a core use for several discourse particles. It will be shown that when the basic use of each item has been correctly isolated, an understanding of the variety of discourse functions that item is capable of serving proceeds directly from considering how its core use is interpretable in particular conversational contexts. In addition the general function of discourse particles will be characterized by showing how they constitute the range of conventionalized responses in English to what will be called the problem of disclosure. Briefly, the disclosure problem is that unexpressed thinking engaged in by conversants concurrent with their participation in a conversation may be relevant to the display of their overt behaviors. It is claimed below that each discourse particle considered mediates in a specific way between the covert thinking of conversants and what they do in the way of talk and other external behaviors.

Since in the position to be developed it will be crucial to have established that conversants do in fact engage in unexpressed thinking-and because most treatments of conversational behavior either conveniently ignore or specifically exclude what is unexpressed--1t will be of use here to briefly review the importance of the 'invisible' aspects of conversation. 


\subsection{Covert Thinking in Conversation}

As a rule, conversants don't say aloud everything that crosses their minds; they select some 'mental contents' as appropriate to verbalize and retain others as inappropriate; or thought may be temporarily 'shelved' and introduced later when--perhaps through deliberate attempts at redirecting the conversation--its verbalization becomes appropriate. It is unimportant to the real matter of this distinction between talk and covert thought whether what is deferred or left unexpressed is 'silent speech' or some form of nonlinguistic or quasilinguistic mental activity; in either case what gets spoken is only part of what comes to mind.

There are obviously aspects of conversational behavior that are nonspontaneous. The turn-taking system may be held partly accountable: well-behaved speakers aren't free to practice an absolute extemporaneity, speaking their minds when moved to. Frequently they bide their time, awaiting a proper moment to insert what they have to say. The numerous recent explorations of conversational structure by sociologists (Sacks, Schegloff, Jefferson, and others) have been helpful in establishing that speakers do not in general voice thoughts when they will, but judiciously retain, shape, reshape, or place them in ways that often display considerable gamesmanship. There is room within the tonus ${ }^{1}$ of a conversation for much private thought. We form overall judgments, plan provisional responses, rank and revise them, store questions, foresee the need for further conversations, and so on, and routinely do these things while someone else is talking, or while we ourselves hold the turn.

Speakers sometimes report thoughts as having occurred covertly during talk by introducing their subsequent verbalization of them with a prefix like those in (1): ${ }^{2}$

(1) I thought of this while you were/I was talking ...

I was going to say ...

Your mentioning cholera a moment ago reminded me ...

Naturally, speakers are free to think while holding the turn or while being addressed. It is not unacceptable, and is often expected, that we ponder what is said, and we may affect this by head scratching or chin pulling, as well as by the considered responsiveness of what we say. Private thought is only troublesome if it becomes preoccupation.

Items like What in the world! represent another way speakers naturalize covert thought into their speech, though here the subcurrent of thought is ostensibly verbalized as it occurs. The dual status of these utterances has been discussed by Goffman. Using them, the speaker "renders readily accessible to witnesses what he chooses to 
assign to his inward state" (Goffman 1978:794). Muttering is much the same (796).

There is of course also mental activity involved in the routine processing of speech. Beyond the basic cognitive processes involved in production and comprehension, we draw inferences, devise and notice implicatures, reconstruct the targets of speech errors, distinguish given and new, recover material elided in ritualized encounters, take note of lurking presuppositions, identify denigrations, and marshal various other monitorings and pragmatic operations the extent of which is apt to be grossly underestimated if we look only at solitary, unsituated sentences. While basic cognitive processing is automatic and unconscious, many aspects of linguistic processing can be consciously noted and verbalized or not, as the speaker chooses.

It is clear, then, that what we call speakers are also thinkers, with one foot in the collaborative world of talk, and the other in the internal world of their thoughts, which they may, or not, choose to display.

The inaccessibility of covert thinking to the researcher is what has sometimes been called the problem of 'intention', 'meaning', or 'motivation' (see Duncan and Fiske 1977:17). Conversation analysts are for the most part ${ }^{3}$ limited to working with what is said or done rather than what is thought, and to the extent that conversants themselves find each other's thoughts indiscernible, it has seemed both necessary and fair to researchers to restrict their attention to what is audibly and, if video equipment is used, visibly expressed. It nevertheless remains true that there is a covert subcurrent of thought 'beneath' the speech and other overt behavior of participants in a conversation, and that the course of their thoughts is not entirely identical to the course of their talk, let alone fully accessible to the most talented researcher.

The bias of researchers toward what is manifest is often simply adopted as a methodological principal (e.g. Duncan and Fiske 1977:17); or, as in the work of Sacks, Schegloff, and others, it may be taken to define the range of phenomena under investigation:

Our analysis has sought to explicate the ways in which the materials are produced by members in orderly ways that exhibit their orderliness, have their orderliness appreciated and used, and have that appreciated and displayed and treated as the basis for subsequent action (Schegloff and Sacks 1970:290).

Even in conversational analyses supposedly limited to 'observables', however, the researcher must often engage in guesswork. Studies of this kind are peppered with qualifiers necessary because what is displayed by conversants permits multiple interpretations all consistent with their talk. 
What is unmanifested is not entirely excludable from the analysis of conversation, then, but neither--practically speaking--can it be fully included. The middle ground, though an unsettled one, is to acknowledge the existence and importance of covert thinking to what is said and done by conversants, and also to acknowledge the difficulties in ascertaining the details of their covert mental activity. This tempered point of view seems to characterize much of the work of Garfinkel and Goffman (see, especially, Garfinkel 1972).

\subsection{Three 'Worlds' of the Speaker}

Though some conversation analysts may, for practical reasons, exclude covert thinking from consideration, speakers do not. To describe the position of the individual participant in a conversation, a tripartite model seems essential. The covert thinking of the speaker, what that speaker has presently in mind and may, or not, disclose, will be referred to below as the private world; what is on display as talk and other behavior on the part of conversants and is thus available to both the speaker and some other(s) will be called the shared world; and the covert thinking of other conversants, which is invisible to the speaker, will be called the other world. This terminology is applicable equally to any of the participants in a conversation, so that what is private world for one conversant may be be other world for some other conversant.

That conversants should be described as orlenting to the existence of these three different spheres of information is certainly not a revolutionary claim, though it seems that conversants are not often conceived of in this way and are more often simply viewed as the manufacturers of the talk which is taken, by the researcher, to be of prfmary interest. A notable exception to this latter tendency is $R$. Lakoff (1974), where we are reminded that language is not only used to present information about the 'real world', but also to encode 'internal' information. 4

There will be repeated occasion in later chapters to refer to the tripartite model of the speaker's world just proposed. The disclosure problem discussed above, which will be the basis for understanding items such a $11 \mathrm{ke}$, well, and $\mathrm{y}^{\prime}$ know, can be restated in the context of this model as follows:

The Disclosure Problem: Current undisclosed material in the private and other worlds may be relevant to what the speaker is now doing, or has just now done, or will just now be dolng, in the shared world.

In the discussion that follows it will be helpful to keep in mind that the 'contents' of the shared world differ in important respects from those of the two covert worlds. Material spoken into the shared world may be strategically placed there and is subject to what Sacks et al. have called recipient design: 
a multitude of respects in which the talk by a party is a conversation is constructed or designed in ways which display an orientation and sensitivity to the particular other(s) who are the co-participants (1974: 727).

Moreover, speakers are constrained by the sequential requirements of conversation. Answers, to take a well-worked example, are contingent upon questions; or, more precisely, what follows a question should be placed there with sensitivity to the conditioned relevance of an answer at that point (see Goffman 1976 for a fuller discussion). The recent literature on conversational repair also illustrates the strategic nature of some contributions of talk. Speakers regularly fail to initiate repair on another's repairable utterance until it becomes obvious that the repairable will not be self-corrected by its speaker (Schegloff et al., 1977). On other occasions participants choose not to initiate repair on some obviously repairable item (Shegloff et al. 1977:375 refer to these occasions as 'opportunities NOT TAKEN'), possibly because the repair, which would involve work by both parties, doesn't seem worth the trouble, or because repair might implicate disagreement. In these situations--delayed repair and intentional nonrepair--it appears that thinking is left temporarily unexpressed in the first case and altogether unexpressed in the second.

The shared world is in general one in which what is placed there is intendedly understandable by interlocutors based on their shared knowledge, including knowledge of what has earlier, and just, been said and done by them in the conversation.

In contrast--though here we have only difficult introspections to guide us--unexpressed thought seems not to respect sequential and politeness conventions governing talk by behaving conversants, and needn't be explicit, complete, or well-formed, since it is not designed or destined for presentation in the shared world. The situation in the covert worlds would appear to be altogether less inhibited than are external behaviors. 'Free' associations are certainly possible; thoughts may be tangential to the present conversation or even apparently unrelated to it. Talk and thought, though occurring in the same speaking situation, need not run parallel. It may even be inappropriate to speak of 'the course of thinking' as if it possessed a cohesiveness and structural integrity similar to what appears in speech. It would be preferable to use a very general term like 'state of consciousness' (Keller 1981) or 'Internal state' (R. Lakoff 1974) to refer to covert thinking rather than suggest, as in Goldberg (1976: 39) that covert thinking constitutes a separate unspoken conversation concurrent with what is actually said, or that what appears as talk $1 \mathrm{~s}$ simply a selection from such an internal conversation or monologue. 5 


\subsection{Routinization}

In the discussion of discourse particles, the question of rout1nization arises constantly. Many such items have come to be so closely associated with particular discourse situations that they may be considered conventional responses to these situations. For example, well, with low-rising intonation, is a conventional response to the situation in which one conversant awaits an overdue response from another. Well, used in this way, may therefore be considered a routine (see Coulmas 1980). Routines are "highly conventionalized prepatterned expressions [or single words] whose occurrence is tied to more or less standardized communication situations" (1bid., 3). The meaning of items of verbal routine is thought to differ from that of other nonroutine items in that the literal meaning may be outshown, overshadowed, or even altogether obscured by the conventional use of the item, or the conventional use may be taken to characterfze the 1 item to the total exclusion of any literal meaning. The routine goodbye, for example (see Clark and French 1981; cf. Laver 1981), occurs in a specifiable discourse situation (leave taking) and constitutes a conventionalized response to this situation, but if we ask the meaning of the item, informants balk. Either we must admit that the item has no particular meaning, or broaden the concept of meaning to include conventional uses, which is, in effect, what lexicographers do with items like this. Webster's Collegiate lists only the following brief definition for goodbye: "a concluding remark or gesture at parting".

Goodbye is a special example in two respects: it has a single predominant routine use, and it has no discernible literal meaning. Neither of these features can be extended to routines in general. often a single item has multiple uses, and often indeed a routine does have some specifiable literal meaning. The speaker who repeatedly issues the word right while listening to a complicated set of instructions may well have a literal meaning of the 1tem ('correct') in mind despite using the word as a point-granting routine. It is unlikely that such routines as how are you?, take care, and see you are entirely devoid of literal meaning. See you, like goodbye, is used for leave taking, but, consonant with its literal reading, is approprlate for temporary rather than permanent leave taking. How are you? even in its basically phatic use (cf. Malinowski 1946:248-251) can elicit a response relevant to its literal meaning.

It would be a mistake, though, to insist too strongly on the 11teral meaning of routines. It is perfectly possible that on specific occasions of utterance their literal meaning is more or less disregarded in favor of their routine function. The sometimes lax attention paid to literal meaning of routines is exemplified by the peculiar item I could care less (Tannen and Öztek 1981) which sometimes replaces I couldn't care less. Tannen and $\theta_{z}$ tek claim that the interchangeab1lity of these two items illustrates the purely conventional nature of the expressions and their loss of all contact with literal meaning. 
But the literal meaning is not really so far away. For one thing, less is a negative item which, under the less attentive conditions under which routines tend to be uttered, might itself be felt by the speaker to convey the missing sentential negation (note that comparatives in general seem to involve an internal negation; thus they occur with negative polarity items: less than anyone); for another thing, it is difficult to imagine this expression evolving at any future point into, for example I couldn't care more, I could say less, or I must care less; notice also that the occurrence of this item in constructions like I could care less about your old shoe speaks quite strongly in favor of the item's retention of literal meaning.

In the discussion of like, well and $y^{\prime}$ know in the following chapters, it will be necessary to keep in mind both the likelihood of their routinization with different functions and the compatability of this routinization with each item's having a basic or core use which remains constant though all the routine functions of the item. The watchword 'routine' should not be taken as a license to forget the basic linguistic value, if any, of an item, although this value, if there is one, might be less than fully present in the mind of the speaker on a given occasion of utterance. This notion seems to be implicit in the following claim by Coulmas:

Every normal member of a speech community can distinguish routine utterances from idiosyncratic ones. Furthermore, he knows that routine usage affects the meaningfulness of expressions, and he knows whether or not an utterance is to be assigned the full force of 1 ts 1iteral meaning (1981:16; emphasis mine).

As Coulmas notes, the degree of meaningfulness of an item may depend to an extent on its frequency of occurrence. The more an item is used routinely, the more it is apt to lose contact with its literal meaning, an idea commemorated in the phrase 'crying wolf'. In the case of the discourse particles under study here, the question is more appropriately formulated as one of use rather than meaning, but the general point still holds. The position taken in the present study is that the basic use of each discourse particle discussed can be dominated by its specific routine functions, but is never completely obliterated, remains available to scrutiny, and, most importantly, defines the possibilities for the multiple routine uses of the item. This position is first developed and exemplified in Chapter 3 with the 1tem like.

\subsection{Use of Speech Materials}

Several types of data were used for this study. Materials designated RTS below are from tape recordings of radio talk show conversations. Callers engage the show's host in a brief discussion related to the chosen topic for that evening, or the host engages a celebrity

'guest caller' in conversation. Two important features of these 
materials are that kinesis plays no role since the callers and the host cannot see each other, and that the recordings themselves are free of any possible investigative bias because there is no personal contact between the investigator and either callers or host. 6

Materials designated LAB consist of three extended dyadic faceto-face conversations between friends ( 3 pairs, 6 speakers total). Pairs of friends were chosen to create as relaxed a situation as possible. The subjects were seated in comfortable chairs a few feet apart and were allowed to talk about whatever they wished. Neither the tape recorder nor the researcher were present in the room where the conversations took place, though microphones were present and visible. Judging by the intimate nature of some of the topics discussed, the LAB conversants were probably not much intimidated by the recording situation.7 All six speakers were undergraduate student volunteers; all were native residents of central Ohio. The only selection criterion was the pre-existing friendship of the members of each pair.

In some cases below part of an analysis will be based on intuitive judgments of acceptability, but because of the well-know problems in interpreting such data, wherever feasible important points are illustrated with several observed examples; in some cases, statistical evaluations of distribution are also presented.

Examples cited in the text appear in different 'reader's' transcription systems, according to the source of the data. Examples cited from published work by other researchers (with one exception noted in Chapter 4) appear in the transcription system used in the quoted source. Examples drawn from RTS and LAB matericls appear in a reader's notation similar to that used in Schenkein (1978), but with a few modifications. Symbols appearing in cited examples are explained in the List of Symbols. Reader's transcription is intended to make a conversation readily accessible to the reader's eye. No attempt is made to render fine phonetic detail or to specify the relative timing of items with great accuracy. 8 Such transcript notations naturally embody numerous claims about what is significant in an excerpted stretch of talk and should not be taken to represent a complete or utterly objective rendering of any conversation. Such transcripts do, however, strive for the inclusion of all and only those vocal sounds occurring in a conversation, and they do purport to accurately indicate the identity of the speaker responsible for each particular contribution of talk. The transcription systems in widest use also permit the transcriber to indicate uncertainty with regard to materials that are partially inaudible or otherwise problematic.

The limited use in this study of statistical analyses of large numbers of instances of the 1tems under study has proved successful enough to suggest the general usefulness of this type of data in performing analyses of conversation structure. The general objection to quantitative analyses of individual conversational items (voiced, for example, in Schegloff 1981) is that the items cannot be productively extracted from their individual situations of utterance--that is, that 
they cannot be fully appreclated without examining their position in the extended, sequentially organized body of talk of which they are parts. This objection to the use of quantitative analysis is 111founded insofar as it assumes that discourse items are to be entirely understood in terms of their role in particular conversational contexts. In the analysis of these items proposed below, attention is paid to the possibility that such items may have a specifiable linquistic use which may govern their distribution with respect to adjacent linguistic items and structures. It seems very likely that the entire area of conversational studies can benefit from a more quantitative approach. It is almost always possible to test the conclusions derived from micro-sequential analyses of the sort done by Schegloff, Jefferson and others through the statistical examination of distributional predictions based on these conclusions. An admirably clear and valuable example is provided by Clark and French (1981).

\subsection{Outline of Remaining Chapters}

In Chapter 2 a class of items referred to as evincives is characterized; these are lexical items the primary function of which is to exhibit the existence of unexpressed thinking at a particular moment of utterance without displaying this thinking in detail. Most of the items discussed in later chapters are evincives in this sense. As an illustration of the evincive nature of items such as well and oh, their function in one particular discourse context, quotation, is discussed at length.

Chapters 2, 4, and 5 discuss particular discourse items (1ike, well and $\mathrm{y}^{\prime}$ know, respectively) whose basic use is related to the disclosure problem. Like and well are evincives, but $\mathrm{y}^{\prime} \mathrm{know}$, while similar to ordinary evincives in some respects, is related to the disclosure problem in a different way.

Chapter 6 contains general remarks on like, well and y'know and discusses implications of the proposed treatment for theories of conversational behavior and for semantic theory. These three items are related to others, including now, I mean, mind you and several items most commonly referred to as interjections. These items are compared to each other in relation to the tripartite model of the speaker's view proposed in Chapter 1 and to the general problem of disclosure that is describable in terms of that model. A useful framework emerges that could be used to compare ways in which the disclosure problem is handled in other languages. 
FOOTNOTES -- CHAPTER 1

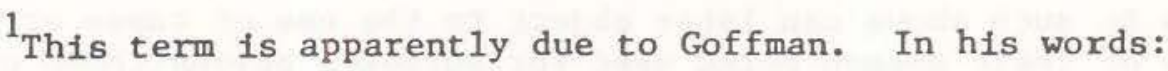

We owe to any social situation in which we find ourselves, evidence that we are reasonably alive to what is already in it--and furthermore to what may arise, whether on schedule or unexpectedly. If need for immediate action is required of us, we will be ready--if not mobilized, mobilizable ... If addressed by anyone in the situation, we should not have far to go to respond (1978:791).

2 Such prefixes only incidentally tell us that thought occurred during speech. Their primary use is to usher in material no longer obviously relevant to what has just occurred in the conversation. As such they are provisions for violating the convention that what one says ought to be discernibly or inferrably relatable to what precedes it in the conversation (Grice's Maxim of Relevance).

3 Deborah Tannen (1979) has experimented with playing tapes of conversations back to those who participated in them and asking them to explain their reactions. The principal limitation of this investigative tool is obvious: there is no way to check the accuracy of hindsight.

${ }^{4}$ There are several interesting parallels between what is proposed here as a framework for the study of discourse particles and that proposed in R. Lakoff (1974). For example, the notion that most sentences "give clues, in one way or another, as to how, precisely, that utterance is to mediate between the speaker's mentality and the real world outside" (p. XVIII-1) is parallel to the claim in the present study that some linguistic items mediate between the private and the shared worlds. An important difference between these two approaches involves the noncongruity of Lakoff's internal world/real world distinction and the distinction between private and shared worlds in the present work. The private world consists of the current unexpressed thoughts of the speaker in conversation (excluding the contents of memory), and the notion shared world is also relevant to a particular moment in a particular conversation and has nothing directly to do with the notion 'information about the real world' (see R. Lakoff 1974: XVIII-1). 
${ }^{5}$ It does, though, sometimes occur that a speaker carries on two lines of talk in the same conversational 'space'; for example, a speaker may intersperse exchanges with a distant interlocutor with quietly muttered self-addressed remarks.

${ }^{6}$ There appear to be legal problems with recording talk shows. In informal consultation with University lawyers I learned that anonymous callers to such shows can later object to the use of tapes or transcripts of their speech being used for purposes beyond those originally intended by them in calling the talk show. Rights of radio stations to control the use of what they broadcast may also be at issue. RTS examples appearing in this dissertation have been altered to conceal their source. Every attempt has been made not to alter features of examples that are crucial to the analysis.

7 The seeming casualness of these conversations is not mentioned in support of their suitability as data. The three particles receiving major attention in this study are by no means peculiar to casual speech. If anything, their occurrence is provoked by more formal speaking situations. In the RTS materials, for example, like, well, and $y^{\prime}$ know occur in large numbers even though callers are presumably aware that what they say is being overheard by a large section of the community in which they live.

${ }^{8}$ Reader's transcripts do make an attempt to correctly indicate the point of onset of overlapping material with respect to what is overlapped, and, sometimes, to indicate the point at which the overlap ends, but only crude attempts, through word spacing, are ever made to indicate what precisely overlaps.what during the perfod of the overlap itself. Transcripts differ widely in how accurately pauses are indicated. Sometimes pauses are recorded to within .1 second; sometimes the pauses are rounded off to the nearest half second or whole second; but often they are not Indicated at all. Moreover, reader's transcripts are not usually accompanied by a statement of the degree of their temporal accuracy. 
CHAPTER TWO

EVINCIVES

\subsection{Interjections as Evincives}

According to James (1974:1-5), traditional descriptions of interjections usually mention two definitive characteristics: (1) forms of this class express some strong emotion on the part of the speaker, and (2) they bear no clear grammatical relationship to other elements in the sentences in which they occur. The concern of this chapter is with the first of these putative characteristics. The claim that emotion is what is involved with these items will be re-examined and a reformulation proposed that captures their relation to disclosure (Chapter 1).

While it is true that interjections are usually viewed as grammatically independent expressions of strong emotion--and this seems patently true of such items as ouch--traditional descriptions mention other features of this class as we11. Jespersen, for example, offers this definition: "interjections are abrupt expressions for sudden sensations and emotions" (1923:415); and Fries describes interjections as "spontaneous reactions to situations suddenly confronting the speaker" (1952:fn26). Based on these quotations from Jespersen and Fries, a third component of the traditional definition of interjections can be identified. This feature is hinted at in their words "abrupt', "sudden" and "spontaneous": interjections are somehow tied to the speaker's present internal state, or to use the terminology proposed in Chapter 1, these quotations suggest that interjections are reflections of the private world.

A fourth possible component of the definition emerges in a further claim by Fries (1952:53) that the meanings of interfections are to be "inferred from the situations in which they usually occur". As mentioned in Chapter 1 , James has argued that some interjections do have a particular meaning that persists regardless of their context of occurrence, but it will be clafmed below that there is nonetheless some truth to what Fries says. While many interjections do have a specifiable meaning, part of their meaning is dependent in an interesting way on interpretation in context.

The idea that what is expressed by interjections is "strong emotion" is incorrect. James (1974) noticed that some interjections, such as oh (in some uses to be discussed below) and well, do not seem to express strong emotion. It will be argued below that a 
generalization that does characterize a large number of items traditionally called interjections is that they indicate some form of unexpressed thinking on the part of the speaker.

The claims that interjections indicate unexpressed thinking, that they are somehow abrupt or spontaneous in that they reflect the current speaker's present internal state, and that they are subject to a certain amount of contextual interpretation while nevertheless having a specifiable core use, can be captured by considering interjections to be evincives, where this term is defined as follows:

EVINCIVE: a linguistic item ${ }^{1}$ that indicates that at the moment at which it is said the speaker is engaged in, or has just then been engaged in, thinking; the evincive item indicates that this thinking is now occurring or has just now occurred but does not completely specify its content.

According to the proposed definition, evincives are tied to the present moment of utterance. This important point deserves elaboration. Items like aha are not simply expressions of the existence of undisclosed thought but express something about the current contents of the private world. There is no occasion (aside from mention) on which this item can be used other than as a direct reflection of the speaker's state of mind at the moment of utterance. Even if the 1 tem is attributed to someone in a quotation,

(1) John said, "Aha, the century plant bloomed".

it is understood to reflect the current contents of the quoted speaker's mind at the retrospectively quoted moment of utterance. In this way items like aha differ from items like happy, which are not tied to the current or quoted moment of utterance:

(2) I was happy to see you.

While items like happy may mask undisclosed thinking, it is not their specific function to do so, and they do not indicate undisclosed thinking.

The term evincive is chosen here rather than interjection so that the term used for these items will adequately reflect the fact that some of what is mentioned or 'brought up' by using such items remains in the private world. Evincives are flags marking the presence of unspoken thought. ${ }^{2}$ This feature of evincives will become clear in the following discussion of particular items, and also underlies the discussion in later chapters.

The distinction between interjections and discourse particles or markers has been lost in the foregoing discussion. This merger was intentional. There is already an overlap between items that go by these different names. James, for example, refers to well and now as interjections, while the same items are considered discourse particles or markers by Goldberg (1980) and Schiffrin (1981a). It should be 
emphasized, though, that the intention here in using the term evincive is not only to avoid the terminological problem, but to clarify the basic nature of these items. It is implied that their status as evincives is more basic than either their membership in the traditional word class interjections or their role in structuring discourse.

The evincive items in linguistic systems enable speakers to express the importance of what they have in mind at a particular point In a conversation, without fully displaying their thinking. For example, the evincive well, as will be argued at length in Chapter 4, indicates that the speaker, at the point at which the item is uttered, is consulting his or her then present thoughts, but does not specify the exact nature of these thoughts. The need for evincives such as well arises primarily from a general restriction on conversational behavior formulated in one clause of Grice's Maxim of Quantity: "Do not make your contribution more informative than is required" (Grice 1975: $45)^{3}$. It is often relevant for a speaker to bring up that something is in mind, but not to bring up exactly what is in mind. For example, the speaker issuing well before a considered reply to a question refrains from displaying for interlocutors all the unessential details of the ruminations that lead to the answer; to mention the details might implicate, possibly to the detriment of communication, that these details are viewed by the speaker as significant enough to mention ('worth mentioning').

Because they are tied to the moment of utterance, evincives have an added virtue: they enable speakers to establish the timeliness of what they have in mind with respect to the measured delivery of their utterances. Thus the use of an 1tem like ah in conversation establishes that the moment of utterance (of ah) corresponds to the occurrence of some covert mental event (ah is discussed further below); that is, it establishes the real time locus of some mentionable covert mental event that may come up in the shared world only later in the conversation. Consider the following hypothetical exchange:

(3) A: There were four concerts today, all in the evening.

B: Ah! That explains why Chris didn't come to the meeting: she must have been asked to work on one of the sound crews.

This use of ah marks as occurring after A's word evening a mental event of $B^{\prime} s$ which is then delineated by $B^{\prime} s$ ensuing talk. Time elapses during the explanation of $B^{\prime}$ 's covert thinking, but through the use of ah, the underlying thought itself is marked as occurring at precisely the relevant spot. Evincives are therefore of obvious use in establishing the speaker's accountability. To say

(4) I didn't make the phone call you asked me to.

can be quite different from saying

(5) Oh! I didn't make the phone call you asked me to.

since oh in (5) can be used to indicate that a thought expressed in 
the sentence following oh just entered the speaker's head and thereby implicate that the speaker's failure to make the call was due to forgetfulness, not malevolent intent.

Evincives as a class are therefore capable of two general and important functions in conversation: most fundamentally, they establish the conversational relevance--but not the details--of undisclosed thinking by the speaker; and they can mark the real time moment of occurrence of that thinking in order to establish the timeliness of a speaker's reaction. These items thus respond to the disclosure problem and to the incongruity of the unrestricted flow of mental events in the private world and the restricted flow of talk in the shared world. Section 2.2 examines the way in which these related properties of evincives can be used to explain their function in directly reported speech.

\subsection{Evincives in Quotations}

To illustrate the role of evincives, it is instructive to examine their use in a particular conversational situation in which they occur with great frequency. An examination of the speech materials used for this study revealed that large numbers of evincive items occur as the first item in direct quotations, as in

(6) Robert said, "We11, posture is important".

(7) Ann said, "Oh, I don't think Malthus was an American".

\subsubsection{Well and $\mathrm{Oh}$ in Quotations}

A corpus of 328 conversational quotations was assembled from the RTS and LAB materials and several published data sources (in Sudnow 1972, Schenkein 1978, Chafe 1980, and Schiffrin 1981a). All clear instances of quotation in each source were included. In this corpus well and oh occur quite frequently in quote-initial position. These two items begin 74 of the 328 quotations ( $22.6 \%$; cf. Table 1 below).

Well is in general found in conversation more at the beginnings of speaking turns than in other positions. Svartvik (1980:169), for example, remarks that half of the well's in a large corpus of British English conversation he studied were turn-initial; the other half were distributed between various other positions. Surveying one 8,000 word $L A B$ conversation, 50 well's were found, of which $23(46 \%)$ are turninitial ${ }^{4}$, a figure comparable to Svartvik's estimate. Of the remaining 27 well's, 10 are quote-initial. As shown in Table 1, well is significantly more likely to occur initial in a turn-internal quotation than in turn-initial position, the position in which well occurs most frequently overall. The situation is essentially the same for oh: there is again a significant disparity between the two positions in the didrection of there being more instances of the item beginning quotes than speaking turns. 
TABLE 1

Turn and Quote Initial Well and Oh in a Conversation of 336 Turns Including 62 Turn Internal Quotations

\begin{tabular}{|c|c|c|c|}
\hline & $\mathrm{Oh}$ & We11 & Combined \\
\hline Turn Initial & 12 & 23 & 35 \\
\hline Quote Initial & 9 & 10 & 19 \\
\hline
\end{tabular}

$$
\begin{aligned}
& \text { Chi-square values }(\mathrm{df}=1) \text { : } \\
& \text { oh: } 10.46(\mathrm{p}<.01) \\
& \text { we11 } 5.94(\mathrm{p}<.02) \\
& \text { combined: } 16.59(\mathrm{p}<.001)
\end{aligned}
$$

When quote-initial items are examined in general, many other apparently evincive items are found in the same position. Table 2 is a list of the interjections occurring in quote-initial position (using, in most cases, the class membership assigned to these items in Webster's Third).

\section{TABLE 2}

111 Quote Initial Interjections in a Corpus of 328 Conversational Quotations

\begin{tabular}{lllll}
\hline wel1 (47) & um (2) & hah & howdy & uuoo-ooo-ooo \\
oh (27) & hi (2) & whoa buzz & \\
hey (7) & {$[ \pm::](2)$} & shh & {$[$ uno $]$} & \\
man (3) & mmm & hhh & poof & \\
aha (2) & ah & wow & {$[$ hæ ] } & \\
hmm (2) & eh & tsk & HHHOHHhh & \\
\hline
\end{tabular}

As apparent from this table, just over a third of the quotations begin with an interjection $(34 \%)$. The usual rate of occurrence of interjections, based on LAB-A turn beginnings, is $13 \%(44 / 337)$. Thus overall difference is significant at $\mathrm{p}<.001$ (chi-square $40.18 ; \mathrm{df}=1$ ). 
Some explanation is required for the preponderance of interjections in quote-initial position as opposed to other discourse positions. This skewing is counterintuitive on the assumption that quotations are direct reports of actually occurring talk. 5 If quotations are factual reports, the incidence of initial interjections in quotations should be no higher than in unquoted utterances. But the assumption that quotations are factual reports is in fact unwarranted. There is much evidence that quotation could not be literal. This is clear from numerous experiments in which neither short-nor long-term memory has proved accessible for strictly verbatim detail when there has been no attempt at verbatim memorization (see Quirk and Svartvik 1966, Sachs 1967, Martin and Strange 1968, Greenbaum 1970, Greenbaum and Quirk 1970, Martin 1971). Moreover, speakers seem to have a tacit understanding of their limitations in this regard and permit each other to present as directly quoted material differing unimportantly from what may have actually been said; a plausible equivalent can pass as a direct quote.

Since in casual talk no one expects quotations to be exact, ordinarily B's response in (8) would be heard as unduly stringent:

(8) A: ...so I asked Harvey for the time, and he said, "Around four thirty".

B: I was there at the time, and what he really said was, "About half past four."

In fact, when speakers quote verbatim, they tend, if it matters, to mark what they say accordingly:

(9) Eve said, and these were her exact words, "Bugaku sickens me".

Since quoted speech is partly constructed anyway, the occurrence of more initial interjections within quotations than occur outside them is not paradoxical. Speakers may insert these items for some reason when they construct quotations. The question that then arises, of course, is why they would do so.

Here it is helpful to enlist the features of evincives mentioned in the previous section. One feature of these 1tems is that they establish the existence of the speaker's undisclosed thought without displaying it in detail. This aspect of evincives makes them potentially quite useful in contextualizing quotations which are, after all, pieces of nonpresent situations. Evincives situate the quotations and the quoted speaker by portraying the speaker as 'with thought' and specifying the general quality or cast of the speaker's thought at that point. It is to the reporting speaker's advantage to prepare the ground on which a quotation can have its desired force by establishing the quoted speaker as present in and mindful of the (recalled or imagined) proceedings--as integral, that is, to the situation from which the quotation is drawn. By using particular evincives, the quoting speaker can do this very easily, and in a number of specifiably different ways. The most popular choices by far are well and oh, though they 
are simply the most statistically prominent members of a fairly large class of items the function of which is to mediate between undisclosed thinking and overt behaviors. Using these forms, speakers can, at a single stroke, bring the tenor of their thoughts and the fact that they are, or have just been, thinking, into play in the conversation, without exhibiting unnecessary detail. This function of evincives will be referred to as backgrounding.

As a backgrounder, well (see Chapter 4) indicates that the speaker is 'with' mental contents at the moment of uttering well, and, more specifically, that the speaker is consulting these mental contents. The discussion of oh, the second most frequently occurring item in Table 2, must take into account at least two distinct items designated by James $\mathrm{oh}_{1}$ and $\mathrm{oh}_{2}$. $\mathrm{Oh}_{1}$, according to James, indicates that the speaker has just become aware of something--a piece of information, a sudden strong emotion, or that $s /$ he should perform some speech act (James 1974:37). $\mathrm{Oh}_{2}$ indicates that the speaker has paused to make a decision or choice between alternatives, no one of which is the correct, right, or accurate one (ibid., 84); because it means this oh also tends to express casualness. Examples of $\mathrm{oh}_{1}$ and $\mathrm{oh}_{2}$ appear in (10) and (11).

(10) Oh! What a lovely drill press!

(11) Sander would probably go for, oh, a nice bordeaux.

$\mathrm{Oh}_{1}$ is clearly evincive: it indicates that some thought has just now occurred but does not, itself, express what the thought is. $\mathrm{Oh}_{2}$, also evincive, indicates that alternatives are under consideration but does not specify them. Typically, but not always, ohl is followed by an explanation; oh2 normally is not.

James notes that ohy can occur in response to a statement; it then indicates that the speaker did not know the information in the statement:

$$
\begin{aligned}
& \text { A: ... So this argument proves that Quantifier-Float is } \\
& \text { Blobal. } \\
& \text { B: Oh. (James 1974:28) }
\end{aligned}
$$

Here the evincive function of oh is preempted by $A^{\prime}$ s statement--what oh evinces precedes it in plain view.

James mentions a third use of oh (hereafter $\mathrm{oh}_{3}$ ) which she claims is close to $\mathrm{oh}_{2}$ but seems to indicate only casualness:

(13) A: There sure aren't very many people here.

B: Oh, more people will probably come. (James 1974:25)

$\mathrm{Oh}_{3}$, though more casual, is very simflar in use to well and thus also appears to be evincive.

The use of oh in quotations usually involves oh 1 , though at times it is hard to distinguish ohl from oh3. The back- 
grounding function of $\mathrm{oh}_{1}$ is to provide that the speaker has just noticed something; it thereby establishes the speaker as present and mindfully reacting in the situation of the quoted utterance. Both well and oh are tied to the particular present moment of utterance of the quoted speaker. Because of this, their use has the effect of invoking or 'creating' the moment at which the utterance occurred, and so providing a 'living' context for the quote. Because forms like well and oh are reflections of the private world, they establish the existence of that world with respect to the quoted speaker and thus portray that speaker as someone with mental contents contributing in an ordinary way to the shared world and also engaging in undisclosed thinking. The claim, then, is that the occurrence of so many evincives in quote-initial position is due to their insertion there by quoting speakers as a routine part of the process of of constructing quotations: such items are optional but are frequently inserted quoteinitially because they background the quotation, enhancing the usefulness of the quotation to the quoting speaker's communicative purpose.

Many of the other items in Table 2 are also evincive, and so serve the same function, but each in a slightly different way. The summons hey, often found preceding a vocative, is the third most frequent it $\overline{\text { em }}$ in Table 2 . Summonses seek attention but also indicate having in mind something to say or do:

(14) Hey! Hand me that socket wrench.

The summons itself does not present thoughts but evinces them as covertly there. For this reason a felicitous summons precedes some indication, linguistic or otherwise, of the speaker's intention in issuing it. Beginning a quotation, hey specifies that the quoted speaker wished to make a contribution. Because it is a summons, hey marks the quotation as directed to some other(s) and situated as part, possibly the first part, of an ordinary proceedings in which speakers oriented to each other in a manner routine for conversations. Hey, like well and oh, backgrounds--it provides context for appreciating the ensuing quotation; specifically, it tells us something about the quoted speaker's 'state of consciousness' (cf. use of this term in Keller 1981).

Aha occurs twice quote-initially. In the present data aha indicates that the speaker now sees a connection previously missed or has pieced together the logic of a situation. Aha evinces that some connection has just now been made, without itself specifying either what the connection is or by what mental process the speaker arrived at 1 .

Ah has a different reading. According to James $(1974: 37)$, it indicates that the speaker has just now thought of something and finds that thing, or having thought of it, pleasing or significant. Ah and aha differ in use:

(15) We went down to ... ah! Spindrift Beach on the Fourth. (16) We went down to ... aha! Spindrift Beach on the Fourth. 
(15) could be said if the speaker is pleased to have remembered the name of the beach, but (16) cannot, I think, have this meaning and would most likely be taken to imply--oddly--that the speaker has only just now deduced the name of the beach. Both ah and aha are evincive but differ in what they attribute to the undisclosed thinking of the speaker.

Man, often a term of address, also has an evincive use:

(17) Man! Is this chili ever hot!

As an evincive, man! indicates that a speaker finds what s/he had in mind at that point amazing or at least mildly surprising. Compare:

(18) Man! A comet just hit Randy.

(19) Man! You can't store water in a sieve.

Anyone saying (19) might be seen as slow-witted. Another item in Table 2, wow, seems quite similar in use to evincive man.

Filled pause is represented in Table 2 by two instances of um. Both um and uh evince mental contents that are momentarily null, indistinct, or unresolvable, and as such have many uses in conversation. We11, in contrast, indicates more pointed deliberation or consideration. Compare (20) and (21) as answers to the questions, "What are you doing over the Fourth?"

(20) We11, I don't know.

(21) Uh, I don't know.

$\mathrm{Hmm}$ and $\mathrm{mmm}$, with sharply falling intonation, can mark conclusive appreciation or consideration; the meaning of these items varies widely, depending on intonation.

A few items in Table 2 (e.g. [t::]) are probably occasional inventions (some of them written in the published eye-dialect renderings of their transcribers), but seem to be evincive. Two items are not evincive: hi and howdy. These greeting words do not mark the occurrence of undisclosed thinking. One may, of course, think privately while uttering such a greeting word, but the word itself does not indicate this.

\subsection{Enquoting}

It is thus possible to explain the inordinate frequency of occurrence of evincives initial in quotations by considering their usefulness as backgrounders in connection with the need of quotations for the kind of backgrounding they provide. Another factor may well be involved in the statistical skewing of evincive items in quotations, though it will be argued that this second factor is less important than the backgrounding function. 
Both well and oh are found almost exclusively in utterance-initial position. In her work based on introspective data James has made much of the fact that both items can occur sentence-internally, as in

(22) There were, we1l, four of them.

(23) There were, oh, four of them.

but in fact this use of these forms is statistically unusual. Al1 110 instances of well and oh in the LAB materials used for this study, for example, are initial. Sentences like (22) and (23) no doubt occur, but not very often.

Since well and oh predominantly occur initially, they may cue initiation, and if so, a second reason for the unexpectedly high frequency of evincives in quote-initial position suggests itself: perhaps quote-initial evincives mark the quote as a 'beginning'. Since most quotations occur within a matrix sentence, issuing an initiator within a sentence, particularly after a verb of saying, may cue a beginning within the utterance unit, which is sile way of describing a turn-internal quotation (the speaker does, in effect, change ${ }^{6}$ ).

\subsection{Quotation}

To quote, speakers must indicate that after a certain point what they say is to be understood as quoted and face an opposite task when the quote is done: how to signal a return to present contributions of talk, from the citation of prior talk or projected future talk. The first task will be called enquoting; the other one, unquoting, will be ignored in what follows.

A primary resource for quotation is introduction of quoted material with a verb of verbal communication, usually say:

(24) Theresa said, "David, just go".

But use of these verbs doesn't itself enquote, as shown by spoken sentences ambiguous between a direct and an indirect reading:?

(25) Theresa said David just left for Ontario.

(26) Asa said I'm to blame.

Since such sentences are on one reading paraphrasable by ones like (27) and $(28)$,

(27) Theresa said that David just left for Ontario.

(28) Asa said that I'm to blame.

enquoting is not accomplished simply by saying (25) or (26). Failure to enquote can lead to misunderstandings: for example, (26) leaves it unclear whether Asa or the speaker of (26) is considered to blame. Narrative go, as in (29) does enquote (Schourup 1982):

(29) Mort goes, "We should leave."

(30) *Mort goes that we should leave. 
but speakers who avoid go 'say', as most over thirty do (Butters 1980), cannot in general enquote by the choice of a verb alone.

But there are other resources available for enquoting involving the quoted material itself. Enquoting occurs when the quoted material exhibits one or more features peculiar to directly reported speech (a list of these appears in Banfield 1973). Thus, for example, WHquestions after said are heard as directly quoted:

(31) Muriel said, "Who are you?"

(32) *Muriel said that who are you?

To enquote, speakers could select for quotation material that will be unambiguously heard as directly reported.

But it is also possible that speakers enlist features of directly reported speech to enquote, refashioning what they wish to quote to make it sound more direct. Possibly speakers insert items like well and oh quote-initially in order to enquote. That they might do so is suggested by the fact that insertion of an evincive does enquote:

(33) Lyle said steak would be fine.

(34) Lyle said oh steak would be fine.

While (33) is ambiguous between a direct and an indirect reading, (34) is only capable of the direct reading.

This interpretation of well and oh as enquoting initiators marches well with a curious fact for which there is otherwise no apparent explanation. Consider spoken sentences capable of two readings, one in which the interjection is quote-initial, and one in which it is the last item before the quotation begins:

(35) John said well plastics are the future.

(36) Marla said oh Grace takes Chemistry 103.

Subjects strongly tend to assign the interjection to the quoted speaker, not the quoting one, even though the interjection could reasonably be attributed to the quoting speaker, as would occur when what follows the interjection is an indirect report:

(37) John said, well, that plastics are the future.

(38) Marla said, oh, that Grace takes Chemistry 103.

A simple experiment was done to establish this point. Sentences (35) and (36) were presented in written form without punctuation or capitalization and subjects were asked to punctuate them. Table 3 shows the result. Most subjects added quote marks before the interjections. 
TABLE 3

Quote Allegiance of Well and $\underline{\mathrm{Oh}}$

Assigned to quoted speaker

Assigned to quoting speaker

\begin{tabular}{|c|c|}
\hline We11 & Oh \\
\hline 51 & 56 \\
\hline 2 & 0 \\
\hline 5 & $\underline{2}$ \\
\hline$\overline{58}$ & $\overline{58}$ \\
\hline
\end{tabular}

Another group of subjects was asked to punctuate the same sentences without the interjections. Only half of these $(12 / 24)$ used quotation marks. Considered in conjunction with Table 3 , this datum suggests that well and oh could serve an important enquoting function in addition to serving as backgrounders.

Whether speakers do heavily use well and oh and other evincives for enquoting is, however, questionable. There is some evidence that the enquoting function of evincives is secondary to their backgrounding function. In many cases a quotation begun with an evincive is introduced with go 'say', so that the enquoting is already performed before the evincive is issued:

(39) ... and she goes "Well if my check's big enough I'll buy ya an eight- or a twelve pack ... (LAB-A,9)

(40) $\ldots$ and he's just goin $(g)$ "Oh come on hurry up" (LAB-A, 16)

Probably the enquoting function of evincives should not be dismissed entirely. It is certainly true that forms like well and oh are capable of this function (as seen in Table 3), but it is equally clear from examples like (39) and (40) that their role in enquoting is not always crucial. 8

The backgrounding function of evincives is logically prior to their enquoting function. It is the capability of evincives to initiate utterances that makes them suitable for enquoting, but their tendency to occur initially is itself due to the fact that they are backgrounders: it is natural that evincives strongly tend to occur in initial position, since this is the natural place for backgrounding material to appear. In quotations, for example, the speaker will wish to first establish the quoted speaker as present in the situation of the quoted utterance, rather than to insist on this after the quote is underway. The enquoting function is discussed further in Chapter 4 in connection with the discourse functions of well. 


\subsection{Summary}

The notion 'evincive' is applicable to a number of items occurring in ordinary conversation. Many forms usually described as interjections are evincive in function. The backgrounding function of many evincives makes them useful in quotation. Backgrounding is not a function only of quoted evincives, but the usefulness of evincives to background quotations is great because quotations stand in need of contextualization. It is not surprising, therefore, that evincives occur more frequently initial in quotations than initial in speaking turns.

Evincives represent one kind of speaker response to the problem of disclosure discussed in Chapter 1. Specifically, evincives like well and oh allow the speaker to call attention to current thought in the private world and to specify, with a broad stroke, the tenor of what is in mind, without placing the details of the speaker's thoughts in the shared world. Using evincives, the speaker may acknowledge the existence and importance of the private world in current conversational behavior and so solve the disclosure problem as it relates to the private world. 
FOOTNOTES -- CHAPTER 2

In this study the noun evincive is reserved for particular lexical items with evincive function. The adjective is not just applicable to individual words. The routine expression let me see, for example, is clearly evincive, and one may evince with novel sentences: I am thinking of a large object with three moving parts. Note, however, that the verb think is not itself primarily evincive. It does not necessarily evince current undisclosed thinking: If I think of it, I'll give you a call.

${ }^{2}$ Items like ouch are apparently not evincive. They appear not to serve important routine discourse functions and are notabie for occurring at virtually any point in an utterance--even within a word. Such items are probably best described as interruptions ( $c f$. Rotenberg 1978).

${ }^{3}$ Other Gricean maxims may also be involved in specific cases, for example, "Do not say that for which you lack adequate evidence (a clause of the Maxim of Quality) and "Be brief" (a clause of the Maxim of Manner).

${ }^{4}$ Turn initiations were identified using three criteria: 1) back channel responses (e.g. uh huh, my God!, etc.) were not considered to be separate turns; ii) talk intermitted or overlapped by such backchannel responses was considered to constitute an unbroken turn; 1ii) only extended contributions following extended contributions by a just prior speaker were considered true turn initiations. These criteria are admittedly too conservative. This limitation seems necessary here, though, in view of the lack of any clear decision procedures for determining the location of turn changes. Probably any theory of turn structure would have to admit at least the changes included for purposes of this statistical count.

${ }^{5}$ This assumption is only relevant for retrospective quotations, but in the present data, and probably in general, this type of quotation is by far the most common.

${ }^{6}$ Even when speakers quote themselves, the turn changes in the sense that the self-reported material entails a suspension of the presently 
motivated contributions of talk. The motivation, situational relevance, etc. of the reported material is in some other conversation or situation than the present one.

7 There are other verbs that enquote, but because their meanings are so specific, their usefulness for enquoting is limited (e.g. print, recite, sing; cf. Sadock 1969:317-319).

8 The use of pauses, intonational breaks, and the adoption of stylized voice quality are probably of considerable importance in initiating quotations in speech, as well as in unquoting. I would hazard a guess, however, that such cues are not as reliable as one might at first think. I have noticed that the tendency for well to be heard as an initiator is quite strong--so strong that pausing, intonation and voice quality adjustments cannot 'coax' well out of a quotation. I asked two volunteers to stand before a class and read aloud the following sentences from cards:

(a) John said, well, "Think of the starving people in India". (b) Mary said, well, "I like fish".

The volunteers were told to go to whatever lengths necessary to make sure that those listening would get the impression that well belonged outside the quotation. Fifteen subjects were asked to write down the sentences just as they heard them, with appropriate punctuation. As the following results show, the subjects were for the most part unable to 'hear' what the two volunteers were saying.

we11 attributed to quoting speaker

we11 attributed to quoted speaker

$\begin{array}{cc}\text { sentence (a) } & \text { sentence (b) } \\ 4 & 1 \\ 11 & 14 \\ \frac{15}{15} & \overline{15}\end{array}$




\subsection{Like in Conversation}

The concern of this chapter is with conversational uses of like beyond those regularly attested as standard in dictionaries. The morc well received uses of like mentioned in Webster's Third New International Dictionary are:

1. as a transitive verb:

I'd like to have my back rubbed.

2. as a noun:

Everyone has likes and dislikes.

the like(s) of which the world has never seen

3. as an adjective with various meanings, including 'the same or nearly so' and 'likely':

tables of like color

I have prepared dishes that are like to please you.

4. as a preposition with numerous meanings, including 'similar to, 'typical of', 'similarly to', 'Inclined to', and 'such as':

His typewriter is like a small airplane. It was like her not to come to her own party. John always acts like a clown.

It looks like rain today.

a subject like physics

5. as an adverb with various meanings, including 'nearly', and 'rather':

The actual interest is more 1 ike 18 percent.

She sauntered over nonchalant likc.

6. as a conjunction, usually meaning 'as' or 'as if':

She holds her pencil like most people hold a toothbrush.

He looked like he wanted a warm place to stay.

Examining the LAB and RTS materials, a great many instances of like were found that could not be adequately characterized in any of the above six ways. 1 One frequent use of the form was preceding descriptions involving exact numbers: 
(1) like one more week

(2) like five til eight

(3) like twenty dollars

(4) like- thirteen bucks

(5) like thirty-eight indictments

(6) like eighty million buildings

(7) like four floors

(8) like two parties

(9) like three years

(10) like eleven guys

(11) like two- two blocks down

(12) like three blocks

(13) like five o'clock Thursday

(14) like - one lane

(15) like Seventeenth and Summit

(16) like ninety, y'know

(17) like ten years ago

(18) like from twenty ta thirty

(19) like at six o'clock

(20) like three weeks

(21) like two years

(22) like just one finger

(23) like twelve years

(24) like on the twenty-sixth

(25) like two weeks before

but in other cases like precedes descriptions that are exact in other ways:

(26) like every other night

(27) like uh quite a few songs

(28) like - lots of singers

(29) like every night

(30) like every other weekend

(31) like chilly enough to where they could possibly have a coat on

(32) like tangible. They're there. I can hear (th)em.

and also descriptions that are obviously imprecise:

(33) He's like maybe ... what ten or something? Twelve? I don't know (Chafe 1981:302).

(34) like - it's right behind (us) in a way

These and other nonstandard uses of like are of ten considered symptomatic of careless or meaningless speech, and those who use like in these ways have been criticized for this by purists such as Newman (1974:15), who, interestingly, chooses a numerical expression to exemplify the abuse: 11ke six feet tall (cf. Major 1970:77: like two years). But if nonstandard like is only a meaningless interjection (see White 1955:303; cf. Wentworth and Flexner 1975:319, Major 1970, Landy 1971, Wood and Hill 1979, and even Wright 1857), why is it common before very exact and obviously inexact descriptions? 
This use of like is reminiscent of, though not equivalent to, its use as an adverb meaning 'nearly' (use \#5 above), but like in (1)(34) does not carry the implication 'less than' conveyed by that definition; in fact, the meaning 'nearly' seems more properly attributed not to like itself but to the entire construction more like $+(\mathrm{NP})$.

Note that, despite the frequent claims to the contrary, there is a specifiable semantic difference between descriptions preceded by like and identical descriptions without like. For example, if someone applying for a driver's license were asked by a clerk in a department of motor vehicles, "How tall are you?", a reply of "I'm like six feet tall" would probably lead the clerk to ask for a more exact response. Apparently, then, like, at least in this use, is not entirely without function. While six feet tall can be standardly used for heights between roughly $5^{\prime} 1^{\prime \prime}$ and $6^{\prime} 1^{\prime \prime}$, in a situation where precision is required, six feet tall can serve as a relatively exact response, but like six feet tall cannot.

For most of the examples (1)-(34) it is reasonable to claim that like is an adverb meaning 'approximately'. Approximately or about or around can be substituted for like in most of these examples without noticeably altering their meaning or acceptability. But the substitution of approximately in some of these examples is not a happy one, especially when the examples are examined in their surrounding context.

For example, consider (7) in more detail:

( $\left.7^{\prime}\right)$ SUE: You know that um - they've been livin(g) in this big three-story house with basements- like four floors y'know- gigantic house on Summit... (LAB-B,22)

It seems fairly clear here that the speaker is not saying simply that the house in question has, say, somewhere between three and five floors, which is normally what would be conveyed by the expressions about four floors and approximately four floors. Rather, the speaker explicitly expresses that the house has exactly three stories, at least in the way that people usually talk about houses having stories. We know from context, on the other hand, that the speaker is concerned with the largeness of this house (referring to it as big and gigan$t i c)$. To further convey a sense of its largeness, it is advantageous to include the basements in the description of the house. But to simply say that the house has four floors would be an unusual use of floors, since basements are conventionally excluded from such descriptions (cf. first floor, etc., referring to floors above ground level). Rather, it appears that like is used by Sue to indicate that four floors is being used with a special meaning. If so, one could offer as a synonym for like in ( $\left.7^{\prime}\right)$ 'as $1 t$ were' or 'so to speak'.

Consider another example:

(27') $\mathrm{H}$ : Is that [i.e. music] a secret ambition?

C: Uh: yes. A matter of fact ... right now we've written like uh quite a few songs - y'know (RTS,13) 
Substitution of about or approximately before quite a few would be odd in $\left(27^{\prime}\right)$ because the quantification quite a few expresses that the speaker finds the number of songs notably large, while approximately allows as possibilities that the quantity was either more than or less than quite a few. Approximately quite a few is thus internally contradictory, roughly parallel to saying, "This lamp cost around

$\$ 26.11 "$. But the contradictoriness disappears if the use of like here is assumed to be similar to its use in $\left(7^{\prime}\right)$, that $1 s$, if it is considered to express the possibility that quite a few may be an imprecise or inappropriate rendering of what the speaker has in mind. (A similar argument can be constructed for like - lots of singers.)

Substitution of approxmately or about is also quite odd in $\left(22^{\prime}\right)$ : (22') EVA: My dog a lotta times when we're playin(g) (a)n(d) stuff $y^{\prime}$ know (m- b- h-) my hand'11 get into ( $\left.h\right)$ is mouth or: like just one finger or sump'm like that ... (LAB-B)

Just as in the case of like quite a few and of like lots of singers, like just one is internally contradictory if like has the meaning 'approximately', since just conveys that the speaker is certain about the number, and about conveys the opposite. But there is again no contradiction if like indicates simply that the speaker's words are an inexact formulation and should not be understood as a complete or accurate portrayal of what the speaker has in mind, rather than conveying that one is approximately the number of fingers involved.

A further indication that like is not equivalent to approximately or about is that these items $\overline{c a n}$ co-occur without any particular redundancy resulting:

(35) And that [.2] the little boy is like approx-about ten years old (Chafe 1980:305)

Like in all of the above cases can be described as indicating a possible discrepancy between what the speaker is about to say and what the speaker feels ideally might or should be said. Like in this use can be seen as a device available to speakers to provide for a loose fit between their chosen words and the conceptual material their words are meant to reflect. Like with this use would thus be similar to the evincive items discussed in Chapter 2 in specifying a general connection between talk and unexpressed thought. More specifically, the hypothesis to be examined below is that like is used to express a possible unspecified minor nonequivalence of what is said and what is meant. In cases where like precedes a very exact description, it would therefore constitute a kind of 'hedge'2, attenuating the overexactness of the speaker's chosen formulation; in the cases where like precedes obviously inexact formulations, it would indicate that the speaker is aware that what follows is an imprecise rendering of what is in mind.

The remainder of this chapter explores how far one can get in understanding the conversational functions of like by applying this 
evincive treatment to the various nonstandard occurrences of like in the present data. It should be noted that several of the standard uses of like mentioned at the beginning of this chapter share with evincive like the notion of approximation, so that evincive like can be viewed as related to the standard comparative uses of the form.

Before leaving the discussion of this general use of like, some parallels in other languages can be mentioned. First note that the double duty of like as both a nonevincive comparative item and as an evincive is not unusual. In the next section parallels in several other languages are discussed. But consider here as an initial example the form nymis in the West Central dialect of Sierra Miwok (Freeland and Broadbent 1960:61; cf. Freeland 1951:169) which means 'like' but is also used to mean 'as it were':

$$
\text { mu-uj-nymis 'in the trail, as it were' }
$$

Forms usually meaning 'like' but also translatable as 'about' are also found, as illustrated in the following examples. In the Sino-Tibetan language Lahu (Matisoff 1973:135), the form qhe can mean 'about', as in

(37) $\eta \hat{a}$ gî
five (people counter) $\frac{\text { ghe }}{11 \mathrm{ke}}$

'about five people'

qhe is usually used to mean 'like', as in

(38) yâ-

ya- ghe te ve

'He acts like a child'

Likewise, in Raluana, spoken in New Britain (Lanyon-Orgill 1960:134), the form då generally has the meaning 'like', as in

(39) 1 mal dă ră parau

he dresses like white man

'He dresses like a whiteman'

but note its use in the following example:

(40) dă ravinun like ten

'about ten'

\subsection{Like Introducing Direct Discourse}

A second use of nonstandard 11 ke in the present data is immediately preceding a direct quotation:

(41) Both sides o(f) the street can hear her yellin(g) at us and she's like "Come in here (a) n(d) have a beer" y'know? [LAB-A, 6].

(42) so I go "Um [:stylized] - Mom (a)n(d) Dad got me pants just about like that and I've worn those already", hint hint, $y^{\prime}$ know. I was like "Come on, Dummy " [LAB-A, 18] 
(43) he goes "I'm sorry but you've only got seventeen dollars in here" - and I'm like "WHAT!!! I THOUGHT I HAD SIXTY DOLLARS IN THERE!!!" [laughs] [LAB-A,21]

(44) It's not that she minds it so much. She's like "Well why () waste all that gas. You know you you can find a ride home with somebody else". [LAB-A,37].

(45) he kep- talkin $(g)$ about how "Oh we're livin(g) together next year=1t' 11 be so much easier for us cuz nobody else' 11 be around" and I'm just like "Buzz, aw" y'know. [LAB-A,50]

(46) I came back an(d) called the police an(d) they told me - that it was there an(d) it was gonna be thirty-six bucks ta get it out an(d) I was just like "Oh my Go: : d" [LAB-A,61]

(47) An(d) then on the way home it started $\operatorname{snowin}(g)$. It was terrible on the way home - I was drivin( $g$ ) twenty-five miles an hour - an(d) I was just l1ke "[i::::]" And then ... [LAB-A,63].

This use of like appears not to have been described previously in the 1iterature 3 ; I do not know its distribution, but it is at least very common among younger speakers in Central Ohio, where the present data were gathered. 4 The construction apparently cannot precede indirect discourse:

(48) ?He was like that he wanted to leave early.

and, if so, the quotative use of like is similar to narrative go 'say' (see Chapter 2) in being potentially useful as an enquoting device.

However, examples (41)-(47) are not true quotations. Speakers who use this construction claim that it prefaces not direct retrospective reports of speech, but internal speaker reactions--what the speaker had in mind to say but did not, or how the speaker felt at the time. One user of this construction suggested that it reports the speaker's "attitude". Thus what like in its quotative use introduces is a direct discourse rendering of what someone was thinking. It is as if the speaker were saying, "What I am about to report is like what so-and-so must have had in mind". Thus here again there is a possible unspecified minor nonequivalence of what is said and what is meant. Even when the item is used in the past tense:

$$
\text { I was like "Oh my Go: :d" }
$$

like mediates between some former attitude the speaker now recalls and some immediately following suggestive or inexact formulation of this in the form of an 'internal' quotation.

Some recent comparative work offers an interesting line of support for this analysis of the origin of like preceding direct discourse in English. Joseph (1981) argues that Hittite (1)-wa( $r$ ), a particle introducing direct discourse, is related to Sanskrit iva 'like, as', citing a claim by MacDonnell that 1va, in addition to 
meaning 'like' or 'as' in similes, was used to modify "a statement not intended to be understood in its strict sense" (MacDonnel1 1971:219220). Joseph suggests that the similarity of (i)wa(r) and iva lies in the fact that both particles "inject into the discourse elements of what the speaker has in mind". This consideration of the uses of (i)wa( $r$ ) and iva therefore provides a striking parallel to the incipient use of like in English to introduce internal quotations. All it would take for the English quotative use of like to become altogether congruent to the quotative use of (i)wa(r) would be for an extension to occur from internal to ordinary quotation. In either case, though, these particles introduce direct discourse.

Joseph also adduces in support of his claim about (i)wa(r) a similar particle with quotative function and meaning 'like' in Tok Pisin (Woolford 1979:117):

(51) Elizabeth i tok olsem, "Yumi mas kisim ol samting pastaim." 'Elizabeth spoke thus, "We must get things first."

Olsem usually has the meaning 'like', as in

Em $i$ kamap yangpela boi olsem James
he VBL.PRT grow-up young boy like
'He grew up (to be) a young boy like James'

And Joseph mentions a similar particle, (na)be, also discussed by Woolford (ibid. 118), in Buang, and the Sanskrit particle iti which is used both as a quotative particle and in constructions like the following:

Tvam ambaya putra iti pratigrhitah

you mother/INST son like be-received

'You have been received by my mother like a son'

To these examples may be added the Lahu form qhe, already mentioned, which Matisoff (1973:134) refers to as "the most general and versatile of all Lahu words of comparison ... usually translatable as 'like', 'as', or 'thus'", as in (38).5 qhe is used to close quotations:

$$
\begin{aligned}
& \text { "te mâ phè?" qhe qô? pî ve yo } \\
& \text { do not able like say BENEF INDIC DECL } \\
& \text { "'Cannot do it" thus he said' }
\end{aligned}
$$

qhe may represent a close parallel to English quotative like; that is, it may be restricted to use with internal quotations. To establish this point would require further research, but it is at least suggesttive that Matisoff (ibid. 468) mentions that of the two quotative particles te and qhe, the former is most likely to appear with longer and more complicated quotations. It is precisely quotations of length and complexity that are most unlikely to be internal. All Examples of English quotative like seem all to involve simple, brief broad-stroke sketches of a speaker's attitude. 
Because of the similarities in Tok Pisin, Buang, Sanskrit, and Lahu, it appears that the parallel between Hittite (i)wa(r) and Ohio quotative like is not accidental but reflects a functional correspondence (cf. Joseph and Schourup 1982). In all five languages an item meaning 'like' does double duty as a quotative particle.

The extension of quotative like in English from internal quotations to quotations in general would not represent a conventionalization of the item at the loss of its proposed use (i.e. to indicate a possible minor unspecified nonequivalence of what is said and what is meant). As argued in Chapter 2, speakers are aware of the inexact nature of retrospective quotations; in view of their inexactness, it is perfectly appropriate to indicate that what the speaker reports as having occurred is only like what may have actually been said. Thus, whether or not the Hittite, Sanskrit, Tok Pisin and Buang cases began as restricted to internal quotation, these languages share with English the property of indicating the approximative nature of a direct discourse report by means of a form meaning 'like'.

\subsection{Like After Questions}

In the following examples like occurs following a question:

(55) [Tape begins: conversation already in progress]

SUE: Wesley Point.

EVA: Last Bonus Weekend like?

SUE: No it was um - What comes up? Labor Day? Weekend? $[\mathrm{LAB}-\mathrm{B}, 27]$

(56) SUE: What radio station do you listen to?

EVA: When I'm down here I listen to Dayton//When I'm at home I listen to Akron.

SUE: ( ) Yeah but which one like.

EVA: W. oh! W.N.Q.X... [LAB-B, 27]

(57) SUE: An(d) $h(h)$ e $g(h)$ ot $t h(h)$ e $b(h) \operatorname{ir}(h) r(h) d$.

EVA: In (h) is mouth like?

SUE: In (h) is mouth. But he ditn' (h)ave a chance ta bite down on $(\mathrm{h})$ im. $\quad$ [LAB-B,21]

These are the only examples in the present data in which like is linked to a preceding sentence. In all three instances the speaker is soliciting clarification of something said by the speaker just previous to her. In the first two examples the speaker asks whether the formulation in the question is discrepant with respect to what the previous speaker intends. These examples are therefore also characterizable by the proposed evincive reading, the only difference being that, since the utterance to which like is attached is a question, it is understood with reference to what the other speaker has in mind (note, though, that a possible discrepancy is implied between the questioner's proposed formulation and what the questioner feels the previous speaker meant). The difference between like in statements and questions reflects a general difference between questions and 
statements, not a difference between two uses of like. The third example differs from the other two in that like was spoken with low stress and pitch. The speaker seems to express a possible discrepancy between the question she is asking and what she thinks it would have been ideally appropriate to ask.

The Oxford English Dictionary lists as dialectal and vulgar the parenthetical use of like after a statement, citing 19 th century examples, including in an ordinary way like and If your honour were amongst us, there might be more discipline like, attributing to these instances a meaning essentially equivalent to the general one proposed above for evincive like: "'as it were', 'so to speak'". Partridge $(1970: 482)$ specifies the meaning of like in this position as "somewhat, not altogether: as it were, in a way; in short, expressive of vagueness or afterthoughted modification". Although the post-sentential or 'tag' uses of like cited in these two sources follow declaratives, the approximative reading seems equally applicable following questions, with the only differences being attendant on differences between questions and statements. In view of the small number of examples in the present sample, it is probably accidental that only interrogative instances occur.

\subsection{The 'For Example' Reading}

Many instances of like appear to have the meaning 'for example', among them the following 6 :

(58) C: The trucks are speeding on the side streets y'know that are one-way (a) n(d) then there's a wide at the end of it $y^{\prime}$ know that there go out like on - oh Broadway for instance or Fifth, or something like that - [RTS,10]

(59) J: Yeah. Because see 1- a lotta people like in business or other - uh things like that, they get internships y'know for the summers.

[ $\mathrm{LAB}-\mathrm{B}, 3$ ]

(60) C: Y'know um - besides taking care of groups of people or - um y'know uh I'm speaking in like a secretarial situation - where you're working for - y'know you're you're hyou're having to - set up your time ... [RTS-1]

(61) C: People would be - would come from all areas - of the um of the States - an(d) uh and uh so I would work in (th)e Graceland Club an(d) and some people would like uh - to hear like uh bluegrass music - so we would do a - a little bit of like uh uh uh $1-$ little bluegrass-flavored music [RTS]

(62) SUE: I mean you don't have to get something really expensive. Just go ta um - like Petrie's. Or that's//not what that's called.

EVA: Mary Ann's. 
In some of these examples the 'for example' reading is strongly reinforced by context. In (58) for instance appears, as does oh (see Chapter 2); in (59) that in business is to be understood as an example is provided for by the continuation or other - uh things like that; in (63) this is indicated by or something, and by use of the interjection say (see James 1974 on say). However, even if these guiding contextual elements are eliminated, the 'for example' reading can persist :

(64) These trucks ... go out like on Broadway

(65) a lot of people like in business

(66) what's gonna stop him from like throwing a knife at (h)im ...

Can the 'for example' reading be regarded as a contextual interpretation of the usual evincive 'discrepancy' reading? Since, for instance, on Broadway is not plausibly discrepant in being an imprecise representation with respect to what the speaker has in mind, the only remaining logically possible discrepancy is that on Broadway is an accurate but selective representation, which is what the 'for example' reading suggests.

Since 1 ike in the treatment proposed here indicates some minor discrepancy between what is said and what is meant (rough1y, 'What I say is like what I mean'), the 'for example' reading should be possible in any case where selectivity of report is conceivably the nature of the discrepancy; in certain contexts (e.g. (58)), this possibility looms larger than in others (e.g. (65)), and in some cases the 'for example' reading is clearly absurd:

(67) When he unbuttoned his pants they like fell to the ground.

It is difficult to adduce tests that will tell us whether the 'for example' reading is a distinct lexical meaning of like. The item does not lend itself to the usual ambiguity tests (a number of which are discussed in Zwicky and Sadock 1973). The position taken tentatively here is that, unless relevant ambiguity tests can be devised that indicate otherwise, the 'for example' reading of like can be taken to involve simply the interpretation of evincive like in contexts where a reasonable kind of discrepancy that could be indicated between what is said and what the speaker has in mind is one of selective mention. However, no firm position on the ambiguity/vagueness issue will be taken here. It does seem quite plausible that the ambiguity is genuine since the 'for example' reading and the ordinary evincive reading differ in one crucial respect: the 'for example reading has a cohesive use in linking specifics of prior discourse to what follows like. Like therefore turns up frequently in sentence-initial position with the 'for example' reading: 
(68) C: ...but just walkin(g) through the middle of a crowd y'know. Now like at the airport - uh - P.R., I don't think there's any way anybody could've attempted to knock off the Pope. [RTS, 35]

(69) [Caller has been attempting to show that Michigan State fans are poor sports]

C: I don't know like just - Like when the Cleveland State plays Michigan State - I mean rightafterwards- there's it sometimes it seems like it's worse - even when they win - y'know. Like I heard that some o(f) the store $y^{\prime}$ know people that sold popcorn 'n stuff they're not gonna sell anythin(g) that's in a bottle [i.e., so the fans can't throw the bottles on the playing field]. [FTF3,4]

(70) [Caller is attempting to show that Michigan drivers are worse than Ohio drivers]

C: ...Like - um - I was on the freeway the other day with uh: :on a - halfway trip comin(g) home to Ann Arbor - some car cuts over on me - never even looked. [RTS3,10]

(71) [Caller is attempting to show that assassinations are very easy to carry out]

C: if somebody really y'know knew about that [i.e. doing papal blessings by television instead of in person] and uh y'know sort o(f) like OK like they go in an(d) - strap $y^{\prime}$ know uh on a - a light coat $y^{\prime}$ know where it'd be like chilly enough to where they could possibly have a coat on - and put on a - little bit o(f) plastic explosive around (h)im - sayin(g) "OK" y'know "I'm gonna be gone." [RTS20, 28]

(72) C: uh:b - you know I - uh (p) I think they could build a like a: - a plastic uh - walkway - for the Pope. Like when he was walkin(g) through that - uh that hotel last Thursday - to (h) is car they could've wrapped a bulletproof plastic...shield - o(f) some sort - He'd still be out in public. [FTS34a, 32]

(73) SUE: Uh Fred's - Fred is my supplier o(f) cigarettes, man. (h)e came up brings me a carton, I go home he' 11 buy me at least two or three packs a week. I mean, Like Saturday night he'11 - buy me three packs o(f) cigarettes...then the next - I see (h) im almost every weekend... [LAB-A,28]

For the only other initial like in the data, the 'for example' reading is at least plausible (i.e. the reading of (74) in which 'she' only sometimes works six days):

(74) I told her anytime she could come down $y^{\prime}$ know? But - I have to - the hours she works - She got two days off in a row. Like she would work six days an(d) then ... [LAB-B,28] 
Schiffrin (1981a:11) has claimed that like is a 'non-causal marker of evidence'. This characterization only seems well suited to the 'for example' reading of like (and especially when this reading is used utterance-initially). The conventional use of like with this reading, however, cannot be used as evidence for the true ambiguity of the item.

\subsection{Like as an Interfection}

In addition to utterance-initial uses of like, many examples in the present data occur preclausally. Taken together these cases are of particular interest because the most often c1ted 'empty' slang use of like is in initial position:

(75) Like, we was up in this freak's pad, man, and she came off real lame. (White 1955:303)

(76) Like do you understand? (Landy 1971:120)

(77) Like, man, I was out in Wyoming ... (Major 1970)

(The controversy over this use of like should not be confused with the unworthy debate, smouldering through most of this century, over whether or not it is proper to use like as a confunction. See Whitman 1974; Krapp 1925:239-240; Literary Digest 1937; Bryant 1962; Follett 1966; Copperud 1980.)

But the preclausal use of like in the present data, unlike the stereotyped use, is not utterance-initial. As the following examples illustrate, like is typically preceded by prefatory material:

(78) but I found like that helped me a lot

(79) so like basically people can differentiate

(80) I'm just wondering like - if somebody can

(81) (be)cause like some countries - y'know

(82) and y'know like say right now he

(83) because $y^{\prime}$ know he has a bulletproof vest

(84) I mean like Saturday night he'11

(85) but like - it's right behind us

(86) And like before I met Fred (h)e was always

(87) and well like Robbie's goln(g)

(88) cuz like - he' 11 just he' $11 \mathrm{fly}$ in your

(89) y'know an(d) - like he buzzed her

(90) I mean- and you know like - most peo- an(d)

(91) So like I- I- I- could

(92) W(e)11 like um - with my brother-in-law

(93) Well like I p- y'know play tennis

(94) So like if you play song-one song-two song-three

In many of these cases the 'for example' reading is completely inappropriate (in (89), for instance, like precedes a problematical descriptive term; 'buzzing' is not one of many things that could have been mentioned, but one way of designating what the speaker's sister's dog did to a parakeet on a particular occasion). It is over cases 
like these that the accusation of meaninglessness waits most menacing$1 y$, and in which it is most tempting to label like 'hesitative' or 'procrastinative' (as does Urdang 1979:78; cf. Landy 1971:120; Major 1970:77; Woolford 1979:1237).

At first the fact that so many of these like's do not occur in absolute utterance-initial position suggests that there may be some specific element of meaning or use that renders like especially useful in this discourse position, but on closer examination, this positional tendency can be construed as evidence for the claim that like is a pausal interjection. In a study of hesitations in spontaneous conversation Boomer, expecting to find hesitations more numerous at the beginning of phonemic clauses, found instead that "the greatest frequency of hesitations is not at the outset but at position 2, after the first word of the clause" (Boomer 1965:151). Schourup (1981:5) suggests that the reason for this is that a speaker may wish to begin a constituent before having fully planned it, because beginning at all preserves the turn by signaling the speaker's intention to continue, while not beginning risks a turn change. Similar reasoning can be applied to the post-prefatory uses of like exemplified above. It is particularly notable that in so many cases like occurs following a conjunction, the use of which clearly indicates intended continuation.

If like can serve as a pausal interjection, this would also explain why it is frequently followed by filled and unfilled pauses. There are in the data 25 instances of like immediately followed by filled and/or unfilled pause, as in:

(95) They may not be nice - y'know like - um so nice. But they have nice dresses. [LAB-A, 12]

In only seven cases is like preceded by pause. There are, moreover, many instances of like preceding a restart (a point at which the present speaker stops an item under construction and recommences):

This like- This movie takes place in 1968

What we do is like- We did a uh

Three distributional facts point to the usefulness of like in positions of pausal interjection: its occurrence a) preclausally but after prefatory material; b) before filled and unfilled pauses; and c) before restarts. Moreover, like is odd in positions in which pausal interjections are in general odd (cf. James 1974:150-151); that is, like is odd in positions in which a pause to consider how to continue would be unmotivated:

(98) *Not, like, only did John go, but he took all his stuff with him.

(99) *I did, like, not!

(100) *Get out of here, and if you don't obey, like, me, I'11 sock you.

(101) *It's Julie's birthday today. We're giving, like, her a surprise party.

(102) * Jack flies planes carefully, but I do, like, so with reckless abandon. 
Interjectional use of like seems to be a conventionalized way in which many speakershandle the recurrent situation in which they intend to continue an utterance but find it difficult to formulate the continuation. Notice that like, at least as used current $1 y^{8}$, sounds peculiar before material that is easily formulable:

(103) Q: Were you born in Austria?

A: Like no.

The evincive reading of like is not strongly present in many of the examples (78)-(94), but this reading is not entirely irrelevant either. Coulmas (1981:2) writes of "the delicate double analyzability of many routine formulae". In the case of the single word routine like the double analyzability is of an interesting kind that can shed light on the reason for the routinization of the item. Notice that the evincive reading of like is very generally applicable and appropriate in conversation because it is not limited to use in highly specific contexts. Like with this reading finds itself potentially at home in almost any utterance. The interjectional use of like may have acheived such great popularity with some speakers precisely because of this. Such speakers may use for hesitation forms the basic contribution of which will not importantly alter what the speaker is saying, but nevertheless have the virtue of being words, so that by using them speakers can be heard as 'saying something' even if a proper formulation of their thoughts for the moment eludes them (cf. Jefferson 1973: 69 on the notion 'utterance lengthener').

The position taken here is that it would be unwarranted to claim that interjectional like makes no contribution to utterances in which 1t occurs: like can be used as a routine hesitation formula but can serve this purpose because its core evincive use is both universally applicable and relatively innocuous to the proceedings. A speaker saying like during a pause to formulate a continuation subtly suggests a reason for the pause: the material about to follow 9 is difficult to formulate appropriately or precisely. This is implied by the proposed evincive reading of the 1tem. Unlike well and oh (Chapter 2) 1ike is not predominantly an initiator, because formulation difficulties can and frequently do arise within an utterance or sentence. It is not surprising that like is found, aside from the favored positions already mentioned, distributed before many different phrase types and word classes:

(106) He was just- 11ke losing it [LAB-A, 16]

I was able to like a(d) just [RTS,12]

he like magnified it [RTSa,4]

he like scuffed up against... [LAB-B, 16]

it w- like bled a little bit [LAB-B,16]

We have like rabbits that hop [ $L A B-B, 24$ ]

It has to do with like uh things [RTSa,9]

$\mathrm{He}^{\prime} \mathrm{s}$ wearing like an apron [Chafe 1980:301]

did ya put it on like a blue...[RTSa,5] 
I can hear like a buzzing [LAB-B,19]

He was like shy [RTSa,3]

get like really heavy or serious [RTSa,1]

eating like Chinese food [RTSa,6]

we had like wicker baskets [Chafe 1980:309]

who'd actually been 1ike--good samaritains [Chafe 1980:317]

It'd be like chilly enough [RTS, 20]

with like - store Levis [LAB-A]

We'd leave like early so I could...[LAB-A, 16]

He was like very funny [RTSa,6]

We're gonna be like basically uh [RTSa, 8]

You see him - like - at a- at a distance [Chafe 1980:302]

supposed to have like a Cambodian character [RTSa,4]

playing like with - I don't remember [Chafe 1980:309]

There's like this situation [RTSa,3]

everything's like thrown off [RTSa,8]

To say that the evincive use of like can be latent--accessible and relevant but not prominent--amounts to proposing that we must speak of degrees of meaningfulness, 11teralness, or usefulness (cf. Powell 1981) of items of verbal routine. However unpleasant the repercussions of this proposal may be--for they tend to cast the study of verbal routines into even murkier depths than they already occupy--some such notion seems unavoidable. If we consider the literal meaning of lexical hesitation forms to have been completely superceded by their routine function, we must account for the unimaginability of, say, unlike or four as hesitation forms. 10 (See also the discussion of this topic in Chapter 1).

Twenty-two subject volunteers were queried to determine to what extent, if any, they were able to assign a particular use or meaning to like in some of its nonstandard positions of occurrence. It was reasoned that if the evincive reading is latent rather than nonexistent, it should be accessible to some extent when subjects have a chance to scrutinize an utterance containing like. Students in an introductory linguistics course were asked to consider the word like in the following six conversation excerpts:

(105) She was very like open about her past.

(106) There was like nothing in any of the cupboards.

(107) So like after the game we went down to the Char Bar.

(108) Dorothy is like constantly asking for attention.

(109) Oh fine. Except Ralph like kept kicking me under the table.

(110) No matter what they say, I'll be like...flattered.

Subjects were asked to write down the meaning, if any, of like in each of the example sentences. They were given as much time as they needed.

Although the 'meanings' assigned to like differed from speaker to speaker and from example to example, virtually all were consistent with the evincive reading in which like indicates a possible minor nonequiva- 
lence of what is said and what is meant. The responses, however, tended to be quite specific about the particular discrepancies involved. For example, subjects agreed that in (105) like somehow suggested a special meaning for open but disagreed about what the special meaning was. One speaker suggested 'indirectly open'; another, 'very open but very blunt'; another, 'open, as you may have known other people to be'; another, 'almost very open'. One speaker even suggested that openness was only one of the qualities involved (the 'for example' reading). In each case like was understood as conveying a difference between the speaker's words and what the speaker intended.

Similar disagreements were found regarding the meaning of like in (106). Subjects saw like as conveying a special sense of the word nothing. Some of the suggested meanings: 'nothing worth having', 'nothing of importance', 'nothing that had appeal or value to the speaker', 'nothing the person wanted', 'nothing of interest or usefulness', 'nothing that she likes', 'almost nothing', 'it just seemed like nothing', 'absolutely nothing'. What these responses have in common is, again, that they convey an extra element of meaning beyond what the words following like would ordinarily convey. Two subjects thought like conveyed that the speaker was surprised or amazed at how empty the cupboards were.

Like in (107) was taken to qualify after the game. Some of the suggested meanings: 'not immediately after', 'a while after', 'soon after but not immediately, 'not immediately following'. Two subjects assigned the 'for example' reading.

Subjects disagreed about whether like in (108) expressed qualifications about constantly or emphasized 1t. One subject felt that like conveyed that the speaker felt the questioning to be 'a burden'. Similar disagreements were found with regard to the extent of the kicking in (109); some subjects felt that like emphasized the amount of kicking that occurred, while others felt that it was less than kept kicking me seemed to indicate.

In a few cases subjects offered more general meanings, also consistent with the evincive reading:

(111) "Speaker is unsure of how to say what he means" [re:(110)]

(112) "hesitant to say what you know" [re:(111)]

(113) "gives the speaker room for qualification" [re:(111)]

(114) "expects the listener to fill in" [re:(111)]

In (110) like was followed by periods, a conventional orthographic indication of pause. One subject noted that the speaker has paused to think of the word flattered but nevertheless assigned an evincive reading to like: 'not sure he' 11 be flattered'. Another subject suggested that like "shows a comparison with a word not there, maybe a word simflar to flattered'. Another suggested that like...flattered means 'as if flattered'. Yet another suggested, 'She feels she is flattered but is not sure if that is the way she should take it'. 
Another: 'really wonders whether he'd be flattered or not'.

These results indicate quite clearly that, while the basic use of like may not be consistently or clearly accessible to introspection, when a reading is assigned in a situation of close attentiveness, the use assigned the form is essentially the proposed evincive one.

\subsection{It's Like}

There are several instances of it's like in the data sentenceinitially without the clear literal sense in which it has a specific discourse referent or a referent in the situation of utterance (as in Carmelita has a hot car. It's like the one that Cecil bought.). Rather, it's like appears to have the same evincive reading that like has by itself--but here again the evincive reading may have been eroded somewhat by routinization of the item as, in this case, a sentence-initiating routine. But the evincive reading is available and appropriate if one were to insist on literalness. In the following examples the pronoun can, if pressed, be taken to refer to what the speaker has in mind to express:

(115) H: Does he thwart you at any time? Y'know w- things that he says?

C: Uh n: :ot really. It's like uh: : uh: :m uh in a playful kinda way I guess - y'know [RTSa, 1]

(116) $\mathrm{H}$ : It doesn't even get to the point where you kinda do a double take? ...

C: Uh $y$ - Well - It's like w(e) 11 sometimes that does happen. [RTSa, 3]

(117) C: They tailor-made it uh - for us - almost - y'know. It's like they wrote it around us [RTSa,3]

(118) C: I mean like uh: : - I I like to use all kin(d)a pipes Ex-Excuse the expression - $y^{\prime}$ know like uh $y^{\prime}$ know wha( $\left.t\right)$ I- It's like what is that thing called? A 'buyer'? $[\mathrm{RTSa}, 5]$

(119) EVA: An(d) it's like - y'know it's (j)us(t) (n-) - ya can't pass anybody anyway. It's one o(f) them- It's like- the road I live on here in Ohio y'know like - one lane or $y^{\prime}$ know it's two-way (ya gotta) go off the side o(f) the road for anything ta pass... and it's like - It's just kinda wild. [LAB-A,64]

(120) H: How does a guy from Cheyenne find relating to let's say a Barbara Streisand kind of an audience? Uh - an easy or a hard job.

C: W- It's like when I went into the service - I went in the Marines - we were - [tells story] [RTS, 13]

(121) $\mathrm{H}$ : Is that a secret ambition? [1.e. doing a musical routine] C: Uh: yes...But it's like uh right now we've written like 
uh quite a few songs. [RTS,13]

(122) C: I met Charlie Goodrich and it's like I met him at Aspen... [RTS , 6]

(123) C: and uh $y^{\prime}$ know it's like uh:m we did a thing on the Ed Sullivan Show. [RTS]

Two additional examples of it's like appear in the data preceding internal quotation (cf. 3.2 above):

(126) It's like "Oh God. There's all these people walking by" hhh. [LAB-A, 6]

(127) People wouldn't touch her for years because it's like "Oh she's a singer" y'know. [RTSa]

Note that, just as like does, it's like frequently occurs before hesitations and other discontinuities. In all but two of the above examples it's like precedes a discontinuity of one kind or another. The only difference between it's like and like seems to be that $1 t^{\prime} s$ like is restricted to clause-(and usually sentence-) initial position. It's like occurs far less frequently than like, and there may be an implicational hierarchy in their use: speakers who use it's like also use like, though the opposite appears not to be the case.

\subsection{Conclusion}

In the preceding discussion it is argued that the current efflorescence of like in conversation, at least among younger speakers, is not a symptom, as Newman would have it, of "the death of English", but the spread from its originally quite restricted range of occurrence of an item which in general indicates a possible loose fit between overt expression and intended meaning. With this use like is particularly suited to conversation, where speakers (even, probably, Edwin Newman) frequently find themselves in the position of having to formulate what they have to say without the time for the considered eloquence possible when they are, say, hunched over a manuscript. The exigencies of speech, and even sometimes of writing, often call for such eminently acceptable locutions as so to speak and as it were, which, by rights, ought to be subject to as much censure as like insofar as they too indicate speakers' inability to forumlate a strictly accurate or appropriate version of what they want to express. No doubt like is the scapegoat of normativists because it is, at least in some positions of occurrence, a newcomer.

To claim that the 'aberrant' uses of like are all meaningless is simply wrong, though this charge may be correctly leveled--but only to an extent--at the routine interjectional use of like in which the evincive reading is less prominent, though still appropriate. The charge of meaninglessness is, on the other hand, clearly unjustified in the case of like before exact or obviously inexact descriptions and 
internal quotations.

To the extent that evincive like is a provision for loose talk, it is understandable that its use has been criticized. However, similar uses of 1 ike have been observed for centuries in English 11 ; and only a pedant would insist that speakers ought to be always able to find the perfect outward expression for their thoughts. In addition to like and the more respectable expressions as it were, so to speak, more or less, in so many words, in a way, etc. (a list appears in G. Lakoff 1972), English has at the moment sorta, kinda, kinda like, sorta like, etc., all of which can under certain circumstances indicate a possible discrepancy between what the speaker has in mind and what is overtly said (though, as Lakoff points out, there are fine differences between some items). Such forms and expressions evince a discrepancy rather than specify it, since if they did specify it, there would be none. 12

Nor can English be considered moribund for requiring items that acknowledge flawed, or possibly flawed, expression. Speech is by nature a selective and often an approximate rendering of mental contents. Though there might be a case for some thoughts being perfectly expressed by some wordings, it seems unlikely that such a perfect connection exists as the rule. In any language one may comment on this fact, but the situation arises so frequently in speech that languages have conventional ways of dealing with it. 13

Like thus joins the rank of maligned conversational items recently being resurrected under the comely title 'discourse particles'. Such items have a specifiable use in conversation but do not lend themselves to static entries in dictionaries. Evincive like, and other evincives, comes to life in the dynamics of ongoing talk with its temporal and turn taking requirements, unexpected turns of topic, sleights, distractions, and on-the-spot negotiations. In this kind of behavior the courses of thought and talk frequently diverge, and it can be helpful to the ends of communication if speakers have a simple way of saying so, or of making it seem so.

Even in the use in which it is most routinized--as a pausal interjection--evincive like has its peculiar virtues. Rather than just filling a hole in an utterance, it offers, at least insofar as its core use is attended to, a reason for the pause. By saying that what follows will be like what should or could be said, the speaker suggests that some thought is difficult to formulate. By being explicated, the pause is detoxified, becoming polite and reasonable, an attempt at expression rather than a failure of communication. 
FOOTNOTES -- CHAPTER 3

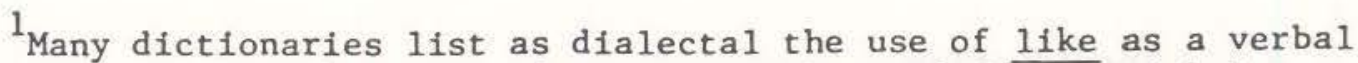
auxiliary meaning 'came near', as in I like to fell out of bed.

${ }^{2}$ This term is due to G. Lakoff (1972).

${ }^{3}$ This usage is, however, mentioned in an editor's note to Schourup 1982 .

${ }^{4}$ In an informal survey of 25 undergraduates at Ohio State, eight claimed to use the construction regularly and all had heard it. The students all agreed that the quotations it introduces are internal.

5' Thus' is probably an attempt at fluent English translation. It is clear that the item's usual meaning is 'like'.

'Webster's Third does list a 'for example' reading for like in its use as a conjunction: when your car gives trouble--like when the motor won't start.

7 Woolford considers the use of like to be peculiar to California. This is certainly not the case.

${ }^{8}$ Did anyone, except the critics, ever really say "Like H1!"? I suspect that this and other bizarre cases are due to overzealous imitation by people who don't use like and are mystified/horrified by 1 .

${ }^{9}$ The material may precede in the case of sentence-final like.

${ }^{10}$ Perhaps this should be a query: do such cases exist?

11 Wright (1957:637-638) cites a pre-19th century example: So, like, I went directly.

${ }^{12}$ Scare quotes are often used in writing to do what like does in speech. Examples are scattered throughout the text of this dissertation.

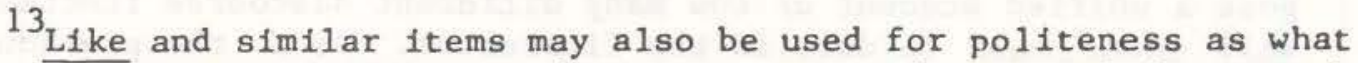
House and Kasper (1981) call 'modality markers'. Such hedges can be used to avoid "a precise propositional specification thus circumventing the potential provocation such a specification might entall" (167). 
CHAPTER FOUR

WELL

\subsection{Introduction}

In this chapter it is argued that the discourse particle well is an evincive with a particular basic use and that this fact is crucial to understanding the various ways in which well is used in conversation. The discourse particle is to be distinguished from the adverb well, as in

(1) She swims well.

and the 'degree word' well, as in

(2) We were well into summer before the fog lifted.

The well discussed in this chapter is usually referred to as an interjection and has no obvious synchronic connection to the adverb or the degree word. The use of the discourse item is illustrated in (3) and (4):

(3) Well, I don't know.

(4) There were, we1l, four of them.

Because it occurs so frequently in ordinary talk, the discourse particle well has been the subject of several recent studies. Particular interest has been shown in the 'discourse function' of well, which has been examined by considering how the appearance of this item in an utterance (imagined or actual) alters the meaning, use, or appropriateness of the utterance. The general result of these studies has been to isolate a number of putatively distinct uses of well, each representing the pairing of some identifiable discourse position and an aspect of the meaning or use of utterances containing well in that position. The great variety of such uses has led, in addition, to general pronouncements about what these uses, or some subgrouping of them, have in common.

The principal aim of this chapter is not to dispute the accuracy or relevance of these previous studies (though some analyses will be questioned, and in some cases revisions will be suggested) but to propose a unified account of the many different discourse functions of well identified to date in the literature. As in the previous two chapters, this w1ll involve having recourse to the notion 'evincive' (see, especially, Chapter 2), which, in the case of wel1, turns out to have considerable explanatory value. The issue to be addressed with 
regard to each of the discourse functions considered will be why well in particular is used to fulfill each specific discourse function. The authors of the functional studies of well to be referred to below have seemed content, with two exceptions to be discussed, to talk about well as if its function were entirely describable by characterizing the function of utterances containing it. It will be argued below that as an evinclve well has in fact a single use and that in particular discourse contexts this single use can lead to a variety of possible interpretations based on the interaction of the basic contribution of the item with the contexts in which it occurs. The claim, then, is that once the use of well has been correctly isolated, the 'functional polysemy' of the item is predictable and understandable.

If, as just claimed, well has a single isolable use, how have so many researchers, many of them native speakers of English, managed to overlook it? The answer is probably that the basic contribution of well is not clearly accessible to introspection. For one thing, to adequately characterize the use of well, a speaker would have to correctly formulate its evincive status. This is a lot to ask. But the problem may be even deeper. In reporting the meaning of a sentence linguistically naive speakers do not carefully sort out pragmatic from strictly linguistic factors, and even competent linguists find it hard to extricate these two bedfellows. When speakers attempt to consult their intuitions about the contribution of well, this contribution is reported as an amalgam of the basic lexical contribution of the word and the implicatures and contextual understandings relevant when that contribution is used in situ (compare, in this regard, the meaning reports in Chapter 3). A third possible reason for difficulty in reporting the contribution of well is that interjections operate some-

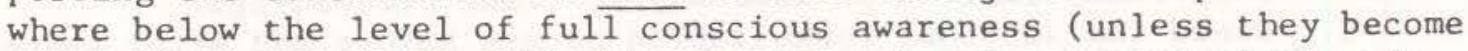
so abundant as to draw attention to themselves). Interjections are not in general heard as crucial to the content of an utterance and are, therefore, typically not faithfully reproduced in, for example, the retelling of a joke. Well does not entirely resist introspection, of course, as the studies discussed below attest. Differences between utterances containing well and those, otherwise the same, that do not, are noticeable, but they represent a combination of the basic contribution of well and contextual interpretations of its use.

The proposal of this chapter is that the basic evincive use of well is to indicate that the present speaker is now examining the contents of the private world. The many distinct uses of well in discourse all share this core use, though the net interpretation of an utterance containing well will only be explicable by answering two questions: 1) Where in the sequential development of a particular sentence, utterance, exchange, conversation, etc., does we 11 occur? and 2) Why does the speaker in that particular context and sequential position choose to draw attention to his or her examination of the private world? In the following sections each of the discourse functions that have been attributed to well is examined individually with a view to showing how each can be appropriately described by answering these two 
questions, provided that in each case well has the basic evincive use just proposed.

\subsection{We11 Before Exclamations}

Svartvik (1980) takes well in examples like Well I'm damned (cf. American English Well I'11 be damned) to be an expression of "exclamatory surprise, etc." (173) and considers this use of well distinct from its other uses. Notice, however, that the expression I'm damned alone conveys exclamatory surprise, so that there is really no clear case for well itself having this meaning. It can be suggested that well is common before items like shit, gee whiz, and hell, because such items are only appropriately uttered when the speaker has clear justification for resorting to emotionally charged language. Because well expresses that the speaker is engaged in private thinking, and does this just prior to the exclamatory utterance, well can be taken here to indicate that grounds for strong language exist. Well does not itself indicate what these grounds might be--1t indicates only that what the speaker says is immediately preceded by internal consultation.

The interpretation of well in this case can be broken down further in a way that will be useful to apply to other functions of well also:

1. Well indicates speaker's current internal consultation of the private world (the core use);

2. since speakers routinely attend to the conversational proceedings in which they are participants, this inward consultation is inferrably related in some way to those proceedings;

3. Since the internal consultation occurs before and after sequentlally placed contributions of talk, well is inferrably relevant in sequence; that is, it is specifically relevant with respect to what occurs before and after it;

4. an addressee may attempt to discern a reason why the speaker has used a marker of internal consultation at a glven sequential position in a conversation and, in making the assumption that the speaker is being cooperative, may try to deduce the reason for the consultation being evinced by use of well rather than brought up explicitly in the shared world; and the speaker using well may expect such inferences and deductions (or guesses) to occur.

In the particular case of Well I'm damned, well is seen as relevant to the uttering of $I^{\prime} m$ damned. Since $I^{\prime} m$ damned is an expression of strong emotion, well is inferrably used here in an attempt to justify the employment of this charged item in the shared world. The speaker appears to be saying, "I'm not simply losing control of myself here --there is a good reason, which I am now internally consulting, for my cholce of this emotive expression." The specifics of the justification that well evinces will in some cases be apparent to both speaker and interlocutors. For example, Well I'm damned could be spoken after another's shocking announcement. But these details may also be 
something to which only the speaker is privy--for example, if Well I'm damned were uttered when the speaker had just felt an ectopic heart beat or suddenly noticed a close visual resemblance between some other conversant and Marie Curie.

The procedure in 1-4 above will be referred to below as the Basic Interpretation Pattern for the use and understanding of well in conversation. This pattern will be alluded to repeatedly below in the discussion of other uses of well; it always applies in the same way, although the particulars in step 4 differ from context to context. Note that no claim is being made that speakers sequentially apply these steps in real time; the intent is simply to enumerate the factors involved in a correct contextual interpretation of well.

\subsection{Well Introducing Direct Discourse}

Svartvik comments that well is used as a "signal indicating the beginning of direct speech, parallel to that of quotation marks in writing" (1980:175). It was argued above in Chapter 2 that well in this position has simply its basic evincive use. Strictly, it is correct in one way, and incorrect in another, to compare the use of well to that of quotation marks--correct in that well can perform the enquoting function (see 2.4), but incorrect in that well is attributed to the quoted speaker. Subjects presented with example sentences like (5) invariably agree that well is part of the quotation, not an item basically attributable to the quoting speaker:

(5) Roger said, "Well, think it over and let me know Tuesday."

Moreover, to claim that well is simply an enquoting mark fails to explain why many other evincive interjections are capable of serving the same function (see 2.2.1).

It was argued in Chapter 2 that well is in general a construction on the part of the quoting speaker inserted by that speaker as backgrounding for the substantive part of the quotation (but intended and heard as attributed to the quoted speaker). Evincive well, because it calls into play the Basic Interpretation Pattern is useful to contextualize a quotation by providing a background against which it can be appreciated. Via the Basic Pattern, well invokes a situation in which the quoted speaker may be seen as having spoken out of some then-current consideration and thereby situates the quotation as an integral part of some nonpresent situation.

Goldberg (1980:113) suggests a similar, but importantly different function of well in utterances like (5). "Perhaps it is because the well ties the utterance-unit back to the preceding utterance-unit that well of ten prefaces reported speech. The quote is used to support or add colour to what has been related." First.notice that, as Svartvik did, Goldberg disregards the fact that well is attributed to the quoted rather than the quoting speaker. If it links anything to something prior, therefore, it should be seen as linking the quoted utterance to 
something prior for the quoted speaker in the reported situation of utterance, not to the contribution of the quoting speaker. If such well's were to be heard as a linking device for tying together utterances of the quoting speaker, we would expect well to occur somewhere before, not after, the verb of verbal communication, since occurring after that verb well is assigned to the quoted speaker (see 2.4).

Note also that Goldberg's comment concerns the utterance-unit containing well rather than well itself. The principal force of her work on well and other discourse particles has been to demonstrate the collocation of these items with particular types of conversational 'moves'l and the interpretation of particles as 'markers' of these move types. In the case of well introducing direct quotation, this leads away from the basic sense of well to an attempt to see well as a marker of a 'holding' or a 'progressive holding' move:

An utterance-unit is ... a holding move if it is a backchannel or if its discourse referents are drawn from those in the utteranceunit (s) which immediately preceded it, that is, referents may be "subtracted" or dropped but new referents may not be added; [an utterance is] a progressive-holding move if it shares some of the same discourse referents as the prior utterance-unit but also adds additional referents not present in the prior utterance-unit.

(Goldberg 1980:89)

The treatment of well as a marker of move type involves a difficult step of reasoning (which proves equally problematic for Goldberg's treatment of $y^{\prime}$ know discussed below in Chapter 6): use of the word 'marker' implies that the item in question cues move type rather than that it is simply a frequent concomitant of certain move types. Presumably something referred to as a 'marker' is used by speakers specifically to mark move type and is understood that way by others. The weaker position, though it is the strongest position supported by Goldberg's data, is that well (because, I would claim, of its basic evincive use) is more likely to occur with some move types than others. The stronger 'marking' position would seem to require for its support a demonstration that conversants can actually identify move types by referring to well exclusive of following material. It seems unlikely that this could ever be demonstrated, however, since well in fact occurs with various move types and could not, therefore, unambiguously indicate any particular one. ${ }^{2}$

As fllustrated in the following section, the evincive treatment of well can be used to explain the frequent occurrence of well with particular move types.

In any case, the applicability of move analysis to well beginning quotations is 111 -founded so long as the analysis attempts to relate the quoted utterance to foregoing material contributed by the quoting speaker. Such well's are more approprlately viewed as backgrounders (Chapter 2) that contextualize the quotation with respect to the quoted speaker's situation of utterance. Such backgrounders are in 
fact heard as speech attributed to the quoted, not the quoting, speaker.

\subsection{Topic Shifting}

Svartvik (1980:174) cites an example (here rewritten in reader's notation) in which well closes previous discourse and focuses on following discourse, offering as synonyms for this use 'all right then', 'so', 'ok', 'consequently':

(6) A: but if they wanted people around to talk to - then I would be very happy to sat - (and) got a letter back saying we have arranged for you to stay - Well let's take the interview first.

This can again be regarded as simply the evincive reading used in conjunction with the Basic Pattern. Without well the speaker would be seen as peremptorily changing topic without taking leave of the other participant to do so. This might lead to unwarranted implicatures (for example, that the speaker is concealing something or is disturbed by the direction the conversation is taking). By evincing covert consultation at the point just before an abrupt topic shift, the speaker can imply that the shift is a considered one and, by announcing that the consideration is occurring, invites the interlocutor to fill in some reasonable motive for the shift (for example, that it is time to get to the business at hand).

Consider the following constructed example:

B: ((talks about his new swimming pool))

A: Do you have the merger papers with you?

B: Yes. So I thought, "Nine feet? Sure, that's deep enough."

A: We11, can we get started on this now?

B: Oh, sure. I'm sorry. The papers are right here.

Goldberg (1980) includes cases of this sort with instances of well prior to continuations following side sequences (see Jefferson 1972), well initiating a (pre-)closing section (see Schegloff and Sacks 1973), and well introducing the first topic of a conversation. She comments, "Well marked moves are essentially 'backward looking' with a forward looking disposition--that is, well marked moves tie the current utterance-unit back to the prior utterance-unit(s) while providing information which progresses the conversation into its next phase" (105).

It was suggested earlier that the fact that well ties previous to following material follows simply from the fact that it occurs after preceding material and before following material (as do all other conversational items except the first and the last) and, given the cooperativeness of speakers, is taken as relevant to the developing conversational sequence in the sense that the speaker is presumed to be mindful of what has been said and prospectively attentive to what is to be said next. Even items like actually, which specify a break with 
preceding material (see Goldberg 1980) are 'backward looking' insofar as they establish a break between what follows and what precedes.

Topic shifts, preclosings, closings, and changes from introductory to topic talk are all straightforwardly what they are. The well often prefixed to these moves indicates that the speaker makes whatever the move is with prior consideration. To mark this consideration as occurring at just that point has the effect of smoothing the transition to the next phase, but well has this effect only by virtue of its basic use applied in the particular context in which it occurs; by drawing attention to the considered nature of the shift, the speaker indirectly provides that the shift is a motivated one and thereby forestalls any possible accusations of noncooperativeness, peremptoriness, or lack of attention to the developing sequence of shared talk.

\subsection{Well Before Answers}

Noting the occurrence of well in examples such as (8) and (9),

(8) What time is it?

We11, the sun just came up.

(9) Did you kill your wife?

We11, yes.

R. Lakoff (1973:458-459) proposes that well preceding an answer expresses either some kind of insufficiency in the answer itself, or that the answerer considers the question to be in some respect insufficient or deficient. Hines' treatment (1977) differs from Lakoff's in treating well as an acknowledgment that the addressee has heard the question and grants the previous speaker's right to ask it. In either view it is expected that well will frequently occur before indirect answers, as in (8): these answers might otherwise be in danger of seeming unresponsive or uncooperative.

Hines claims that if well precedes a direct answer, it expresses either that the speaker is unsure whether the answer is responsive to all that is meant by the question, or that the question is itself deficient in some way--for example, in that it asks for information the questioner may be presumed to have already (cf. Hines 1977:311).

In Hines' treatment well does not itself indicate insufficiency but rather is used to implicate insufficiency. For example, occurring before a direct answer, as in (10),

(10) Q: What time is it?

A: Well, three o'clock.

well is, in this view, heard as basically acknowledging the questioner's right to ask the question. If the answerer acknowledges the speaker's right to ask the question where such an acknowledgment is not obviously called for, as in (10), the answerer thereby implicates that the right to ask the question was questionable. 
The evincive treatment of well offers a simple explanation for why well is found so commonly before indirect answers and after questions the answerer finds problematical. Again, the Basic Pattern can be called into use. The primary fact here is that the speaker chooses to express that inner consultation is occurring prior to answering. Hines' term 'acknowledgment' is functionally apt in cases like this, but the evincive treatment explains why well is capable of performing this acknowledgment.

Since well evinces current inner consultation and is placed between the two parts of a question/answer sequence, between the question that just occurred and the answer that is about to, well is inferrably related to the question and/or the answer. In any case the question is taken into consideration and thus, in effect, acknowledged.

The evincive treatment also provides a reason for the 'insufficiency'. To evince internal consultation at a given point embodies a claim that to announce such consultation there is deemed relevant by the speaker. Since the expected response to a nonrhetorical question is a prompt and direct answer, any failure of a direct answer to follow the question in timely fashion implies difficulty on the speaker's part in answering. Either the meaning, appropriateness, etc. of the question, or the answering process, may be the source of the difficulty. We may predict, as a third case not mentioned by Lakoff or Hines, sequences in which both question and answer are deemably insufficient. (11) is a hypothetical example:

$$
\begin{aligned}
& \text { Q: When did it all begin? } \\
& \text { A: Well, if you mean the universe, I don't think it had } \\
& \text { to have a beginning, per se. }
\end{aligned}
$$

The fourth case in which no insufficlency is really involved but an inner consultation nevertheless occurs is not a real possibility. That well after questions implicates an insufficiency follows from the fact that it is issued between the question and the response or answer. Labov and Fanschel (1977:189) note that well has a "temporizing and delaying" function. This follows from the evincive treatment: the speaker has paused to consult his or her thoughts. If so, the speaker must have been 'given pause' by something. This will be interpretable as indicating some insufficiency in the question or the answer or both.

\subsection{We11 Before Questions}

in

R. Lakoff (1973) comments that well used before questions, as

(12) Well, who's going to take out the garbage?

expresses insufficiency felt by the user of well to obtain in the utterance or action to which the question is a response. Here again, an interpretation invited by a particular discourse context has been mistaken for a property of the word well itself. (12) conveys the speaker's impatience (due to an insufficiency in the existing situation). 
But why would the speaker of (12) want to indicate inner consultation? The Garbage needs to be taken out (if this is a bona fide indirect request) and nobody is clearly intending to do it (another condition on sincere requests). We1l is used to indicate that the speaker's indirect request is based on consideration of the existing situation, which itself involves an insufficiency. Well does not convey the insufficiency--the question following well implicates it.

\section{Or consider (13):}

(13) We11, why didn't Harvard trounce 'em?

This well merely indicates that "Why didn't Harvard trounce 'em?" is a considered question. It is certainly true that there is something lacking in the situation to which the question is a response, but does well convey this? The question itself does so. If a question was asked, it must be because not all of the information the speaker of the question needs is apparent or has been provided. The only difference attendant on the use of well here is that by issuing it the speaker expresses inner consultation for one of various reasons none of which is explicitly announced by well itself, but which may thereafter be hinted at, implied, explained, or left hanging by the speaker, and for the addressee's part, may be guessed at, inferred, or, for that matter, left unquestioned. Since a question follows this announced inner consultation, the consultation is heard as leading to the question. The speaker appears to be saying, "On the basis of consideration, I am led to ask this..." But this interpretation is grounded in pragmatics: to understand how well is used here, one must ask why it is that a speaker might 'announce' inner consultation prior to asking a particular question.

\subsection{Well and Self-Repair}

Svartvik (1980:75) and Goldberg (1980:229) cite work by DuBois in which he claims that well is one type of 'editing marker', specifically, a 'claim editing' marker, in contrast to markers of 'reference editing' (e.g. that is), 'nuance editing' (e.g. rather), and 'mistake editing' (e.g. I mean). The repair following a well of this kind "embodies a modification from the less accurate, more excessive, flamboyant or exaggerated to the more moderate and accurate" (Goldberg 1980: 229). This observation appears to be essentially correct; it may be pointed out, though, that once again the usefulness of well for a particular discourse function (here, claim editing) is only understandable when the basic evincive use of well is taken into account.

Well does not itself directly indicate correction of any kind. Note the discourse context in which these instances of well are found: after a repairable item and before a correction. The occurrence together of a repairable and a correction itself indicates that correction is being undertaken and what kind of correction is being made. To understand the role well plays in self-repair, it is only necessary to examine the consequences of inserting a marker of inner consultation 
between the two 'halves' of certain repair sequences. The other marker types mentioned by DuBois all serve their function by virtue of an element of meaning they bear. This is obvious from comparing the ascribed correction functions and the literal meanings of I mean, that $1 \mathrm{~s}$, and rather. As an evincive, well indicates looking inward at present mental contents. The repair cases in which such inner consultations are most likely to be of use are those in which the speaker wishes to reconsider something $s /$ he has just said and restate it more in accordance with those mental contents. This is all that well does at repair sites. The notion that the correction involved is more accurate, less excessive, etc. than the original is not a fact about well, or even about 'claim editing'; it is a fact about correction 1tself. Virtually all correction and editing involves improvements in the direction of more accuracy. To say that well marked repairs have this function is therefore not very illuminating.

Items like I mean, that is, and rather can help clarify the nature of a particular correction where this might be in doubt, but well indicates only that the speaker is reconsidering. The oddness of $a$ correction like (14)

(14) ? I have a dog, well, cat named Flora.

is due to the appearance it gives that the speaker is reconsidering the zootaxy of his or her pet. Such semantic substitution errors arise when the speaker slips and selects the wrong form from the mental lexicon. The speaker of an error like that in (14) does not mean cat as an inaccurate approximation of $\mathrm{dog}$, so no reconsideration is necessary-only substitution of the correct form. The item I mean is acceptable in semantic substitution errors

I have a dog, I mean, cat named Flora.

precisely because it specifically clarifies (with its literal reading) that the repairable is an incorrect (not simply inaccurate) representation of what the speaker has in mind to say.

Not all self-repair involves correction. Well, as noted by James (see 2.3 above), can occur at sentence-internal points of pause:

(4) There were, well, four of them.

Since the sentence is incomplete at the point where well is issued, the inferrable reason for the pause is that the speaker has paused to consider how to continue the sentence.

Although James in general defers to R. Lakoff (1973) for discussion of the meaning of well, she does make several comments regarding the sentence-internal use of the item. (James' discussion of well is in fact limited to these sentence-internal uses, and she even claims (1974:9) that well is primarily sentence-internal, although this is clearly far from the truth (see Chapter 2). One use of well mentioned by James is to indicate that "the speaker can be stopping to think of the best way of saying what he has to say" (1974:17). In this use 
well is only acceptable "when the speaker could have said something other than what he does say; when there is thus a reason for him to stop and think". Interjectional well thus "implies the presence of alternatives". Thus in her discussion of (16)

(16) Sue won't ever finish her novel, well, Bill thinks. James says, "it seems that in saying ... well before 'Bill thinks', the speaker is indicating that there are other things he could say in addition to, or instead of, merely saying 'Bill thinks'" (1974:192).

However, James also mentions two other possibilities. Well could indicate merely "reluctance to speak"3 (ibid. 196):

(17) I'm afraid John is, we11, dead.

or it could indicate that the speaker is "stopping to think about whether to suspend a presupposition", as in

(18) John doesn't beat his wife anymore, well, if he ever did. (James 1974:189)

But it can be suggested that these three uses of well are not actually distinct--that in each case well indicates Inner consultation and that the differences between these three uses are superficial and transparently related to the contexts in which well is employed.

James places considerable emphasis on the notion of interjectional 'reference'. She takes well in

(19) The girl who said she liked, well, Vivaldi dried the dishes. to 'refer' to Vivaldi in the sense that "it is that thing which, while pausing and saying the interjection, the speaker is selecting to mention over other things, trying to think of the best description of, or trying to remember, etc." (1974:113). James sees reference, in this unusual sense of the word, as a property of pausal interjections she studied and uses the notion to demonstrate several syntactic restrictions on the use of these forms. The position taken in the present work is that 'reference' is not a property of interjections, but a pragmatic notion that exists quite independently of them. The fact that interjections appear to 'refer' to constituents probably just indicates that constituents are units of utterance planning. Notice that even if an unfilled pause occurs instead of an interjection, the notion of 'reference' is still applicable :

(20) The girl who said she liked...Vivaldi dried the dishes. The idea that this speaker has stopped to consider the formulation Vivaldi dried the dishes is just as absurd here as in the case of (19). The notion 'reference' adds nothing to our understanding of the use of well in particular. The fact that well seems to 'refer' to what follows rather than what precedes (James 1974:125) results from the fact that James' internal well's precede continuations not corrections 
(which latter cases James does not consider). In the case of corrections it is clear that well is forward-referring only in the sense that what follows remains to be formulated; in corrections both the correctible and the correction are necessarily involved to some extent in the inner consultation.

\subsection{Well and Other-Repair}

Goldberg (1980) discusses instances of 'other-repair', such as

(21) B: It's very expensive here, I've discovered.

A: Yeah (.) Well it would be just as expensive here as in the States, do(n't) you think? (235)

She comments, "When prefaced by a well the speaker of the other-initiated repair is heard as challenging the repairable speaker's competence or expertise by indicating that the offered repair is a matter of common knowledge and that the speaker of the troublesome item should also share that knowledge" (ibid. 234).

Again an understanding of the evincive status of well can explain why well is used as it is in this particular discourse situation.

The 'challenge' aspect of other-repair with well follows from the fact that well evinces internal consultation following something the other speaker has said. Since the speaker issuing well, if cooperating, is presumed to be mindful of what was just said, to say well just afterward indicates that the speaker wants to be seen as internally consulting at that point. The occasion for this inner consultation inferrably involves the preceding utterance. Notice that even if well alone is uttered in this position, it can be heard as a challenge:

(22) A: I've known lots of people who've died by spontaneous combustion.

B : We11...

$B$ is not only internally consulting but announces that this is so following another speaker's statement. The Basic Pattern operates to yield a challenge: consideration following a statement by someone implicates that something about the statement has provoked the speaker's inner consultation. The challenge is not something inherent in the meaning or use of well but results from applying the usual evincive reading in yet another discourse environment.

The claim that the offered repair is a matter of common knowledge is not entirely accurate. The following exchange seems plausible:

(23) A: A friend of mine had hepatitis.

B: Which kind?

A: It was viral.

B: Well, a doctor friend of mine explained to me the other day that, contrary to popular belief, both major kinds of hepatitis are viral. 
Here $B$ is clearly not presupposing that the viral nature of both kinds of hepatitis is common knowledge. Other-repair this certainly is, however. (Notice that in (22) the shared knowledge aspect of $\mathrm{A}^{\prime} \mathrm{s}$ claim is explicitly indicated by do(n't) you think?)

tion:

Goldberg comments on well used in another kind of repair situa-

Well prefaced acknowledgments of the other's repair convey a sense of impatience or displeasure. The other-repair is marked as unwarranted at best and an uncondonable interruption at worst (Goldberg 1980:240).

She cites the following example:

(24) J: He went right down on the fie:ld'n'e w'js sittin there talkin like a nigger, en all the guys (mean) all these niggers er a:11// up there in-

R: You mean Ne:gro: don'tcha.

(.)

$\mathrm{J}$ : Weh en // there all-ih-u... (1bid. 240)

But is well really the culprit in this tense situation? The scenario: $\mathrm{J}$ is speaking; $\mathrm{R}$ indicates other-repair on an item that $\mathrm{J}$ considers not to be in need of repair. B's well (weh) indicates internal consultation regarding what has just occurred--the unwarrantedseeming repair. Repair in itself, as researchers working on this subject have found (e.g. Schegloff et al. 1977:380) is a risky business, however subtly initiated, because it can be the occasion for disagreement. The occurrence of an unwarranted or only questionably warranted repair can be taken as a 'face threat' of some magnitude. The possibility of impatience or displeasure on the part of $\mathrm{J}$ is implicit in this situation itself: the use of well with its ordinary evincive contribution in this situation can suggest that the impatience or displeasure that might arise there in fact has.

Goldberg claims that well in examples like (21) implies acceptance of the correction and points to a later element of that particular exchange that illustrates this. This is probably not a necessary feature of these exchanges. Consider the following:

$$
\begin{aligned}
& \text { A: I visited my Aunt Pete. } \\
& \text { B: Do you mean your aunt Greta? } \\
& \text { A: Well, I don't have any Aunt Greta. }
\end{aligned}
$$

Well here could only (indirectly by means of the Basic Pattern) Indicate acceptance to the extent of having understood and given due consideration to $\mathrm{B}^{\prime} \mathrm{s}$ question. In general one finds a polite attempt by speakers to see the good in repairs if possible, but it does occur from time to time that a repair is entirely unwarranted, and well does not seem to be excluded in such cases. 
4.9 Sentence-final Well finally:

It is frequently pointed out that well is inappropriate sentence-

(26) *My neighbor might wait for me for ten minutes, well. (James 1974:125)

In the evincive treatment, this distributional aspect of well proceeds from the fact that well is predominantly used as an infitiator (see Chapter 2). As an evincive initiator (a 'backgrounder') noninternal well's carry the strong implication that something will, or ought to, follow. Pronounced with a corresponding initiatory intonation, (26) becomes acceptable:

(27) My neighbor might wait for me for ten minutes. We11... Here the implication is that the speaker is reconsidering what $\mathrm{s} / \mathrm{he}$ has just said and considers beginning (but does not express) a reformulation; whereas, the speaker of (26) is in the peculiar position of assigning utterance-final intouation to an item strongly associated with initiation.

\subsection{Reduced Well}

Excluding suprasegmental variation, the two principal phonological variants of well are the full form [wE1] and reduced [w] ]. The occurrence of a particular variant is partly correlated with discourse position: the reduced variant does not occur as a pausal interjection:

$$
\text { *There were, }[w]] \text {, four of them. }
$$

The reason for this restriction is probably that well in sentences like (28) is used to embody a genuine pause for consideration and, if reduced, seems to indicate that the pause is only perfunctory.

A second interesting restriction is that [w] preceding a direct answer can be used (via the Basic Pattern) to indicate an insufficiency of the question, but not the inadequacy of the answer:

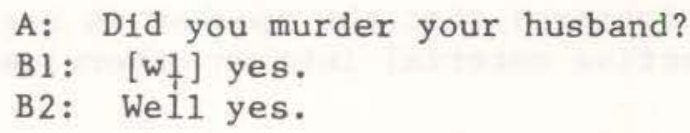

Responses B1 and B2 are used differently. B1 would typically be used to convey that the question asked by $A$ is inappropriate (e.g., because A already knew the answer). B2, on the other hand, is susceptible of this same 'inappropriateness' interpretation, but also, equally, of an interpretation in which the answer 'yes' is a qualified one. This difference is, again, probably attributable to the implication involved in using a reduced variant rather than to something about the meaning of well. This distributional restriction follows from an inherent difference between inappropriate questions and insufficient answers. Inappropriateness of a question is immediately apparent. The well preceding a considered reply, on the other hand, should, if it is to be 
taken seriously, be accompanied by a real pause to reflect. The reduced variant makes the inner consultation appear to be mechanical or perfunctory and so undermines the communicative aim of the speaker in uttering it.

\subsection{Wel1 and Narrative E1ision}

R. Lakoff distinguishes the use of well in narratives to "indicate that details have been omitted, that [the] narrative is not really complete" (1973:464). She cites the following example:

... So the man went to the old witch doctors who lived in each of the pyramids, as he had been instructed. He went to one after another, but none could help him. Finally, he reached the witch doctor who lived in the very last pyramid, and he asked him, 'How can I get the silver screw out of my bellybutton?' Well, to make a long story short, the witch doctor who lived in the last pyramid went into his pyramid and came out with a little silver screwdriver. He inserted this in the silver screw that was in the man's bellybutton, and he unscrewed and unscrewed and unscrewed, and finally the screw came out.

Lakoff offers this example (as does Hines 1977) in further support of the claim that well indicates an insufficiency, but the example cannot serve as evidence for this claim because material follows well that explicitly states that the narrative will be shortened. Moreover, if well also indicates narrative shortening. (30) should be redundant, but it isn't. Consider another case of initial well in a narrative:

(31) ... So what does Bill do? He gets out of the car and says he's going to walk if she won't take him. Well, that's a very long walk, but Bill walked the whole way without looking back once.

Elision is a possible reading of what is going on in (31), but it doesn't seem more likely than various other interpretations. Well could, for example, simply indicate that the speaker is pausing to consider or formulate what he will say next, or could indicate indirectly (via the Basic Pattern) that the speaker is beginning an aside to interject subjective material into an otherwise objective narrative account.

Or consider (32), for which the elision reading seems remote:

... She handed Robin the pancake on a plate and he said, 'but this pancake is GRAY!' He just stared at it with a look of horror on his face. Well, neither of them said a word for about a whole minute or so. Not a muscle moved, and then there's this loud bang from a passing car that backfired...

It is hard to see what could have been elided here, since nothing happended between the moment when Roger began starring at the pancake and the bang out in the street. What is much more likely is that the 
speaker paused for inner consultation. Of course, if one is pausing in the middle of a narrative, the subject of one's thoughts may well be how to continue or complete the narrative, or whether to elide certain material, but the particular reason for the consultation is not expressed by the well itself; it is something known to the speaker but left to be guessed at or inquired after by the addressee, or explicated later by the speaker issuing the well.

\subsection{Wel1 and 'Intension'}

Murray (2979) has proposed a unified account of well capable of handling a number of its uses. She makes the following claims (730):

A. We 11 signals (draws attention to) some expectation, hope, fear or other nominalization of an intensional verb, to which parties to the discourse are presumed to have access.

B. A pragmatic condition is attached to the use of well: it is appropriate to use well only if what follows is addressed to the same "intension".

The first claim runs into difficulty in cases like the following. Consider two people sitting in chairs in a livingroom reading. One says to the other:

(33) Well, how do you like that! Microbes are being used to build computers.

This is clearly not a case in which, in Murray's words, "there is an intension to which parties to the discourse are supposed to be privy" (731). This well can, however, be used to indicate that the speaker's statement is based on internal consultation (here, presumably, reflection on the reading material).

Discussing how her proposal relates to well preceding answers, Murray claims that "in question answers well is simply a signal that its speaker is aware of what some party to the discourse wants to be told" (730). This claim is problematic in cases like the following:

(34) A: Are you being flotsamed and jetsamed?

B: We11, I'm not sure what you're getting at.

The generalization that the speaker is engaged in internal consultation can, however, be easily used to account for this occurrence of well. since the speaker is here presumably considering how to interpret the question. examples:

As further evidence for her claim, Murray cites the following

$$
\begin{aligned}
& \text { (35) }\left\{\begin{array}{c}
\text { Oh } \\
\star \text { We } 11
\end{array}\right\} \text {, I've been forgetting to say ... } \\
& \text { (36) }\left\{\begin{array}{c}
\text { Oh } \\
\star W e 11
\end{array}\right\} \text {, by the way } \ldots
\end{aligned}
$$


(37) $\left\{\begin{array}{c}* 0 h \\ \text { We11 }\end{array}\right\}$, once upon a time $\ldots$

(38)

$\left\{\begin{array}{c}\star_{0 h} \\ \text { We } 11\end{array}\right\}$, so we' 11 meet at three ...

She comments, "Clearly, only well may introduce an anticipated topic, and only oh a new one". This observation is correct and consistent with Murray's claims, but does not support them against the evincive treatment. Oh 1 , by virtue of its core contribution (see Chapter 2), is used before material that just entered the speaker's mind. The unacceptability of well in (35) and (36) results from the fact that well indicates current consideration, which is inconsistent with the unexpected spontaneous arising of thought. The unacceptability of oh in (37) and (38) results from the fact that once upon a time and so we'll meet at three are initiations that would normally precede material that did not suddenly and spontaneously arise in the speaker's mind.

The first of Murray's claims is also problematic in cases where well seems to draw attention to the nominalization of an extensional rather than an intensional verb (assuming, for the sake of argument, that it makes sense to speak of well doing such a thing). Consider an exchange like the following:

(39) Could you please state your last two addresses? Well. I lived at $43218 \mathrm{th}$, and then at 1604 Canberra.

If well here is spoken with sharply falling intonation (conveying certainty, definiteness), it can be used to signal knowing (know is factive, not an intensional verb). If well is to be characterized as in Murray's first claim (A above), (39) should be at least mildly contradictory, but it is not. The evincive treatment is, however, straightforwardly applicable to (39): the speaker could be stopping to remember the addresses (with a positive expectation of being able to do so--conveyed by the intonation) and wish to indicate that this is so.

The pragmatic limitation mentioned in Murray's second claim (B above) follows directly from the fact that well is predominantly used as an initiator; as claimed above in Chapter 2, the association of well with initiation is closely related to its status as an evincive.

Thus Murray's proposals are interesting and remarkably comprehensive, but all of her examples submit readily to the evincive treatment, and her proposal fails to capture the behavior of well in some environments which the evincive treatment can easily handle.

\subsection{Conclusion}

The discourse particle well is primarily an evincive indicating consultation by the speaker of his or her current thoughts. The form 
cannot, therefore, be considered (as in Fries 1952:105) 'meaningless'. The particulars of the consultation evinced by well are not displayed by uttering it, though they may, of course, be elaborated in the speaker's ensuing talk. Inter-sentential well is heard as an initiator (see Chapter 2), based on its usefulness for backgrounding. With its basic evincive use, well serves many secondary discourse functions: introducing questions or answers, direct quotations, topic shifts, exclamations, self- and other-repairs, and so on. In each case the evincive use is primary and the secondary discourse function is a product of applying the Basic Interpretation Pattern to the use of evincive well in particular discourse environments.

The purpose above has not been to discredit the functional approaches to the uses of well, which are of interest in themselves, but to provide a unified treatment of well which has the following advantages over previous treatments:

1. It maintains that there is in fact only one discourse particle well, rather than a multiplicity of particles well each with a separate discourse function. This treatment is therefore much simpler and more comprehensive than existing treatments.

2. It explains why well in particular gets used for the discourse functions it serves and not for others, and therefore accounts for the item's observed functional 'polysemy'.

An important general feature of the use of well is that it is not used to indicate all internal consultation, but only consultation the speaker wishes to $\overline{\mathrm{br}}$ ing up. Many of the functions well may serve depend on the addressee's constructing the speaker's probable reason for bringing up the existence of covert thinking at a given point. Note also that well can be used to indicate current inner consultation of the private world even if no such consultation is actually in progress at the time--that is, well can be used wherever it is appropriate or desirable to indicate current inner consultation.

A previous attempt to specify the meaning of well by Hines (1977) failed to capture the evincive quality of the item. Hines suggested a link between adverbial well and the discourse particle (see also Sadock 1969:298), claiming that:

well is a word with positive connotations. It is used in an evaluative sense as an adverb to indicate a point just above adequacy. When it occurs as an introductory word, it also has positive connotations; it is an affirmation of the right of the previous speaker to say what he says ( 317$)$.

As implied in 4.5, this affirmative quality of well stems from its use in response to a question, which it indirectly acknowledges. Any real sense of affirmation beyond such acknowledgment evaporates when the item occurs preceding an explicit denial of affirmation: 
(37) A: Short people should be kept under pool tables.

B: Well, I hardly think you have the right to say something like that.

There is apparently no current semantic connection whatsoever between adverbial well and evincive well.

Consideration of the use of well is complicated by the fact that semantic nuances may be conveyed by the intonation with which the item is spoken. For example, the famed Jack Benny well, spoken alone to convey exasperation, is said with rise-fall intonation and breathy voice (literal exasperation). This same meaning could be conveyed by paralinguistic noises uttered with the same intonation and voice quality. This and other special uses of well seem to result from a combination of the evincive use with the separate contribution of intonation and other suprasegmental parameters 4 .

Here, as in the discussion of like in Chapter 3, the question of routinization must also be addressed. Has well become conventionalized as the embodiment of the various discourse functions it serves, so that its basic evincive use has been obscured? The contribution of this chapter to an answer to this question has been to establish that the basic evincive use of the item is respected by all of the separate discourse functions the item can serve. This seems to indicate that the basic use persists and underlies these discourse functions. 
FOOTNOTES -- CHAPTER 4

${ }^{1}$ Goldberg cites Goffman's characterization of conversational moves as having "a distinctive unitary bearing on some set or other of the circumstances in which participants find themsevles" (Goffman $1976: 272)$.

${ }^{2}$ Goldberg entertains a fallback position in which rather than marking move type, discourse particles merely reinforce move type (1980:127), a much weaker and vaguer claim.

${ }^{3}$ The reason for this particular pause could also be that the speaker is deciding whether to use a euphemism or not. The point is that we don't really know what particulars underlie a use of well, though some such particulars are often suggested by the context.

${ }^{4}$ Svartvik (1980) offers some interesting exploratory comments on intonation patterns associated with well. 


\section{CHAPTER FIVE}

$\mathrm{Y}^{\prime} \mathrm{KNOW}^{1}$

\subsection{Preliminary Remarks}

The discourse particle $\mathrm{y}^{\prime}$ know (hereafter YK), as in (1)-(3)

(1) $\ldots$ if you look YK in the- newspaper ... (RTS,26)

(2) ... I feel that-YK I think it's wrong ... (RTS,27)

(3) $\ldots$ but uh - YK ya get a feeling that ... (RTS, 34)

is of interest if for no other reason than that it occurs so frequent$1 y$ in conversation. It can appear so often that its use by some speakers is apt to be stigmatized, even by the speakers themselves, as a dysfluency. Others use YK sparingly, but those who use it not at a11 are uncommon, and it is rare that multi-party talk of any duration fails to contain at least a few instances.

YK is popularly known as the brunt of prescriptivist railings against uncommunicative speech. English teachers are apt to characterize it with epithets like 'verbal garbage' or 'anemic phrase', or to describe YK as a 'crutch' used when one has nothing to say, or when one cannot, or will not bother to, find the proper words to express something (cf. Lomas and Richardson 1956:194-195). ${ }^{2}$ These allegations presuppose that YK lacks a specific or important communicative function: YK is seen not as a functional linguistic item so much as a disfigurement of speech (e.g. Newman 1974:14). Since, however, so many other discourse items accused of being meaningless (e.g. by Fries 1952:102) have proved on closer examination to be semantically interesting (James 1972, 1973, 1974, 1978), these accusations regarding YK are suspicious and provoking.

Probably because it pervades ordinary talk, a good deal of scholarIy attention has been paid to this item by researchers in various fields. By far the most extensive discussions are in Goldberg (1976, $1980,1981 \mathrm{a}, 1981 \mathrm{~b})$, though that by Bernstein (1962) is also ambitious; and more modest contributions have been made by Duncan and Fiske (1977), Jefferson (1972, 1973), Sacks, Schegloff, and Jefferson (1974), and Crystal and Davies (1975). The item is briefly mentioned by numerous other writers.

In this chapter the foregoing treatment of evincives is extended to include YK; this will involve a considerable broadening of the perspective of the last three chapters, since YK does not lend itself to the evincive treatment accorded like and well. In fact, the 
notion 'evincive' will be seen in this chapter to be one of a set of notions that between them can be used to describe speakers' disclosure activity (see Chapter 1).

Not all the diverse proposals regarding the function of YK will be discussed below, though the most substantive ones will all be considered. ${ }^{3}$ Section 5.2 deals with the differences between YK as a truth parenthetical and as a discourse particle. This distinction is important here because only the discourse particle displays properties relevant to the discussion of disclosure. In Section 5.3 the core use of the discourse particle is related to the several discourse functions that have been attributed to YK (5.3 parallels the treatment of like and well in Chapters 3 and 4 ). Some of these functional proposals will require substantive modification. The notion 'topic tracking' (Goldberg 1981, 1981a), in particular, is criticized at length. Section 5.5 is a summary and general discussion of the use of YK in conversation.

\subsection{YK as a Truth Parenthetical}

A sharp distinction must be drawn between two kinds of YK. One is an ordinary truth parenthetical precisely parallel to other truth parentheticals such as I think, we feel, it's true, I'm sure, etc. Sentences containing such parentheticals are commonly thought to be derived from structures in which the main proposition is the embedded complement of the parenthetical. In the analysis proposed by Ross (1972) structures like $(4)^{4}$

(4)

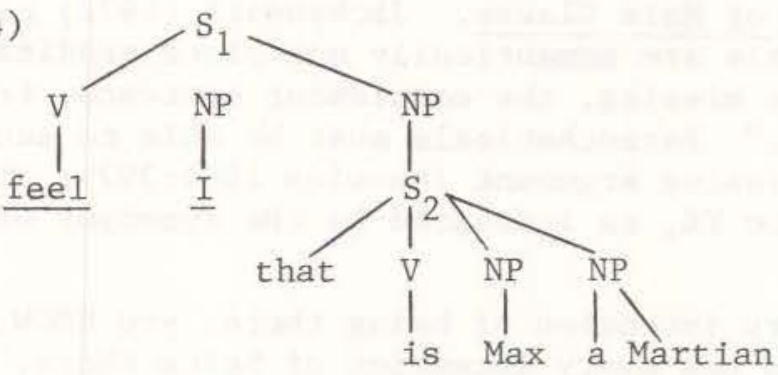

are converted by SLIFTING to structures like (5).

(5)

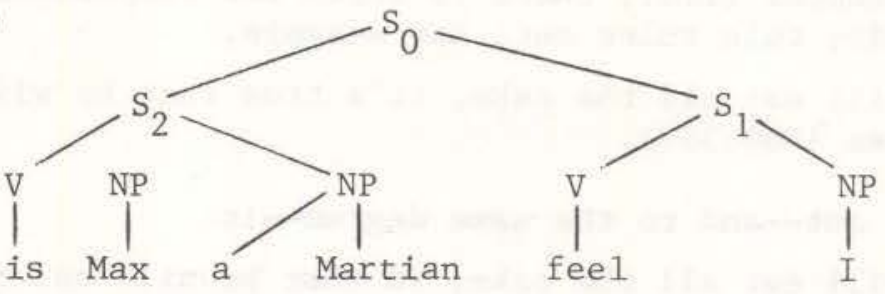

(Parentheticals may also, of course, occur within the main sentence in various positions; this is accomplished by NICHING in Ross's 
analysis.) When YK is an ordinary truth parenthetical of this kind it shares many properties with other truth parentheticals in general.

A number of diagnostic tests for truth parentheticality are suggested in Knowles (1980); when applied to YK, these indicate that YK, in one use, should be classed with ordinary truth parentheticals. In applying these tests, it is sometimes hard to distinguish the discourse particle from the truth parenthetical. There is, fortunately, a way to avoid the ambiguity: only when YK is a truth parenthetical can know be stressed and pronounced with falling intonation. Thus (6) can only have the reading in which the main proposition is understood as the embedded complement of y(ou) KNOW:

(6) It's going to be a long evening, y(ou) KNOW.

In applying the following tests, therefore, know will be stressed whenever this would make the presentation clearer by excluding the irrelevant reading.

\subsubsection{YK and Properties of Truth Parentheticals}

1) Parenthetical verbs. Only certain verbs occur in truth parentheticals (Urmson 1963:220); know is unquestionably one of these:

(7) Gertrude, I know, has no intention of inviting Ezra to tea.

(8) Clyde had, we knew, been to Europe often during the previous four months.

2) Acceptance of Main Clause. Jackendoff (1972) claims that "al1 the parentheticals are semantically one-place predicates. Exactly one argument is missing, the complement sentence, from the functional structure." Parentheticals must be able to accept the main clause as the missing argument (Knowles 1980:397). This is certainly the case for YK, as indicated by the synonymy of (9) and (10):

(9) John has every intention of being there, you KNOW.

(10) You kNOW John has every intention of being there.

3) Truncated Form. Truth parentheticals are realized by elliptical sentences (i.e., those in which the complement sentence has been elided); this rules out, for example,

(11) *John will eat all the cake, it's true that he will eat cake. (Knowles 1980:397).

Likewise ruled out--and to the same degree--is

(12) *John will eat all the cake, YK that he will eat cake.

4) Polarity. After an affirmative main clause, truth parentheticals are odd if negative (Knowles 1980:382): 
(13) *John hates al1 liberated women, it isn't true.

Compare:

(14) *John hates al1 liberated women, you don't know.

5) Comma Intonation. A truth parenthetical is "set aside intonationally from the intonation contour of the main proposition and has the potential for a slight (comma) pause on either side" (Knowles 1980:381). This is equally true of YK:

(15) Fred...you KNOW...feeds his angelfish only choice brine shrimp.

6) Distribution. Truth parentheticals, and YK, may be 'niched' into various positions in a sentence. The positions are the same for YK and other truth parentheticals :

(16) It's true John went to Paris on Sunday. You KNOW John went to Paris on Sunday.

(17) John, it's true, went to Paris on Sunday. John, you KNOW, went to Paris on Sunday.

(18) John went, it's true, to Paris on Sunday. John went, you KNOW, to Paris on Sunday.

(19) John went to Paris, it's true, on Sunday. John went to Paris, you KNOW, on Sunday.

(20) John went to Paris on Sunday, it's true. John went to Paris on Sunday, you kNOW.

7) Claim to Truth. A declarative truth parenthetical implies a positive claim to truth of the main proposition ${ }^{5}$ :

(21) *John, it isn't true, had a good time Saturday.

Compare:

(22) *John, you don't KNOW, had a good time Saturday.

8) Occurrence After Imperatives. In general truth parentheticals cannot occur after imperatives (cf. Knowles 1980:402):

(23) *Get out of my way, $\left\{\begin{array}{l}\text { it's true. } \\ \text { I expect. }\end{array}\right.$

Compare:

(24) *Get out of my way, you KNOW.

\subsection{Evidence for Two Types of YK}

In an early presentation of her ideas, Goldberg argues that there are three types of YK (YKI, II and III); it will be argued below that there are in fact only two clearly distinct types, which will be referred to as $\mathrm{YKa}$ and $\mathrm{YKb}$. In this section evidence for such a two-way distinction is considered. 
Goldberg (1976:14) cites examples such as (25) in which YK I (the truth parenthetical) has its full literal meaning, and the sentence is not acceptable:

(25) *YK that Harry is an idiot is believed by Martha. Compare:

(26) YK, that Harry is an idiot is believed by Martha. Goldberg explains the unacceptability of (25) as follows: "When a sentence is embedded in an island, it cannot easily contain the primary information the speaker is interested in conveying to his addressee" (1976:14). Probably the explanation for the unacceptability of (25) is simpler though: subject complements require a complementizer, which is lacking here. The sentence becomes acceptable with the addition of that:

(27) That you know that Harry is an idiot is believed by Martha. YK is not part of the subject complement in (26) and is therefore not ruled out.

Certain tagged sentences may be cited as evidence for a distinction between two types of YK:

(28) You know Alice is a sharp tens player, don't you?

(29) *Y'know, Alice is a sharp tens player, don't you?

As Goldberg (1976:28) points out in regard to similar sentences, the unacceptability results because don't you requires an antecedent in the main proposition, but only in sentences like (28)

is such an antecedent present. This is not, of course, evidence for a difference between truth parenthetical YK and the discourse particle, since in (28) YK is not parenthetical at all, and in fact (28) becomes unacceptable if there is a comma pause after YK (oddly, in Goldberg's examples, a comma follows YK; that is why other examples are used here).

A third example cited by Goldberg (1976:23) involves indirect speech acts:

(30) YK it's cold in here.

(31) YK, it's cold in here.

Only (31), she claims, can be taken as an indirect speech act. Probably the claim should be that $(30)$ is a more forceful indirect speech act than (31). Note that (32) can serve as a very pointed indirect request:

(32) YK (that) I like salt on my potatoes.

(33) can also be an indirect request, though a more polite one:

(33) YK, I like salt on my potatoes.

In terms of the typology of levels of directness proposed by House and Kasper (1981:163-164), (33) ranks only as a 'strong hint', while (32) is more direct in that it "asserts a preparatory condition 
holding for the execution of the action".

Goldberg claims that YK I does not necessarily imply that "the speaker believes or knows the proposition to hold. YK I literally claims only that the addressee does know the proposition... If on the other hand a speaker uses YK II, the speaker himself must know or believe in the proposition." No examples are cited, but if this claim is applied straightforwardly to examples like (34) and (35), its truth is doubtful:

(34) YK John will come if you ask him to.

(35) YK, John will come if you ask him to.

My strong intuition is that (34) does indeed imply that the speaker believes that John will come if asked. I do, however, agree with Goldberg's assessment that (34) makes a stronger claim about the addressee's knowledge than does (35).

The arguments in Goldberg (1976) favoring a distinction between truth parenthetical YK and the discourse particle are all inconclusive, but a clear difference emerges when the core use of $\mathrm{YKb}$ is considered.

5.4. The Use of YKb

Goldberg (1976) suggests as a synonym for YK II, 'you know what I mean'. This synonym seems particularly apt for interrogative YK, for which it can be acceptably substituted without apparent change in meaning or force:

(36) We al1 had frostbite, YK?

(37) We all had frostbite, YK what I mean?

The substitution is somewhat odd, though, in declaratives with 1ow, parenthetical stress:

(38) So I gave her my phone bill, YK.

(39) ?So I gave her my pone bill, YK what I mean.

Possibly the oddity of (39) is due to a restriction on the length of tagged, low stress parenthetical clauses. Notice that the following sentences are also odd:

(40) ?So I gave her my phone bill, I think you get my point here.

(41) ?So I gave her my phone bill, I guess you see why I'm saying this.

The interrogative has rising intonation and is essentially indistinguishable from two structurally independent paratactic sentences.

Other near paraphrases of YK II are possible, though some are nearer than others: 
(42) I find this boring, y'know?

$$
\left.\begin{array}{l|l}
\text { (you) } & \begin{array}{l}
\text { dig } \\
\text { see } \\
\text { understand }
\end{array} \\
\text { (you) } & \begin{array}{l}
\text { see } \\
\text { get } \\
\text { dig } \\
\text { understand } \\
\text { hear } \\
\text { follow }
\end{array}
\end{array}\right\} \text { what I }\left\{\begin{array}{l}
\text { mean saying } \\
\text { 'm say }
\end{array}\right\} \text { ? }
$$

These al1 have in common that the speaker is questioning whether what is said has been correctly understood by some other(s). Notice that the verb know in one sense means 'understand' or 'grasp', as in

\section{(43) I know how sewing machines work.}

for $\mathrm{YKb}$ :

To be more specific, though, the following use is proposed

$\mathrm{YKb}$ indicates that the speaker expects that there is no significant discrepancy between what is now in the private world and what is now in the other world, with respect to what is now in the shared world.

This proposed use is not, in broad outline, anything particularly new. It is fairly close to Goldberg's 'you know what I mean', and to other loose characterizations by Labov and Fanshel (1977), Crystal and Davy (1975), R. Lakoff (1974), Bernstein (1962), and Fowler (1978). However, the proposed 'definition' is more specific than these others, and some justification for it will. now be offered before considering how this proposal can illuminate the varied discourse functions of YKb.

First note that the proposed use provides an explanation for the odd fact that YKb cannot occur after true questions:

(44) * Who are you, YK?

(45) *What time is it, YK?

The anomaly results because a true question seeks information from some other, while, according to the proposed use, YKb presumes a fundamental correspondence between what is in the private world and what is in the other world. Notice that YKb is perfectly acceptable after rhetorical questions, in which the speaker is not really seeking information:

(46) The first thing I did after I inherited the billion was walk into my local Rolls dealer and say, "Give me four of the yellow ones". The guy looked at me funny and said, "Are you sure about that?" I said, "Sure I'm sure." I mean, what's a Rolls cost, YK? 
The proposed use also explains why YKb cannot occur with perfunctory conversational items:

(47) $* \mathrm{He} 11 \mathrm{O}, \mathrm{YK}(?)^{7}$

*Oh he11, YK(?)

*Bye now, YK(?)

*Oops, YK(?)

In these cases the speaker issues items that are so transparent in use or meaning that it would be peculiar for the speaker to be interested in affirming that they have been properly appreciated.

Statements about the speaker's personal thoughts or feelings which an addressee could not be aware of provide an interesting perspective on the use of $\mathrm{YKb}$. Consider the following sentences:

(48) I feel a chill, YK?

(49) I was born in Brooklyn, YK?

(50) I disagree with you, YK?

$\mathrm{YKb}$ is only appropriate in these cases when there is some room for shared contents between the private and other worlds; the 'room for agreement' differs according to details of the sentence to which YK is attached. Thus in (48) the speaker could be asking if the addressee is also chilled and therefore able to appreciate the sentence I feel a chilt-or whether the addressee is familiar with the sensation of feeling a chill. Suppose, for the sake of argument, that in (49) the speaker conveys information the addressee was not aware of. An answer of "Yeah, I have a grandmother who lives there" would be an appropriate response in that it acknowledges some shared ground between the private and other worlds with respect to what has been said. Although in (50) a correspondence between private and other worlds is specifically denied in the main proposition, the sentence is nevertheless acceptable with YKb if the particle is taken to imply something like, "We share an understanding of my motive for disagreeing". Thus application of the proposed use of YKb in different contexts has strikingly different results.

Although YKb expects a correspondence between the private and other worlds, it is issued in cases of uncertainty about that correspondence: if there were no such uncertainty, there would be no point in mentioning the presumed correspondence. This uncertainty can be concerning something connected with the sentence in which YKb occurs, for example, an awkwardness of expression:

(51) For our ducks we had them install a sort of largish poo1like thing, YK?

(cf. 5.5.3. below on the use of YKb at repair sites). Or the uncertainty can be occasioned by a possible difficulty in appreciating the sequential relevance of the item with which YKb occurs. Assume that the speakers in the following exchange are acting cooperatively 
and that they are strangers passing each other on a sidewalk:

(52) A: Excuse me. Do you have the time?

B: It's six o'clock, YK.

$\mathrm{YKb}$ is odd here because there is nothing apparently problematic about B's utterance given its context, so that it is odd for B to bring up the existence of a possible discrepancy between the private and other world. But as part of a narrative, B's YKb tagged utterance can become acceptable when there is conceivably some difficulty for an addressee in appreciating the sequential relevance of the statement:

(53) So Baby Face turns the dial and listens to the tumblers with his fingers. A light goes on outside the bank, but it's only a street lamp. It's six o'clock, YK.

The speaker in this hypothetical example wishes to confirm that the addressee has caught the significance of it's six o'clock with respect to the fact that the street lamps went on. Notice that it is not the propositional content of the sentence it's six o'clock that is at issue here, so that it is incorrect to say that YKb checks to see if speaker and addressee are together with regard to the propositional content of the utterance; rather, it is the sequential relevance of it's six o'clock that is at issue.

In the following sections it will be assumed that the use of $\mathrm{YKb}$ is that proposed above and that the only difference between the declarative and interrogative uses is their declarativity and interrogativity (the interrogative is, however, discussed separately in section 5.55). Note that YKb tentatively posits some area of speaker/ addressee solidarity with respect to the sentence to which $\mathrm{YKb}$ is attached, but the basis of this solidarity can vary greatly from case to case.

\subsection{Goldberg's YK III}

There appears to be no substantive difference between Goldberg's YK II and YK III. She assigns to category III instances of YK in positions of hesitation, as in (54),

(54) I have some...YK...salami in my room if you'd like some. (Goldberg 1976:8)

claiming there are two differences between types II and III, and that the second of these is crucial for distinguishing the two types:

i) Pause length. YK II is "embedded in pauses of perceptually longer duration than the normal juncture pauses of [types I and III]" (48).

ii) Distribution. "Y'know III as a filled pause can occur in syntactic environments prohibited to y'know I and II" (49). 
The first of these differences does seem insufficient to distinguish the two types, but the second difference is insufficient also. The data given in support of the syntactic restrictions are:

$$
\begin{aligned}
& \text { a. *any, you know, peas } \\
& \text { b. *any, y'know, peas } \\
& \text { c. any...you know... peas }
\end{aligned}
$$

I find a-c all acceptable. But my objection goes beyond this intuitive disagreement: it is circular to claim a distinction between II and III and then, as the only evidence for the distinction, cite cases where III occurs but II does not. This presupposes the distinction being argued for.

The point of view adopted below is that YK III is really just $\mathrm{YKb}$ used in a position of interjection (a matter of where, rather than what). Since YKb is structurally independent of the main sentence it is not surprising that it can fit into virtually any slot in a sentence. ${ }^{8}$ A hesitation pause can accomodate $\mathrm{YKb}$ as we 11 as the beginning or end of a sentence can. There is no fundamental difference in use between putative cases of YK II and YK III; the use proposed above for $\mathrm{YKb}$ is suitable in both cases, except that in the heistation cases $\mathrm{YKb}$ is interpreted in the context of the matter then at hand, that is, the situation in which a pause occurs before some item next to be issued. This use of $\mathrm{YKb}$ is discussed more fully below.

\subsection{Discourse Functions of $\mathrm{YKb}$}

In this section it is shown how the discourse functions of YKB follow from the proposed core use of the particle. As in previous chapters, the claim will be that there is an underlying unity in all the uses of this item and that functional differences arise when the item is used in particular discourse contexts. As is true for like and well, the core use of YKb naturally results in the item's functional 'polysemy'; thus instead of emphasizing this polysemy, its source will be emphasized. Once the identity of all uses of $\mathrm{YKb}$ is established, it will then be possible to specify the general role of $\mathrm{YKb}$ in conversation and to relate this role to those of other discourse particles.

\subsubsection{Topic Introduction}

Goldberg (1980, 1981b) remarks the frequent occurrence of YK before the introduction of a new topic, as in (56)

(56) President Nixon is talking to John Dean. Dean has just entered the room.

P: Hi John, how are you?

D: Good morning. Good morning. 
P: Sit down. Sit down. Trying to get my remarks ready to [unintelligible] the building trades.

D: So I understand.

P: Yes, indeed, yeah. You know, I was thinking we ought to get the odds and ends, uh [unintelligible] we talked, and, uh, it was confirmed that--you remember we talked about resignations and so forth and so on--that I should have in hand, not to be released.

[White House:16-4-73am:187]

(Cit. by Goldberg 1980:96)

Goldberg notes that topic introduction is problematical because it is 'face-threatening' (cf. Brown and Levinson 1978):

The speaker who initiates a new topic before the ongoing topic has been terminated can be regarded as threatening the other's face by suggesting that what the other is saying is of no interest to the speaker or, if the speaker interrupts himself then he can be heard as saying that what was being said is not intended for the other to hear. Similarly, if after the ongoing talk has reached a successful end a new topic is initiated but fails to receive the other's support, then the speaker who initiated the new topic is subject to a face threat (Goldberg 1981b:3).

IK used to introduce a new topic, it is claimed, serves to alleviate the face-threatening potential of an obvious and abrupt topic change:

A strategy most often employed to this end is to go even more baldly on record as initiating a topic change. Bounded topic initiation is blatant at the best of times so why not carry this property to its extreme: call attention to it, notify the addressees that this is the speaker's intent (Goldberg 1981b: 5).

YK in this view is considered one of a set of items referred to as 'disjunct markers' the function of which is to flag initiating utterance-units. Other members of this set are hey, oh 1 , by the way, speaking of, guess what, vocatives, etc.

This analysis is a later development of ideas presented in Goldberg (1980), where it was reported that $73 \%$ of YK marked moves in the corpora used for that study were (re-)introducing moves. This statistic by itself, of course, does not establish the role of YK as a topic introducer. The $73 \%$ figure is not compared to the overall frequencies of all move types in the data, so that it is, by itself, uninterpretable.

The claim (Goldberg 1980) that YK is a 'marker' of introducing moves is replaced in her later anlaysis (1981b) by the 'disjunct marker' approach. As implied in the second quotation above, it is difficult to regard YK as marking introduction because bounded topic changes are themselves "blatant"; moreover, they are usually prefaced by a facilitating pause. Between these two indications of 
topic change, it is unnecessary to mark intiation itself. It remains superficially reasonable, though, to claim that YK prefacing a topic change somehow calls attention to the change and so, by a strange twist, undercuts the possible face threats involved in the change by pointing to it. The supposed effect, in this view, would be parallel to that obtained by saying, "You might think this rude of me, but..." It seems very clear from Goldberg's numerous examples that $\mathrm{YKb}$ is particularly at home in that discourse position. Her characterization of YK as "possibly the least obtrusive and disruptive" of the disjunctive items, also seems correct.

The approach to be taken here to this use of $\mathrm{YKb}$ is to claim that the particle, by virtue of its basic use, receives a special interpretation depending on its occurrence in pretopical discourse position. The fundamental question is this: does the basic use of $\mathrm{YKb}$ provide an explanation of why the particle appears so frequently before topic initiations?

All utterance-initial uses of YKb have a general peculiarity. With the proposed use, YKb presumes some shared ground between the private and other worlds with respect to what has been presented in the shared world; but initial YKb posits this presumed correspondence before the utterance in question has in fact been entered in the shared world. The use of the item in this position with its basic use amounts to a prediction of common ground. As such, YKb in this position can be considered a type of 'intimacy ploy' (for this term see Schegloff 1968:1078). It is as if the speaker were saying, "We trust each other; our sensibilities are so attuned that I can count on your appreciation of essentials of what I say even before I say it". This peculiarity of initial YKb no doubt explains why the item carries a sense of 'folksiness'. Newman seems more or less on target when he notes $(1975: 28)$ that initial YK used in television commercials conveys "that the person doing the commercial is down to earth, regular, not stuck up, and therefore to be trusted."9

This use of $\mathrm{YKb}$ asserts the existence of a shared orientation from the outset, which then buffers the introduction of new material. We thus have, in the use of $\mathrm{YKb}$ here with its proposed contribution, an underlying reason for why YKb performs topic initiations that are, in Goldberg's terms, not "obtrusive and disruptive".

It is again possible, then, to use the discourse context in conjunction with the core use of a discourse particle to account for one of its special functions. In the present case, the relevant position of $\mathrm{YKb}$ is between two utterances that are topically unrelated, or else before the very first topic. With its basic use YKb asserts an overriding continuity despite the obvious topical discontinuity. The item doesn't exaggerate the discontinuity, as Goldberg claims, but attenuates it by asserting that a shared understanding spans the topical switch: "You can understand, comfortably encompass, go along with, my current act of topic changing/initiating". There is some truth in the notion that the speaker of YKb in this position 
is "baldly announcing" the topic initiation. By asserting continuity of understanding, the speaker does implicate the existence of discontinuity; the real force of $\mathrm{YKb}$ here, though, is not to exaggerate the discontinuity but to play it down.

\subsection{2, Topic Tracking}

Goldberg (1980, 1981a) argues extensitve1y that YK can be used as a 'topic tracking device' "optimally employed, in English, for indicating the central line of development or other important, noteworthy items" in extended talk by a speaker (1980:142). It is specifically those YK's not used (solely) for repair that are thought to have this property (143). Topic tracking YK's tag: i) topically significant items; ii) repetitions of topically significant items; and iii) parallel structures or contrastive items in the presentation of the topic talk. The function of topic tracking is to clarify which items are 'on' the topical core and distinguish them from items 'off' the core. This is seen as necessary because "items which are off the main line of development may inadvertently pull the talk onto tangential topics" (145). The function of topic tracking is therefore to prevent these "potential drifts" (147) and also to prevent topics being subsumed by other topics (167). Determination of what is on and off the core is conducted by an algorithm details of which will not be discussed here (see Goldberg 1980) since they do not bear directly on the claims made below.

In written language, indications of topical value are "usually accomplished...by grammatical subordination, relativization, and pronominalization" (Goldberg 1980:148), but in unplanned conversation, topic tracking with YK is thought to predominate (149); reiterations are also used, though to a lesser extent (150-156).

The claim that "free floating" YK's tag topical value is a strong-one, as Goldberg is aware, and cannot be adequately supported simply by citing examples. In this connection, the following qualification is important:

This tracking account of $y^{\prime}$ know has the status of a description rather than an explanation. Support for this account comes in the form of examples... of course, given that the tagging of topically significant items is optional, the descriptive account itself is in danger of being vacuous. Until a stronger account is offered, the one I have proposed seems reasonable (Goldberg 1980:168-169).

In the remainder of this section several arguments are given to show that there is currently no evidence that YK is in fact a topic tracking device and that the notion should be abandoned. These arguments are summarized in the following list, then discussed separately:

1) Simpler alternatives to topic tracking (TT) exist. IT is not the most straightforward account of the occurrence of "free floating" $\mathrm{YKb}$ 's; 
2) TT is excessively powerful. The range of possible TT points is too unconstrained; almost anything can, in some interpretation, be considered topically significant;

3) TT lacks distributional accountability. TT offers no account of the diversity of placement positions of $\mathrm{YKb}$ within utterances;

4) TT lacks positive support. TT is not unambiguous1y supported by the existing data;

5) Counterexamples to TT exist. Clear cases of YKb marking utterances off the topical core occur frequently;

6) A unified approach to YKb is possible. An account is proposed that facilitates inclusion of all instances of YKb within a single completely adequate description.

1. Simpler alternatives. Consider an extended example. The following passage used by Goldberg (1980: 163-164) to exemplify TT is from a transcript appearing in Sharrock and Turner (1978:190196).

(57) C: I ha:ve a complaint um my neighbor is (0.5) le-sub1well renting her garage out, and ah there are young boys, now they seem awfully nice an(d) everything but I don't know they're missing an awful lot of school, they're fifteen-year-old types, $(0.5)$ an, they've got, apparently they've got seven old cars, I guess they buy these old cars, but about a month ago they went to town sma:shing one of them ewith a pick axe ju:st absolutely annoying you know ${ }^{1}$ pounding all day.=

P: $(\mathrm{Mm})$

C: =and I: have a dog that ba:rks a lot an' I guess he's not taking too kindly to these kids.

P: $\quad(\mathrm{Mm})$

C: But anyway there is two more cars in the-eh garage now: and-ah, the neighbor works in fact she's away all day ' $n$ ' she doesn't know what's going on but these kids are just spending their (h-e) one particular is spending most of the day there, and I know: :? that he's taking parts like driveshaft I- I just saw the muffler going with him just now?, (0.5) They take them an' we live close by, it's in ((section of Newton)) Willow Heights an' it's by Gullypark; an' they take these (1.0) you know ${ }^{2}$, big enough parts to ca:rry an' I think they're dumping them into the gully; (1.0) and I'm just getting a little, annoyed about it because e-ah you know ${ }^{3}$ I think they've got about seven cars, I talked to one of the boys and I didn't let on that I was you know ${ }^{4}(1.0)$ annoyed or anything but and I wasn't at the//time,

P: Do these cars all got license on them lady?

C: A: h, e they're in a garage; I don't know;, I really don't know that.

P: What is your name please. 
C: Ah my name is Missis Tho:mpson, and it's at her address is twenty-nine thirty-four west thirty-four.

P: Thirty-nine,

C: No twenty-nine twenty-fi-- ah twen- ((rapidly)) I'm twenty-nine twenty-five. Twenty-nine, thirty-four $(1 \cdot 0)$ west thirty- // four

P: West thirty-four, (that's) $=$

C: $=$ An' they're taking, you know ${ }^{5}$ these pa:rts, an' my daughter, (I got) a ten-year-old, was saying that she's seen all sorts of these parts down at the gully, I guess they go they follow the la:ne east, (it's inna) into the next $\mathrm{blo}: \mathrm{ck}$, and whether they're dumping or assembling something down there I really don't know but- (1.0) (i-e) they're sorta taking over the area with this business of eyou know ${ }^{6}$, ( ) sma//shing up these things, =

P: (repairing)

C: =an I know it's their business if their dads allow them to do it but (0.5) they're not they're not doing it by their house they've they live further down this one particular I know where he lives ' $n$ ' and ah

In every case in this passage (and, in fact, in all of Goldberg's putative examples of TT), the appearance of YKb can be explained on other grounds having to do with the particular discourse context in which the item appears and the basic use of $\mathrm{YKb}$. It is therefore not necessary to enrich the theory of speakers' competence by the inclusion of TT.

YKb 非, with its usual use, 'presumes' that the addressee (a police officer) grasps the speaker's intent. To understand the placement of $\mathrm{YKb}$ in this passage, it is important to keep in mind the nature of the telephone call: a complaint to the police. It is crucial that one who wishes to be heard as issuing a legitimate complaint establish that some law has been violated, or may well have been violated. It is equally important to the complainer that the call not be heard as a mere 'gripe', based solely on personal ill feeling toward the parties complained against. In this particular complaint call the caller repeatedly (see the full text of the call in Sharrock and Turner 1978) allows the call to appear to be a gripe and moves to correct this impression, or talks in ways obviously geared to forestall the conclusion that the call is a gripe. Immediately before YK \#1, the caller has issued annoying, and, immediately following $\equiv 1$, pounding. Annoying is a gripe word, which gets replaced with a factual description: pounding all day. Pounding all day is not simply a replacement but a grammatical continuation. YKb is here at a repair site. Despite the absence of pauses, which, for Goldberg, are crucial for determining where a repair occurs, the occurrence of a repair here is obvious. (Moreover, it is not clear that there is no pause, since in this transcript only longish pauses are noted, and these are only grossly indicated.) 
\#2 is also at a repair site. This is indicated both by the one second pause preceding 非 2 and by the discontinuity of the utterance when 非 2 is removed (an' they take these big enough parts). It is reasonable to suppose that the speaker cannot think of a smooth continuation of the utterance having begun it with they take these and pauses before settling for the awkward big enough parts to carry (awkward both because it doesn't fit well after these and because it doesn't make especially good sense--Are some parts not big enough to carry?). 非 therefore also occupies a repair site.

The same thing is true of $\sharp 3$. Whatever the transcription e-ah is intended to convey phonetically, it seems clear that the speaker is experiencing a dysfluency. Notice that here again the speaker is shifting from personal annoyance to a factual description: I think they've got about seven cars. The reason for the break in continuity is probably that the caller is 'changing gears'--I think..., after a11, stands better as a reformulation than a continatuion of the clause introduced by because.

\#⿰ 4 is also at a trouble spot. The caller has previously retracted annoy twice, if the instance at $\$ 3$ is counted, and here pauses a full second before issuing the retracted word. Notice that annoy is followed immediately by a 'downgrader' (see House and Kasper 1981: 166) which lessens its force. The speaker is transparently involved in repair.

非 5 is another instance of the recurrence of a trouble source. The same trouble that occurred at 非 occurs here again. This time the abbreviated these pa:rts is chosen. This is not an instance of repair but of the introduction of a difficult designation (and, simultaneously, reintroduction of the earlier topic). The core use of $\mathrm{YKb}$ is reasonable here: the caller has previously described these parts (after \#2) and can be taken as pointing to the shared ground already established between speaker and addressee.

非 6 is at a repair site. Whatever eyou indicates phonetically, it is clear that some kind of discontinuity has occurred--a hesitation noise interrupted by $\mathrm{YKb}$ or some word cut off by $\mathrm{YKb}$. And, again, the site is a delicate one at which it is important to establish the factual basis of the complaint. (It may be relevant that the police officer initiates other-repair on what the caller formulates.)

It can be argued, then, that these instances of YKb all occur at points of difficulty of one kind or another and that it is therefore not necessary to resort to TT to explain their occurrence. There is some positive indication of difficulty, discontinuity, or outright repair at the site of each $\mathrm{YKb}$ in the passage, and since $\mathrm{YKb}$ is common at repair sites in general, and there has its usual use (see 5.6.3), TT lacks appeal. This passage is only one of several cited by Goldberg; the others also submit readily to reanlaysis based on the core use of $\mathrm{YKb}$. 
2. Excessive Power. The TT anlaysis is viable only if 'topic' can be defined in a way that permits uncontroversial assignment of utterances to topics; the analysis also requires some way to distinguish more important utterances in a particular topic from those that are less important. The problem that arises here is that when these notions are applied intuitively--as they generally are (especially the latter one)--there is a methodological danger that the utterances viewed as topically important will be taken, circularly, to be those tagged by YK. Indeed, it is only by dint of much stretching of the original simple TT idea that certain stray YKb's can be brought into the TT fold. Not only are 'global topics' considered to be (optionally) so marked, but so are 'local topics', 'sublocal topics', and utterances that tie local to global and local to sublocal topics (Goldberg 1980:147, 183).

Instances of YK not immediately classifiable as marking topical value can often be conveniently shunted into the repair category. Goldberg claims, "when a repairable or repaired item is a significant item of a passage, the tracking usage of the particle may combine with the repair usage." But how is this possible? If YK in these cases serves to track the topic, there must be some way to tell a tracking repair from a nontracking one. The only way to do this is to appeal to some a priori notion of topical significance, but if this is done, the TT notion is vacuous. This rasies the ineluctable question: if the analyst can determine what is topically significant independent of the YK tag (which is Goldberg's claim) why cannot addressees do the same thing?

3. Distributional Accountability. The TT analysis offers no explanation for the fact that YKb can appear at various positions within an utterance with different effects. All placements are regarded as functiona1ly equivalent in that they mark the utterance as one of topical importance. With its core use, however, YKb can function to indicate that the speaker presumes addressee/speaker solidarity with respect to part of an utterance, or even various parts of one:

(58) I YK sort of budged the YK rootish looking thing into my...YK, whachacallit, Cusinart!--and ran like hell.

YKb in such cases is essentially forward looking (cf. Goldberg 1980: 105).

4. Lack of Positive Evidence. The TT idea lacks positive evidence in its support. As Goldberg concedes, citing possible examples cannot clinch the case. There are two separate problems here:

i) Examples would have to be chosen randomly or considered exhaustively within a large corpus to be of conclusive value to the claim; and the examples would have to be unambiguous between TT and repair;

ii) the TT function implies that addressees are able to reconstruct the topical value of YK tagged utterances within a topic 
independent of the content and sequential placement of the utterances; some positive evidence that they do so is required. If addressees do not use YKb to track topics, the TT notion is of no demonstrated communicative importance and remains a hypothesis in search of data.

5. Counterexamples. According to the TT hypothesis, it should not be possible to find YKb marked utterances which are both 1) off the topical core and 2) not a repair site. However, such examples occur often. For example, Goldberg considers off the topical core utterances that "provide more background to an understanding of [some previous item]" (1980:145). Thus she considers the fifth sentence in the following passage to be off-core:

(59) I discovered that the mother mouse wasn't in the cage. She just wasn't there. She had been there the day before. She was so big that she couldn't easily get through the bars of the cage. She was big because she had just had two litters. Her absence, was, therefore, very odd. (Goldberg $1980: 144)^{10}$

In (60)-(62) below, however, are presented three cases from a single $\mathrm{LAB}$ conversation in which YKb occurs with an utterance which, in just this way, provides background to an understanding of previous talk by that speaker.

(60) EVA: She goes in there she goes - "Fanny!" [1oud whisper] and she was tryin(g) to do it without wakin(g) up Janice cuz Janice hadn't got up yet YK - and she just tries wakin(g) her up and wakin(g) her up and she just raises up (h)er head - and she looks at (h)er and she just passes out again. [LABA,2]

(61) EVA: And I don't remember that- I don't remember- Charlie callin(g) me I forgot he did call me that day but I had forgotten about it an(d) I know he would never

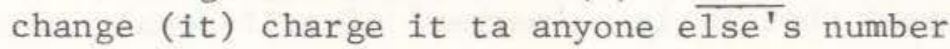

SUE: Yeah [

EVA: because YK he just pays for it automatically. And I said "Well I don't remember gettin(g) any phone calls" an(d) I said "and I'm the only one that's even near Dayton" I said "So I'm sure the phone call would've been for me"...

(62) SUE: Are you gonna sublet yours?

EVA: We're gonna. I dunno. Janice was $\operatorname{talkin}(\mathrm{g})$ about gettin(g) a job down here - nex( $t$ ) summer

could be because- 
EVA: Carla (was-) wants to too and (I-) and well like Ron's goin $(\mathrm{g})$ ta school this summer so she might go the nex(t) summer too cuz she's engaged an(d) I'm sure she wants ta get out as soon as possible YK

SUE: Yeah.

6. A Unified Approach. The proposed use of YKb can be applied to explain the occurrence of $\mathrm{YKb}$ wherever it is found in conversation. There is no evidence for a split between two categories: repair and nonrepair.

It is certainly true that $\mathrm{YKb}$ often occurs with topically significant utterances in a conversation. With its basic use YKb is suitable for checking (with a positive expectation) whether speaker and addressee are 'on the same track'. It stands to reason that speakers might be particularly likely to perform such checking at points where to do so is most crucial--when a misunderstanding would have the most detrimental effect on communication. Key points in topical talk might thus be expected to be statistically very likely to co-occur with YKb--but so might utterances that are awkward or clearly repairable in some way. The speaker is simply checking to see how $\mathrm{s} /$ he is doing at points where this seems to him or her to matter. It is a rather long step--both experimentally and theoretically--from this simple claim to the idea that addressees can, in an unexplained way, identify some YK's (but not others) as utterance-level tags marking topical importance.

\subsubsection{YKb and Repair}

There is now an extensive literature on conversational repair (see Jefferson 1972, 1974, 1978; Schegloff et al. 1977, Schegloff 1978; DuBois 1974; Goodwin 1975; Shimanoff and Brunak 1977). YKb occurs frequently at sites of self-repair. In Goldberg (1980) it is argued that YK is a 'marker' of self-repair in examples like the following:

(63) Chuck, Chuck has gone through, you know, has worked on the list, and Dean's working the, the thing through IRS and, uh, in some cases, I think, some other (----) things. [White House: 15-9-72:1]

(Cit. by Goldberg 1980:216)

(64) A: We11, then in two weeks there's his birthday which comes out on a Saturday night. So, we'11 probably, y'know, maybe we'11 do something then, =

[S/S:Arrangements: 201]

(Cit. by Goldberg 1980:218)

In self-correction the speaker of some repairable executes repair on it (to be contrasted with other-repair in which the speaker performs 
repair on another's utterance). The reader is referred to the studies mentioned above for details on repair and correction. Familiarity with these studies will not be assumed below.

In Goldberg (1980) a sharp distinction is drawn between TT YK and the repair marker. Three differences are found to obtain between the two types:

i) repair YK's are not confined to clausal or phrasal boundaries, but repair TT YK's are;

ii) repair YK's are "preceded by (and may be followed by) a 'noticed' pause of a microsecond or longer";

iii) the pronoun of repair YK's tends to be heard as lightly stressed, while that of the TT use is heard as elided.

The first difference cannot be considered criterial for distinguishing the two types. The distinction is (circularly) presupposed and then used to support the distributional difference. The second difference is likewise dependent on the proposed distinction itself; moreover, YK's used at repair sites needn't always be preceded by a noticeable pause (the figure of one microsecond is puzzling since most of the transcripts Goldberg uses are not annotated with precise pause measurements). There is, for example, no pause in the following examples:

$$
\begin{aligned}
& \text { C: ...after it's been YKafter the person's been shot } \\
& \text { C: …RTS,99] think that's YK I think we should do that... } \\
& \text { [RTS,131]. }
\end{aligned}
$$

The third difference is difficult to interpret. Is an articulatory/ acoustical difference referred to or a perceptual/phonological one? In either case the distinction is dubious. The transcripts for the present study abound with apparent counterexamples in which YKb at a repair site lacks any perceptible stress on you.

$\mathrm{YKb}$ at repair sites is not substantially different from instances of YKb elsewhere.

In Goldberg's treatment YK at repair sites indicates "that a repair has been initiated [and tends] to occur in the same turn as the trouble-source" $(1980: 214)$. The repairs marked by YK "tend to clarify person, event, time, place, and other types of information. The repair upgrades the item's specificity" (217). The tendency for such repairs to "clarify" is, of course, an implicit feature of most all repair (otherwise why repair?), but the claim that repairs involving YK upgrade specificity could possibly distinguish them from some other types of repair. Repairs introduced by I mean are claimed to involve "a change in emphasis, direction, or meaning" (cf. Chapter 4). If YK repairs are in fact toward greater specificity, the basic use of the item is entirely appropriate. Notice the oddity of (67): 
(67) ? I got a dog, YK, cat for my birthday.

compared to

(68) I got a dog, I mean, cat for my birthday.

The fairly radical change of dog to cat is not very appropriately marked by YKb because it would be absurd (without further context) to expect that the addressee could grasp the speaker's intention from that speaker's having uttered dog. YKb is much more suited to repairs of the following type:

(69) I had to turn ... YK swerve to avoid the truck. [RTS-1]

Swerve is plausibly the intention of the speaker in uttering turn. A parallel comment would apply in the following case:

(70) They have nice dresses in there. They may not be nice YK like - so nice but they have nice dresses. [LAB-A,8]

It is, however, probably too restrictive to say that YKb upgrades specificity. The correct generalization seems to be that $\mathrm{YKb}$ (as might be expected from its core use) can appear in those repair sites where the speaker wishes to confirm addressee understanding. The following examples from Goldberg's own work (1980) fit this latter characterization but do not seem to upgrade specificity in any obvious way:

(71) A: But, uh, at that // price=

B: Yeah, but I had nothing, YK any (.) all that I had were either junky or dirty//or drab. [S/S: Sheets:28] (Goldberg 1980:217).

(72) P: They, they, they'd like to get Haldeman or Colson, Erlichman. They, they've got--

C: Or possibly Dean. You know, who, you know, who's huh-anybody they can--I'm a small fish, but-- [White House: $\overline{28-2-3: 46]}$ (Goldberg 1980:218).

Goldberg makes the interesting comment that some YK marked repairs are 'semi-overt' (cf. DuBois 1974:III-5) in the sense that in these cases the repairable is "detected and deleted before it is vocalized but the YK marker is not" (Goldberg 1980:215). She cites (73) as an example of this:

(73) We11, it's just none of their-you know, that's really none of their business. [White House:28-2-73:43].

Goldberg's claim is that the complete repair structure is X-YK-X' and she speculates that cases of semi-overt repair "may have prompted the labeling of YK as a 'hesitation' marker".

The issue of whether or not YK can mark hesitations (versus instances of correction) hinges on whether or not examples can be 
found in which YK flanked by one or two pauses can appear clause internally where no correction is evident--for example in the case of a word search. Such examples are not hard to find:

(74) C: ... an employee should be able to evaluate their employer - and his abilities as a manager - and uh - YK time manager etcet'ra [RTS,1]

(75) And the/n/ one of them is..playing like with [.4] I don't remember, I used to play with /it/ when I was a kid, [.9 but [.75]] it's like a...wooden paddle [.6[.3] that [.15]] there's an elastic string attached to and there's a ball, [.3] you know that kind of thing that you [.4] you [.15] I..don't remember the name of them [.35] but I played /with them/ for hours. (Chafe 1980:309)

These could, of course, be dismissed as cases of TT YK but this seems intuitively odd, and the pauses must be explained. With its ordinary use $\mathrm{YKb}$ is suitable for word searches and would function there to 'repair' (in the extended sense of this term: see Schegloff et al. 1977:363) the silence occasioned by the search. Ths speaker issuing YKb in a case like (74) or (75) is saying, in effect, "you know what I'm getting at, even if this word/formulation for the moment escapes me".

Or such cases could be dismissed on grounds that some repairable has been covertly deleted before issue and replaced. There is no evidence for this, however. It is not enough to cite cases of $\mathrm{X}-$ YK $-X^{\prime}$ repairs as representing the full form of YK repairs, since this assumes, without justification, that $X-Y K-X^{\prime}$ is the full form of all YK repairs.

The status of $\mathrm{YKb}$ as a hesitation marker is questionable, but more for the claim that it is a marker than for the claim that it occurs at points of hesitation. At a great many repair sites in which YKb occurs it is flanked on one or both sides by pause. Any midutterance pause is a potential place for a YKb since the speaker has faltered momentarily and is therefore in danger of seeming communicatively incompetent. To use YKb with its usual contribution in such pauses invites the addressee to sanction the time out--say for a word search or to formulate a correction. Whether the YKb is flanked by pauses is of no consequence in this interpretation--the pauses simply show that time was taken before the utterance could be resumed.

To summarize the claims in this section: YK at repair sites is YKb. To claim that this YK"patterns differently than the YK which has been characterized as a discourse particle and move marker" (Goldberg $1980: 218$ ) presupposes, without justification, that there is such a distinction. YKb has its usual use in positions of hesitation or misstep; with this core use it there invites addressees to go along with the discontinuity on the grounds that the speaker knows what $s /$ he wants to get across but temporarily lacks a proper formulation. If the discontinuity is too great to go along with (e.g. dog/ cat), a stronger phrase like I mean is apt to be used. YKb implies 
that the speaker hopes the addressee can divine the continuation or grasp the point of the unfinished utterance. Use of I mean implies that the speaker thinks the addressee cannot.

\subsection{YKb as a 'Sympathetic Circularity Sequence'}

Bernstein (1962:238) classifies YKas a 'sociocentric sequence', a term describing the conceptual content of his term 'sympathetic circularity sequence'. Bernstein has proposed an elaborate sociological account of the use of these sequences in conversation.

The 'S.C.' class includes YK and tags such as isn't it, ain't it, and wouldn't he, all of which are also designated 'terminal sequences'. Bernstein found that S.C. sequences are used more by working class than by middle class speakers (1962:224). His explanaton for this finding is given in terms of his widely discussed distinction between restricted and elaborated codes (Bernstein 1961a, 1961b, $1962 \mathrm{a}, 1962 \mathrm{~b})$, the claim being that S.C. sequences occur far more in restricted than elaborated codes.

Restricted codes are thought to be less explicit, and one who uses such a code is thought to assume much about knowledge shared by speaker and hearer; speech in a restricted code is therefore condensed and less redundant than speech in an elaborated code $(1962: 235)$.

Bernstein's hypothesis about the sociologocal function of S.C. sequences is intricate and far-reaching. At its core, however, are the following observations:

The S.C. sequences may be transmitted as a response of the speaker to the condensation of his own meanings. The speaker requires assurance that the message has been received and the listener requires an opportunity to indicate the contrary. It is as if the speaker is saying 'Check--are we together on this?'. On the whole the speaker expects affirmation (1962b:235).

...these sequences may set up different constraints on the flow of communication, particularly on its logical development and elaboration. Inasmuch as the S.C. sequences, which are generated basically by uncertainty, invite implicit affirmation of the previous sequence then they tend to close communication in a particular area rather than facilitate its development and elaboration. The sequences tend to act to maintain the reduction in redundancy and so the condensation of meaning (ibid. 237).

Bernstein's reasoning, only highlights of which are quoted here, is marvelous and consistent. His interpretation of YK, though limited to final 'tag' position (where a minority of the total instances of YK occur) depends on the items having a use very near that proposed for YKb above. His formulation 'Check--Are we together on this' is suitably vague with regard to whether the speaker and addressee are in agreement with respect to the truth of the proposition tagged by YK. In the data for the present study cases frequently occur where YKb accompanies a proposition the truth of which the addressee is in no position to ascertain: 
(76) ...Yesterday I was in my bedroom, YK? And the air conditioning doesn't even cool it off... [LAB-B, 10]

(77) EVA: =You didn't see that postcard, it's a-=

SUE: $\quad$ uh-uh.

EVA: =Huh! It's a shopping cart? Full of pot,

SUE: $\quad$ (Mm)

SUE: ((Laughs))

EVA: Pot all over on the ground, too, YK? [LAB-A, 8]

(78) ...I had a friend who took it an(d) she said it was a piece o(f) cake. She got a 'A' out o(f) the course YK an (d) no trouble really... [Lab-B, 8]

(79) ...there's this sheriff...He hit a person- uh a person (th) at was in jail with a ball bat an everything YK... $[\mathrm{LAB}-\mathrm{A}$ ]

Bernstein's implication that terminal YK occurs at points where the speaker's meaning has been condensed is consistent with the evincive treatment proposed in the present work, but squarely at odds with the TT proposal. It should be possible to statistically examine the consequences of Bernstein's claim. What would be needed would be an objective measure of condensation of meaning. Lacking this, Bernstein's claim, though elegant, remains undemonstrated.

The position taken here is that the range of occurrence of YK is much wider than that envisioned by Bernstein. This range should include locutions that are problematical for the rarity, slanginess, etc. of the words in them:

(80) Sue: =God, (he) went to all this trouble ( ) I'm meeked out, YK? [LAB-A, 13]

for difficulties relating to sequential relevance of an utterance:

(81) [In this passage SUE tries to prove to EVA that FREDDY feels helpless as a shopper and hates to shop; the YK tagged utterance is not itself intended to show this but to be taken as setting up a situation in which the main point of the talk is then illustrated]

SUE: He hates the- He went...shoppin(g) him and (h) is brother and (h) is sister went Christmas shoppin(g) when (h)e bought me my brown pants YK? - and he said- he was just like $\operatorname{losin}(\mathrm{g})$ it...

for difficulties having to do with whether the addressee shares appreciation of some aspect of common experience: 
(82) SUE: I was- ...dumb freshman ... comin(g) from the hicks. Here I thought I was gonna take over the whole world YK? [LAB-A, 63].

for the awkwardness of their wording:

(83) SUE: Big- He thinks he's a big man walkin(g) tall guy YK? [LAB-A, 29]

and so on. Whether these different possibilities should all be properly considered 'condensations' is very questionable. What they all have in common is the fact that they represent situations in discourse in which a speaker might wish to check up on the correspondence of his or her own communicative aims and the addressee's grasp of what that speaker has said.

\subsection{Interrogative YK}

The interrogative use of YK mentioned and exemplified frequently above is very common, though not predominant, in the conversational materials used for this study. For example, of $74 \mathrm{YKb}$ 's in LAB-A 17 are interrogatives $(23 \%)$. Goldberg $(1980: 135-136,170)$ considers this type of YK equivalent in function to declarative TT YK (see Goldberg 1980:135-136) and specifically argues against calling it a turn-exit device (see 5.9 below). YK? will be treated here as simply the interrogative counterpart of YKb.

First note that YK? does not serve well as the interrogative counterpart of YKa. It is difficult to get a literal truth parenthetical tag reading for a sentence like:

(84) I like oranges, YK?

This sentence would not typically be used as a paraphrase of:

(85) YK that I like oranges?

Rather, (84) seems to invite a YKb reading and is thus better paraphrasable by:

(86) I like oranges, you know what I mean?

I find this to be true even if there is a substantial intonation break between oranges and YK in (84). But the dispreference for YKa in sentences like (84) is probably due to the extreme accessibility of the YKb reading, rather than to the YKa reading being disallowed. Thus notice that

(87) I like oranges; you knew?

in which the $\mathrm{YKb}$ reading is not in competition does easily permit a truth parenthetical tag reading. 
If YK? has interrogative force, it could be followed by a response of some kind on the part of the addressee. In fact, this is often what happens. The following examples are taken from LAB-A.

(88) SUF: ...I was thinkin(g) o(f)-writin(g) a check for Jean (a)n(d) Mom's (a)n(d) spendin(g) the rest o(f) that

EVA: YEAH. whole- my whole paycheck on me YK?

(89) EVA: I mean when- when (h)e's not drunk he won't talk $t(o)$ me - as though I didn't even exist YK?

SUE: Yeah. - He's too shy ta talk $t(0)$ you... [LAB-A,54]

(90) SUE: ...But ya see three $i(t)$ 'd hafta be like th(e) whole summer, YK?

(p)

EVA: Yeah.

[LAB-A, 58]

(91) SUE: ...that's all I can see is - like eighty million buildings $\mathrm{a}(\mathrm{h}) 11$ (th)e way around me YK? ( )

EVA:

Rea11y

In cases where no verbal response occurs, there may have been a kinesic one; or, since the question routinely expects a positive response, silence may be taken as compliance.

In the RTS transcript callers to a radio talk show frequently use YKb, but in 169 instances, there is not a single case of interrogative YK. A possible reason for this is that callers realized that in conversations with a talk show host--with anonymous listeners potentially numbering in the thousands--it is not entirely appropriate to ask for confirmation of understanding, the host being the only one in a position to respond.

\subsection{YK and Turn Taking}

Several writers have proposed a connection between YK and the turn taking system for conversation.

1. Utterance lengthener. Jefferson (1973:69ff) characterizes YK as an 'utterance lengthener' and has also referred to it as a 'standard completion signal (1972:329). As a lengthener, YK is classed with other items, such as an' everything, "which indicate to the recipient that the utterance can have been completed so that he may begin to talk, while as well providing that the ongoing speaker has not stopped talking" (1973:69). The function of YK in this view depends on its placement at a point of possible utterance termination. YK in itself is only a signal that "can be included among a series of utterables which provide that a speaker has not stopped talking although a possible utterance has been produced" (1973:73). Tagpositioned address terms, when also used this way, are described as "mere sound" and as "sound particle[s] in the service of another type of interactional work" (1973:74). 
Utterance lengtheners may be used after what Jefferson calls a "problematic component", as in (92):

$$
\begin{aligned}
& \text { Jim: And a goodlooking girl comes up to you and asks you } \\
& \text { y'know, } \\
& \text { Roger: Gi(hh)rl asks you to- Alright }
\end{aligned}
$$

The lengthener here indicates "that one does not intend to talk about" the problematic component, "by REPLACING such talk with a signal that transition is now underway" (1973:69).

Note that Jefferson is here talking about YK as an item that can occur after a problematic component, but this is not considered an essential feature of its use as a lengthener. She finds that it is in general a 'standard completion signal' which displays the speaker's willingness for the recipient to begin talking during or right after the signal, but, because it allows the present speaker to continue talking, does not make the more pointed offer of turn that would be made if the present turn-holder simply stopped talking and waited for another to begin.

Jefferson refers to YK? as a 'plea' (1973:74) which is, like the declarative, an utterance lengthener, though presumably the status of YK? as a plea would preclude its being considered a meaningless particle of sound.

2. Sociocentric sequence. Duncan and Fiske (1977) consider YK to be a 'sociocentric sequence' (a term originally due to Bernstein; see 5.7), listing as other examples of this class but uh, and or something. Such items (like is excluded; see p. 170) are described as being "stereotyped expressions" which typically follow "a more substantive statement" (171).

Duncan and Fiske regard sociocentric sequences as one type of 'speaker turn signal' (185) indicating the speaker's willingness to yield the turn. As such, sociocentric sequences are one of several kinds of turn signals, the others being: occurrence of an intonation marked phonemic clause; completion of a grammatical clause; 'paralinguistic drawl'; onset of gestural signals; and "decrease of paralinguistic pitch and/or loudness on a sociocentric sequence" either during the whole sequence, or its final syllable(s).

Duncan and Fiske are thus in agreement with Sacks et a1. that YK is 'transition relevant'--inviting a change of speaker turn. This raises the question of how often the turn offer embodied in the use of YK is actually accepted by auditors. If turn changes occur frequently, this would support the claim that YK is a turn signal. Only a partial and indirect answer to this question is provided by the discussion in Duncan and Fiske. The answer is indirect because they do not report results for YK alone, but for the entire class of sociocentric sequences. It is partial because the data are grouped in a way that happens to obscure the location of turn attempts with respect to sociocentric 
sequences: turn attempts during these sequences were tallied, but those occurring just after a sociocentric sequence are lumped together with turn attempts after units not terminating with a sociocentric sequence. We can therefore only look at turn attempts during sociocentric sequences in general. Of 100 attempts in the Duncan Fiske exploratory study, six occurred in this position. There were, however, 21 back channel responses in this position (i.e., brief responses, e.g. $\mathrm{m} \mathrm{hm}$, offered by an auditor during the turn of another speaker and not used to take the floor). Even the figure of $6 / 100$ is difficult to interpret with respect to the present question since included were turn attempts and back channel responses beginning simultaneously with or even just prior to the onset of the sociocentric sequence. In such cases the turn attempt or back channel response could not be viewed as a response to the sociocentric sequence.

3. Recompleter. Utterance-final YK, according to Sacks et al. (1974) is a

generally available 'exit technique' for a turn. That is, a current speaker having constructed a turn's talk to a possible transition-relevance space without having selected a next, and finding no other self-selecting to be next may, employing his option to continue, do a tag question, selecting another as next speaker upon the tag question's completion, and thereby exiting from the turn. In this regard, the tag question is one member of a class we may call 'recompleters' ... (Sacks et al. 1974:718)

Goldberg (1980) criticizes the position of Sacks et al. on several grounds hoping to establish that terminal YK is in fact not involved in the dynamics of turn taking, but is instead better characterized by the TT proposal. The TT analysis has been argued against in sections 5.6.2, but Goldberg's arguments against regarding YK as a turn exit device can be examined on their merits. She suggests six such arguments.

1. She claims that the turn exit idea predicts, falseiy, that there should be a pause just prior to YK at transitional relevance places. The pause is thought necessary for the speaker to ascertain that there are no self-appointed next speakers (Goldberg 1980:136). The form of this argument is valid against the specific proposal of Sacks et al. quoted above, since they require the speaker to check first to see if self-selection occurs, but YK could still be a turn exit device without this checking. Moreover, Goldberg seems to presume, without justification, that such pauses to check for self-selection do not occur.

2. Goldberg argues that there are cases of turns interrupted during items following issue of a YK at a transition relevance point $(1980: 136)$. This alone is not a valid argument against the turn exit idea since it presupposes that the interrupting speaker wished to interrupt earlier, at the point just following YK, and did not. The decision to interrupt could, however, be made at or just before the point of interruption itself. 
3. Goldberg argues that the turn exit idea is faulty because there are cases of locution-final YK that are turn-medial. 11 These, however, cannot be used to argue against the turn exit idea because the argument presupposes that all turn offers are accepted, which is certainly not to be expected (see Sacks et al. 1974:706).

4. Goldberg cites the following instance of overlapped YK:

(93) Ken: She's gotta gun in it. She's gotta gun hangin' there? And I said what's the gun for. She said in case any a' my neighbors wanna come in, // yuh know?

A1: heh

Roger: hehh. An' she invi(h)tes you $i(h) n$ to // see it. hehh Ken: Y/know?

Ken: I s'd-well // well you know, all yer neighbors've gotta do is just put a little mud in that little air hole up there in the top an' yer all done. eheh. [GTS:2:2:19] (Goldberg 1980:137).

She argues that "on the basis of Ken's immediately subsequent 'turn' it appears that Ken has not, in fact, completed his turn which ended with Al's and Roger's interruptions. Ken demonstrates the unwarranted nature of the interruption by his interruption of Roger" (Goldberg: $1980: 137)$. This argument is also questionable; it assumes without justification, that Ken wanted to continue his turn at the point at which he uttered the first YK, which is speculative.

5. In a later defense of the TT idea Goldberg (1981a) argues that the turn exit idea is clearly irrelevant in cases where the speaker is engaged, for example, in a long narrative and, for obvious reasons, wants to retain the floor until completion of the narrative. A problem with this argument is that in Goldberg's examples none of the YK's are interrogative, and it is specifically interrogative YK's that Sacks et al. claim are instances of turn exiting (see the quotation at the beginning of this section). This argument thus strikes beside its target.

The position taken in the present work is that neither Goldberg's TT account nor the Sacks et al. view of YK? as a turn exit device is an adequate description of the facts. Terminal YK? only once results in a turn change in the present data, although it does frequently elicit a back channel response, such as $\mathrm{m} \mathrm{hm}$, uh-huh, or yeah (12 back channel responses to 24 instances of YK?). This is what would be expected if YK? is used with its usual contribution. We would not expect a full change of turn, but simply a brief response to the speaker's question (i.e. to, roughly, "You follow, don't you?) or a perfunctory nod of agreement, or at the very least a peaceable silence. This position is in harmony with Goldberg's on one point: the turn exit idea is incorrect. But the YK's in question cannot be assigned TT status by default. 
5.10. Distributiona1 Properties of YK: Quantitative Results

In this section the occurrence of tokens of YKb in LAB and RTS materials is examined quantitatively to determine gross distributional properties of the item which support the treatment proposed above and tend to disconfirm other approaches.

1. YK and filled pause. In popular works on language use, and even in some serious research, YK is often suggested to be a hesitation form amounting to nothing more than a filled pause. This view is, of course, squarely at odds with the claim that YKb has a specifiable linguistic contribution and that it is this contribution that determines where $\mathrm{YKb}$ is used in conversation. It is therefore possible to predict differences between the positions of occurrence of YKb and filled pauses. Such hypotheses will be easy to test since both filled pauses (um, uh) and YK occur in large numbers in the tapes used for this study.

Uh (cf. Chapters 2 and 6 ) may be viewed as an evincive item indicating that the speaker's thoughts are momentarily null, unclear, or unpresentable. As such, uh issued mid-utterance expresses that the speaker has faltered for some reason, but hopes to be able to continue. 12 If the uh is followed by silence, a problem arises: the speaker may be seen as wishing to continue but unable to do so. This both constitutes a face threat to the speaker, whose conversational competence or cooperativeness may be impugned and can lead to unwanted loss of the turn.

Mid-utterance YK, on the other hand, is a sign not that the speaker is simply faltering, but that the speaker is actively and competently engaged in the communication. This follows from the core use of $\mathrm{YKb}$ to indicate that the speaker is concerned with whether what is said is 'getting across', recognizes that there may be some difficult on the addressee's part in this regard, and displays current control of his or her communicative role by acknowledging this difficulty before continuing. $\mathrm{YKb}$, because it demonstrates control, is especially apt to occur in situations where an addressee might suspect that this control has been lost. Since the position in which uh has just been issued is one such place, we might expect $\mathrm{YKb}$ to commonly fcllow uh as an attempt to reassert control.

The tapes were examined for cases of adjacent uh and YK to see whether these items appear significantly more often in the order uh YK than the other way around. YKb occurs adjacent to uh frequent$\overline{1 y}$ in the RTS transcripts, but only once in the face-to-face conversations. This may reflect the relative casualness/formality of these two speaking situations. The face-to-face conversations are more fluent and relaxed than the RTS conversations, no doubt because the latter take place before a vast and imaginably astute radio audience. In situations of moderate casualness (e.g. the Pear Story recountings, Chafe 1980), a moderate number of YK and uh adjacencies are found. 
In the RTS materials 45 cases of adjacent $\mathrm{YKb}$ and uh occur. of these 35 are in the order uh YK, and ten are in the opposite order (chi square $6.94 ; \mathrm{p}<.01 ; \mathrm{df}=1)$.

Unfilled pauses are an even more stark sign of loss of control; relatively more pauses before than after YKb would therefore be expected. This expectation is strongly confirmed by the present data. Of 117 adjacencies of YK and pause, 88 are with the pause preceding, 19 with it following (chi-square $14.88 ; \mathrm{p}<.001 ; \mathrm{df}=1$ ).

Two other differences in the way YK and uh pattern were noted. 1) In many cases some item is followed by YKb after which that item is exactly repeated before the speaker continues. These are clauseinternal 'restarts':

(100) ...they can get- YK they can get close (ta you) [RTS18, 56]

(101) ...for instance they YK they have a- an area where [RTS6, 52)

YK is significantly less likely to intermit in these cases than is uh (clause-internal retracted restarts with YK/all clause internal $\overline{Y K}^{\prime} s=1 / 46 ;$ for $u h=15 / 76 ;$ chi-square $\left.16.68 ; \mathrm{p}<.001 ; \mathrm{df}=1\right)$. Why this should be the case is not clear. 2) The proposed core use of YK provides an explanation for the tendency of uh to occur much more frequently than YK after conjunctions. In issuing a conjunction, the speaker gives the addressee little to go on for the purpose of guessing what might come next. Conjunctions can be used to hold the speaking turn before the speaker has planned anything substantive to say. We would therefore expect to find uh after conjunctions more frequently than YK, and this is the case 13 (YK after conjunctions/ total $\mathrm{YK}^{\prime} \mathrm{s}=23 / 347$; for $\underline{\mathrm{uh}}=114 / 459$; chi-square $46.44 ; \mathrm{p}<.001$; $\mathrm{df}=1$ ).

\subsection{Conclusion}

In this chapter various hypotheses about the function of the discourse particle YK were examined. In each case it was argued that some particular function can be served by YKb because the basic use of the item is appropriate to that function. As in previous chapters, the intent was not to show that the item does not have multiple functions, but to show that a unified account of these functions proceeds naturally from considering how the basic use of the item is interpretable in particular conversational contexts. It is therefore inaccurate to consider YKb to be a 'device' especially 'marking' these functions. This claim would be odd in the same way that it would be odd to claim that "Can you tell me when there are trains to Boston" is a device for marking train schedule inquiries. Certainly this is the principal function to which this sentence can be put, but if it is considered a marker, we face the uncomforatble prospect of an essentially infinite set of such devices. 
These remarks should be tempered with some discussion of the conventionalization or routinization of $\mathrm{YKb}$. It is certainly true that, as a standard way of seeking or inviting confirmation of understanding, YKB has come to be routinely associated with several common conversational situations in which the speaker is uncertain how well $\mathrm{s} /$ he is getting across. But, just as in the case of well and like, the routinization has not obliterated the core use of $\mathrm{YKb}$, since, as in the case of well and like, the core use of YKb is consistent with the routine functions. In this chapter statistical evidence was brought to bear on this issue: distributional tendencies of the item demonstrate the relevance of the core use of YKb to its placement in conversation.

This analysis is not functional per se, but complements functional analyses by providing an answer to a fundamental question these other analyses raise: why is the particular item YKb used for the specific functions that it is, rather than some other item?

The basic use of YKb proposed above is not in the nature of a discovery--many writers have tried to specify the use of the item, and some have come relatively close to the formulation used in the present work. The addition attempted here has been to refine the statement of this item's use and to relate it to the diverse functional claims that have been made about YK. There seems to have been a failure to directly associate these functions with proposals about the general contribution of the item, perhaps because to do so weakens the claim that YKb stands as a 'marker' of any single function. YKb is not associated with certain discourse functions because it marks them but because its basic use is appropriate to each such function. The effort to identify distinct functions of $\mathrm{YKb}$ is not a waste of time: we must understand both the functions and their linguistic underpinning to have a balanced and complete account of this particle.

The present approach differs, however, from that in Goldberg $(1980,1981 \mathrm{a}, 1982 \mathrm{~b})$ in not claiming, as she does, "that there are [discourse] structural and functional properties which underlie the use of items like y'know". Rather, the principal claim made in the present work is that the range of functions of such items represents an interaction of the basic linguistic value of the item and specific discourse contexts.

The great frequency of occurrence of $\mathrm{YKb}$ in conversation is predictable from its core use. It appears in so many different places becuase this use is appropriate at any point at which the speaker is unsure of how well $\mathrm{s} /$ he is coming across. YKb is at home--though clearly optional--wherever the speaker feels that what $\mathrm{s} /$ he has just said, or will just now say in the shared world may not have had its desired effect in the other world. The frequency of use of YKb will obviously differ depending on many factors, including the relationship between conversants, the degree of fluency and clarity of what they say, feelings about the overuse of YK, and the perceived importance of the addressee's having understood some particular utterance. 
FOOTNOTES -- CHAPTER 5

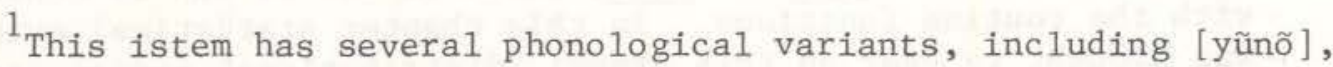
[yวัnõ], and [yõ]. The question of which variants occur in what discourse, phonological, and syntactic environments is not considered here. There is at least no straightforward correlation between any of these variants and the distinction drawn in this chapter between

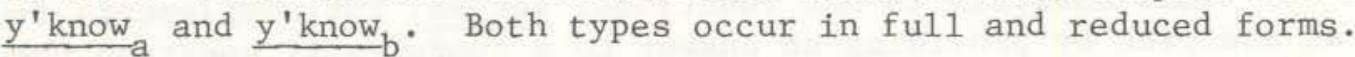

${ }^{2}$ As 'verbal garbage' $\mathrm{y}^{\prime}$ know is often classed with like (Chapter 3 ). This grouping finds its way into the popular literature on speech abuse in Newman's claim that YK and like are "much the same thing" $(1974: 15)$. As a comparison of the conclusions of Chapters 3 and 5 will indicate, YK and like are in fact quite different in function and distribution.

${ }^{3}$ A copy of a brief monograph on YK by Östman (1981) was received too late for review here. His formulation of the use of YK is similar in some ways to what is proposed below. I would, however, take issue with some aspects of Östman's statement of the "prototypical meaning" of YK and most importantly the emphasis he places on the propositional content of utterances with which YK occurs (cf. 5.4 below). Ostman's monograph contains intriguing sections on the acquisition of YK by children and on the differential use of YK by men and women.

${ }^{4}$ These trees are drawn as Ross drew them, with the verb first. This practice has since been abandoned.

${ }^{5}$ As Knowles points out, the constraint is semantic, not syntactic. Consider: John, I don't doubt, will win the race.

${ }^{6}$ Though superficially identical, y'see differs from YK in that only the former is necessarily cohesive. Thus (a) would be bizarre as the first utterance in a conversation, while (b) would not:

(a) Y'see, there's nothing like a Coke.

(b) Y'know, there's nothing like a Coke.

${ }^{7}$ YK is acceptable in these cases if, for example, Hello is understood as a quotation. YK is frequently used in the present data for unquoting. 
8 The usual restrictions on where speakers may insert interjectional pauses, however, remain in force (see p. 40) above.

${ }^{9} \mathrm{Claims}$ that initial $\mathrm{YK}$ is an attention getting device used in pretopical position square nicely with the core use of $\mathrm{YKb}$. The presumption of shared ground prior to issuing any contentive material has the effect of asserting something about the addressee's state of mind--namely its predictability in one respect. Speakers approach the matter of asserting the mental contents of others who are present gingerly. The potential face-threat involved withYK is normally attenuated by the obvious sociable intent of the speaker, but if intimacy is undesired by the addressee, the potential for offense is still present.

${ }^{10}$ This passage is an expansion of the propositional constituents of a segment of natural conversation, but it serves here to illustrate the point being made.

${ }^{11}$ The fact that there are cases where a turn change occurs just after YK would not, itself, constitute even weak evidence for the claim that YK is a turn signal. Statistical evidence is required since turns can change at any point. What must be shown is that turn change is more likely after a tag-positioned YK than at other points.

12 This view of uh is consistent with what is known about its positions of occurrence in conversation. No reliable differences have been found between the positions of occurrence of filled and unfilled pauses. It is known that unfilled pauses tend to occur at constituent boundaries, before the first content word of a phonological phrase, and bisecting major constituents (see Boomer 1965, Rochester 1973, and, especially, Grosjean et a1. 1979).

${ }^{13}$ Only the two most frequently occurring conjunctions in the present data were counted: and and but. No other conjunctions approach these in text frequency. 
6.1 General Remarks on Like, We11, and $\underline{Y^{\prime} \text { know }}$

This study has focused attention on the discourse particles like, well, and y'know, attempting to isolate a single core use for each one. This was possible in each case: like indicates a possible minor nonequivalence of what the current speaker will now immediately say (or has just now said) and what the speaker now has (or just now had) in mind to convey; well indicates that the speaker, at the time well is uttered, is consulting his or her current thoughts; y'know (Y $\overline{\mathrm{Kb}}$ ) checks (with a positive expectation) on the correspondence between what the speaker intends to convey and what the addressee has been able to grasp in regard to what the speaker has just said or is just about to say. In each case this core use survives regardless of the 'local' purpose the speaker may have in using the item at a particular position in discourse; and in each case the set of functions the item may serve makes sense in terms of its core use. Previous analyses of these items have not attended closely to the question of whether such a core use can be formulated, so that although various functions for these items have been identified, these analyses are in general unable to explain why individual particles serve the particular functions they do.

The question of what the linguistic contribution of these items is is complicated by their routinization as standard ways of dealing with recurrent conversational situations. Thus, for example, well can be used as a conventional way to introduce an abrupt change of topic. The point repeatedly made above regarding the varied conversational uses of these items is that the items do not, simply by virtue of becoming routines, lose their basic use. What can happen (as argued for like in Chapter 3) is that the basic use of the item can be dominated by some particular routine value. But that the basic use is only dominated, not obscured or lost entirely, through routinization is indicated by the fact that the conversational uses of the item are underlain, informed by, and consistent with the basic use, and by the fact that when the particles are scrutinized in situ in discourse their basic use illuminates descriptions offered by subjects of the 'meaning' of utterances containing the items (see Chapter 3 ).

Probably the failure of subjects to be able to isolate immediately the core use of $11 \mathrm{ke}$, well, and $\mathrm{YKb}$ is largely due to their inability to differentiate the core use from contextual and pragmatic factors, an expected and very general limitation on the usefulness of

$$
-102-
$$


linguistic intuitions.

In the most general portrayal these particles are all related to the disclosure of covert thinking. They all represent responses to problems arising due to the 'invisibility' of undisclosed thinking. Each participant in a conversation is aware of three 'worlds' of conversational activity: the private world of current disclosable thought; the shared world in which speakers collaborate in placing linguistic, paralinguistic and kinesic elements in view of each other in a particular sequence; and the other world, containing the disclosable but otherwise invisible thinking of some co-participant(s).

Particles such as like and well (and many others: see Chapter 2) are evincives: they permit the speaker to bring up, without thereby specifying, contents of the private world. Such items are a means of calling attention in a general way to the relevance at some particular point of thinking the speaker leaves partially undisclosed. The reasons for such partial disclosure are varied, depending on context and the speaker's communicative abilities and intentions. It is, notice, the partialness of the disclosure that renders an item evincive at all, for if disclosure were complete, the item would assume the status of an ordinary lexical item with a conventional and therefore shared meaning; notice also that while ordinary lexical items may be spoken accompanied by undisclosed thinking, only evincives specifically indicate that some such undisclosed thinking is underway.

YKb responds to the disclosure problem in a different way: here the speaker is concerned about the undisclosed contents of the other world and is, in particular, interested in whether the desired effect of his or her words obtains in that other world. A positive response, indicating that the private, and other worlds are in essential respects in harmony, is anticipated.

A distinction may be drawn between the disclosure problem just discussed and the kind of disclosure solicited when asking a question such as "What time is it?" By using this sentence the speaker also, obviously, seeks disclosure of information, but not specifically of thinking then current in the addressee's mind. Disclosure in the case of the discourse items well, l1ke, and YKb is of current (in real time) thought arising in connection with the events of an ongoing conversation ${ }^{2}$. Each of these items thus inhabits or responds to the 'now' of actual talk rather than some imagined, recalled, or profected now. The frequent characterization of these items as lubricants, punctuation devices, and so on, hints at their temporally local domain. Even when retrospectively quoted, these particles occupy some real (albeit reported) now at which they were spoken. They represent an acknowledgment by speakers that, despite the negotiated pace of actual talk, in both the private and the other world thinking runs apace: covert reactions occur always now and must be placed in the shared world if they are to be fointly known and responded to. 
Previous work on conversational behavior has largely--and understandably--been limited to what occurs in the shared world. As correctly and repeatedly stated by soclologists, what occurs there can be understood in terms of what else is said and done--what stands 'bonesout' for examination. The logic of the shared world of talk and other behavior is accessible because in general speakers place in that world what they mean to be understandable. On the other hand, however inaccessible they are to the nonparticipant researcher, the private and other worlds are of no less importance to the participants in a conversation than is the shared one. In fact, a major question for the speaker in conversation is how to effectively introduce what is private into the shared world, and how to properly and effectively obtain disclosure from the other world. A game of poker is an excellent analogy.

If we limit our attention to the shared world of talk, we thereby exclude two 'thirds' of what is involved when people converse. The importance of the unseen aspects of conversation is clearly shown by the very frequent use in conversation of discourse particles that specifically relate the covert worlds to the overt one. What conversants are thinking to themselves, unless disclosed or inferrable from what is said or done by them, remains perforce a mystery to anyone but them, but we can watch conversants orient in their talk to what is undisclosed and perform and solicit partial disclosures, and we can be mindful of the fact that linguistic behavior, from the speaker's vantage point, is even richer and more complex than displayed, recordable speech. This is not just a matter of some things being 'bewteen the lines'--a problem of inference and implicatures--but of material that underlies the proceedings but is not inferrable by all the coconversants.

Most of the remainder of this chapter is an attempt to provide a more general perspective on the discourse particles found in English conversations by answering the following question: What kinds of disclosure functions are represented by these particles? Or, to state the question in human terms: How do speakers connect public to private when they use discourse particles? In doing this, it will be necessary to discuss work by others on several particles beyond the three already discussed above at length (some of these additional items are first mentioned in Chapter 2; the reader is referred there for background).

\subsection{Now}

Schiffrin (1981b) finds that the 'discourse marker' now is used "to preface evidence, to precede a change in topic or sub-topic, a switch from main to subordinate topic, a switch in speaker stance, in speaker-hearer relationship, and so on" (14), and abstracts two common features of these environments: "they open something new and current in the discourse context [and there 1s] some kind of switch, or contrast with the immediately adjacent discourse" (14-15). 
This analysis of now fits the data of the present study, but a slightly different characterization of the use of now can be offered based on the notion of disclosure. In this connection it is of interest that now opens "something new and current". In this now is alligned with well, like, and YKb for being tied to a particular discourse moment. 3 We do not find the particle now leaving the present speaker's moment of utterance though, of course, the usual adverbial use of now may do so:

(1) They saw that they were now in the deepest part of the jungle.

Items tied to their moment of utterance may be viewed as intrusions fro.a the private world. R. Lakoff (1974) suggests the word 'stance' for what such items indicate; this may be clarified: it is the speaker's current stance toward what is right now occurring or has just now occurred or will now immediately occur in the conversation. The time line of the shared world is dictated by requirements of turntaking, topic development, sequencing conventions, and the necessity of taking time to say what may already be in mind. The items being discussed here, however, are not so bound. Although placed at particular points in the collaborative time line, they are used and taken as unfettered then-current reflections from the private world.

Viewed this way now is an item used by a speaker to indicate that what $\mathrm{s} /$ he is now/will now be saying ${ }^{4}$, is viewed by the speaker as a 'switch' from what has come just before and, by contrasting what came before with what is said next, also represents a larger continuity subsuming the switch. Thus now at the beginning of a lecture or a meeting evokes some pre-existing situation which (within the confines of the present proceedings) will now be abandoned in favor of an ensuing one. Now is an evincive since it has the two coincident properties of evincives: it is tied to the speaker's now of actual utterance, 5 and it indicates but does not specify current covert thinking on the part of the speaker. This second property is reflected in the fact that now indicates the existence of some perceived (by the speaker) discontinuity-within-continuity which the speaker has in mind, but leaves $1 t$ to the addressee to (if possible) determine the precise nature of the discontinuity. 6

Consistent with this portrayal of now its primary use is to indicate 'This belongs now'. Other aspects of the use of the 1 tem arise from what issuing an evincive with this basic use implicates in particular conversational contexts. Since speakers say things purposefully, someone who would indicate 'This belongs now' would normally only do so in situations in which to so indicate would advance that speaker's communicative purposes. Presumably, then, now--if 'This belongs now' were its basic use--would only be said if it mattered.

Consider the separate elements of use isolated by Schiffrin:

1. It opens something new. To indicate 'Th1s belongs now' $1 \mathrm{~m}$ plies that what follows requires a disjunctive preface; since the speaker is bringing up the fact that what happens next belongs next, the 
appropriateness of bringing it up next is brought into question. If the prefaced item is not obviously something that belongs next, it will be 'new'.

2. It opens something current. This follows from the evincive status of now: its use is related to the now of the current speaker's current utterance, the now in which the sequentially next item of talk is about to occur.

3. There is a switch or contrast with the immediately adjacent discourse. This follows i) from the fact that cooperative speakers should not abruptly change to completely unrelated material in a conversation without providing for the reasonableness (or the unreasonableness) of the switch in some way (e.g. by issuing by the way, or I know this is unconnected but...); since 'This belongs now' does not specifically provide for an abrupt and complete change, the usual convention is in order: what is said should be related somehow to foregoing material (which is, roughly, Grice's Maxim of Relevance); and ii) from the fact that the speaker nevertheless has some reason to utter 'This belongs now'. The continuity is presumed, and the discontinuity-withincontinuity is provided for by now itself. The material now introduces is both presumed relevant (a contribution of a cooperative speaker) and implicated to be discontinuous with preceding material. As Schriffrin points out, the contexts in which this item receives its interpretation may be of various kinds: discourse, referential, expressive. The particular discontinuity is something the speaker is privy to but which addressees must reconstruct, if they can and if they wish, for themselves.

\subsection{I mean}

The discourse item I mean is discussed at length in Goldberg (1976, 1980); Crystal and Davy (1975) devote two concise pages to it. The use of the phrase is suggested by its literal meaning; the item is found in repair situations where it "marks the contribution as a modifying or clarifying continuation of the previous (usually the speaker's own) contribution" (Goldberg 1980:124-125). The functions of the item in particular discourse environments may vary according to how the basic corrective or clarifying core use is applicable in the particular context at hand. Thus I mean "may redirect the ongoing talk by introducing 'modifications' which both correct and add to the previous contribution" (125), or it may regain the floor (25la) by signaling "that the intervening turn interrupted the speaker" (127), or, in utterancemedial position, "tends to repair a prior phonological or grammatical error" (244). The description of the item offered by Crystal and Davy is essentially in harmony with Goldberg's. They claim

The meaning of this phrase is extraordinarily difficult to define: it seems to perform a variety of semantic functions, some of which are more important than others in any given instance. Generally speaking, its main function is to indicate that the speaker wishes 
to clarify the meaning of his immediately preceding expression. This clarification may stem from a number of reasons and take a number of forms (1975:97).

In the framework of the present study, I mean may be regarded as an item with a disclosure function. I mean appears to be used to indicate that what the speaker has said and what the speaker has in mind to express are not well matched. Or one might say that I mean indicates a nonequivalence of what is in the shared world and what is in the private world. This is similar to the characterization of 1 ike, but the items differ in that like indicates a minor nonequivalence, one the speaker finds unlikely to result in an important misunderstanding of the intended meaning; while I mean indicates that what is said and what is meant may well be substantially nonequivalent and, unless repair is undertaken, could lead to misunderstanding. It is thus important that I mean, but not like, prefaces corrections.

I mean is evincive since it is tied to its moment of utterance and indicates but does not itself specify the nature of the nonequivalence the speaker finds to exist between what is said and what is meant. Typically (but not in every, case) the speaker's intention is spelled out in what follows I mean. 7

\subsection{Mind You}

Mind you as a feature of British English is discussed in Crystal and Davy (1975:99-100). They comment:

This is another phrase whose meaning is extremely difficult to delimit. We have noted a number of different 'strands' of meaning, of which the most important seems to be the expression of some kind of contradiction, with a reduced or apologetic force. The speaker feels the need to state a different or additional viewpoint from what he or other speakers have already expressed, but he wishes to do this without causing offense... In addition, mind you is used to express the speaker's awareness that he is (a) saying something controversial, and is worried about the possibility of being disagreed with later, or (b) saying something which he thinks is obvious but which his listener may dispute (100).

Taking this description at face value, it would seem that the use of mind you parallels that of the other items so far discussed, but that the specific function of this item is to indicate a nonequivalence of what the speaker has injected into the shared world and what $s / h e$ expects may have arisen in the other world as a result. The 1tem is thus also characterizable as having a disclosure function in that it indicates the possibility of the topical relevance but ultimate insignificance of material that has just arisen or may now arise in the other world. This characterization of mind you is intended as a provisional and possibly incomplete one, but one which captures certain key features of the item's use. 
6.5 Sort of, Kind of, And everything, And stuff, And so on, etc.

Such items as sort $o(f)$ and kind o(f) (discussed in Crystal and Davy 1975:98-99) were claimed above (Chapter 3) to be related in function to like in indicating a possible minor nonequivalence of what is said and what is meant. The analysis of Crystal and Davy accords well with this assessment: "These phrases may be used immediately befor any word or phrase about which there is uncertainty, vagueness, or idiosyncracy". Such phrases may follow the item in question, of course:

(2) She was carrying it in (h)er hands sort of.

These items differ from like in not being used to introduce utterances:

(3) * Sort of, I handed her the letter of intent.

Several items can be used utterance-finally to indicate that the speaker is not saying everything that might be said. For example:

(4) He came home last night bangin(g) the door an(d) everything. $[\mathrm{LAB}-\mathrm{A}, 30]$

(5) Somebody would have ta get up at four $0^{\prime} c l o c k$ in the morning ta take me ta Wooster y'know and all that stuff. [LAB-A,36]

(6) I really don't think they'd play in any bar or anything [LAB-A]

These items fairly obviously indicate that some contents of the private world are being withheld from the shared world because they would add nothing essential to what has been said, or because for some other reason the speaker chooses not to express them. They therefore evince the availability of more material in the private world than is presented in the shared world.

\subsection{Interjections}

There appears to be a fundamental identity between many items referred to as interjections and those considered discourse particles or markers. Both represent partial intrusions from the private world and arise from the necessities of disclosure. Some of these items, because of their basic use, have multiple discourse functions connected with such notions as topic development and topic change, but all share the property of being free, in interpretation if not always in placement, of the 'negotiated' time line of shared talk, and of acknowledging the existence, relevance, and (most often) general tenor of undisclosed thought. The use of several items first discussed in Chapter 2 can now be fully appreciated:

1. $\mathrm{Oh}_{1}$ indicates that the speaker has just now become aware of something covertly and wishes to display that this private world event, the exact nature of which is not specified by ohl, has occurred.

2. $\mathrm{Oh}_{2}$ indicates that the speaker has now paused to make a decision or choice between alternatives, no one of which is the correct or accurate one (see James 1974); the 1tem is evincive because the alterna- 
tives and the course of the decision process are not displayed by $\mathrm{oh}_{2}$ itself.

3. $\mathrm{Oh}_{3}$ is similar in use to well; it evinces introspection.

4. Hey indicates that the speaker is with thought at the time of uttering hey and desires the addressee's attention in order to place material into the shared world.

5. Aha indicates that the speaker has just now covertly pieced together the logic of a situation or seen a connection previously missed. The particulars of the connection seen are not displayed by using aha itself.

6. Ah indicates that the speaker has fust now thought of something and finds that thing, or having thought of it, pleasing or significant (see James 1974), but does not say what the thing is exactly.

7. Uh, according to James (1974), indicates "speaker is hesitating to try to think of the best or most accurate thing to say next, or to remember something, or is reluctant to say what is to follow". She adds, "uh is very commonly used when the speaker has any uncertainty at all about what he is saying, or about whether he is using the right words, or even about how his addressees are reacting to him" (1974:87). The use she assigns to uh is thus not very specific. Apparently it boils down to the speaker's having paused for some reason--any reason-and marking this as a pause (rather than, say, a definitive halt). James shows that there are several differences between uh and the other interjections she studied, but looking at her arguments carefully one finds that in every case the 'meaning difference' is a result of some other interjection having an element of meaning that uh lacks. The item thus appears to mark pauses of unspecified nature.

In every case, these interjections are capable of serving as discourse particles in the sense that with their basic contribution they can take on particular discourse functions. Thus, for example, even uh can assume such a function if uttered in the proper context. Consider the uh issued by a member of a large audience three sentences into a formal lecture by a well-known visiting scholar. Or consider the role of oh 1 in its use by the same scholar upon discovering a page of text missing in the lecture. Clearly such items are important for structuring discourse.

\subsection{A Taxonomy}

The relevance of disclosure to the analysis of the frequently occurring discourse particles in English conversation should by now be clear. The items discussed include most of those found in large numbers in the conversations used for this study. Because of this, it is possible here to offer a tentative sketch of the domain of discourse particles in English. This taxonomy reveals the types of disclosure functions served by the most common discourse particles. 
Table 4 lists the disclosure relationships relevant for the description of items discussed in this study. Items listed in each category constitute exemplary members of a set each member of which differs from the others in the set but is generally classifiable in the way indicated.

TABLE 4

DISCLOSURE RELATIONSHIPS AND DISCOURSE PARTICLES

Items

wel1, let me see, $\underline{o h}_{3}$

$\underline{\mathrm{uh}}$, um

mind you (Br. E.)

like, sort o(f), kind o(f)

I mean, that is

aha, ah, oh, man, hey

y'know, $y^{\prime}$ see

an(d) stuff, oh 2
General Disclosure Function

indicates:

$P$ now active

$P$ now faltering temporarily

$\mathrm{O} \neq \mathrm{P}$ but $\mathrm{S}=\mathrm{P}$

$\mathrm{S} \cong \mathrm{P}$

$\mathrm{P} \neq \mathrm{S}$

something has arisen in $\mathrm{P}$

check:

$0=P$, doesn't it?

$S \ll P$

$$
\begin{aligned}
& P=\text { Private world } \\
& S=\text { Shared world } \\
& O=\text { Other world }
\end{aligned}
$$

The relationships not occurring in this taxonomy can, in some cases, be expressed through circumlocutions. But the existence of common routine items for expressing certain relationships and not others probably reflects the prevailing dynamics of conversations. It is not surprising, for instance, that there are no items for marking 
that something has suddenly arisen in the other world. To claim the existence of undisclosed thought in the other world is ripe with potentially disastrous implicatures ('you are predictable--you mind is an open book') The offense occurs enough to have names: putting words in someone's mouth, second guessing.

\subsection{Conclusion}

The problem of disclosure arises within the general communicative purpose of speech. The problem arises because conversants are engaged in a complex form of behavior in which some of what occurs is displayed as occurring by being placed in view in the shared world, while thoughts may remain undisclosed. Speakers frequently call attention, for reasons varying with their communicative aims, to what is occurring beneath the 'visible' surface of a conversation. The disclosure problem is that what is covert may to some extent and for some reason be relevant to what is not. In this study the function of items usually called discourse particles and interjections has been examined. It was found that each such item has a core use related to disclosure and, based on that core use, a variety of secondary functions depending on specific conversational contexts.

Each of the items discussed is used, generally speaking, to relate what is covert to what is overt in ongoing conversational behavior. The relationships involved here have been described in terms of three 'worlds': the one known to the speaker alone, that known to the addressee $(s)^{8}$ alone, and the world known to both. The disclosure problem may in individual cases involve the incongruity between what is shared and what is private, the invisibility of the other world to the speaker, the incongruity between what is presumed to be in the other world and what is in the private one, and so on.

The particles discussed in this study differ in the ways in which they respond to the general problem of disclosure. Like is a response to the nonequivalence of what is shared and what is privately intended; well indicates in the shared world that consideration is occurring in the private world; YKb responds to the need of speakers to be assured of the equivalence of the private and other worlds in some crucial respects with regard to what is being said. Several other discourse items may be characterized in similar ways, and, in fact, it appears that disclosure may be relevant to the description of almost all discourse particles and many of the items traditionally referred to as interjections.

The program of this study has been to isolate a core use for each discourse particle considered and then examine the disclosure functions of the entire set of such items. Therefore, in contrast to earlier studies of disclourse particles, the emphasis here has not been on identifying multiple discourse functions for each item, but on providing an explanation for why each particle is capable of serving the various context-specific functions that it does. The results of this study 
therefore contribute to our understanding of the general function of discourse particles. In that sense, the view proposed here is not an alternative to functional analyses like those of Goldberg but illuminates what is correct in these other studies both by clarifying the core use of particular items and providing a general framework in which their core uses can be compared.

The results of this study also bear importantly on a basic issue in semantics: that of ambiguity versus vagueness (see Zwicky and Sadock 1973). For each of the three discourse particles examined at length above, it has been possible to find a way through the multiple readings to a single basic use. Additional readings of each item can be predicted from features of the context and conversational implicatures. This work is thus aligned with recent work (e.g. Atlas 1977, Kempson 1980 , 1981) suggesting that in most cases it is possible to regard additional understandings of an item as due to lack of specificity rather than to true ambiguity.

So long as conversation is viewed as solely a matter of what is displayed and openly reacted to by conversants, and of background understandings they share, and of what is inferrable from their external behaviors, it remains accessible to the researcher. As a working assumption, most conversation studies take the shared world to be somehow independent of what occurs privately in the minds of the conversants. This methodological tack is not only convenient but has a powerful logic to recommend it--after all, individual conversants, in choosing what they will do and say next, attend to what they and their co-conversants have said and done. Examination of discourse particles, such as well, like and y'know, however, points up the fact that each individual participant in a conversation is aware that some thoughts are not disclosed and of the fact that conversants enter material selectively in the shared world. Although the private and other worlds are essentially inaccessible to the nonparticipant observer, their existence cannot be ignored--particularly since speakers themselves often acknowledge to each other, in a number of ways, the existence and importance of their own unexpressed thinking. 
${ }^{1}$ It is interesting, though probably not very fruitful, to ask how the addressee is to know whether his or her understanding matches the intent of the speaker.

${ }^{2}$ of course, much is left unsaid in conversation in general, but this is not indicated by most of the items we use in talk.

${ }^{3}$ As the reader will have gathered already, the conversational 'now' is not a single point in time; it has dimension and can contain, at least, a whole utterance.

${ }^{4}$ This wording is necessary because now can be embedded in an utterance it introduces:

There were, now, three bears in that part of the forest.

${ }^{5}$ Because it is tied to the present speaker's moment of utterance and because it is used predominantly as an initiator, now enquotes (see Chapter 2):

She thought there were typewriters in Greece at that time. She thought now there were typewriters in Greece at that time.

${ }^{6}$ other kinds of lexical items also require contextual interpretation (for example, deictic terms) but not tied to the present moment of utternace and cannot be viewed as intrusions from the private world.

${ }^{7}$ I mean also occasionally follows the clarification it announces:

There were five apples in the basket, I mean.

${ }^{8}$ The term 'addressee' has been used throughout this study. It is not entirely acceptable, but then neither are '1istener', 'interlocutor', 'auditor', 'hearer', etc. In general I have used the term simply to mean 'some attentive participant in a conversation other than the current speaker'. 


\section{LIST OF REFERENCES}

Atlas, J. 1977. Negation, ambiguity, and presupposition. Linguistics and Philosophy 1.321-336.

Banfield, Ann. 1973. Narrative style and the grammar of direct and indirect speech. Foundations of Language 10.1.1-40.

Bernstein, Basil. 1961a. Social class and linguistic development: a theory of social learning. Education, economy and society, A. H. Halsey, J. Fluid and A. Anderson (eds.).

1961b. Social structure, language and learning. Educational Research 3.

1962a. Social class, linguistic codes, and grammatical elements. Language and Speech 5.221-240.

1962b. Linguistic codes, hesitation phenomena and intelligence. Language and Speech 5

Boomer, Donald S. 1965. Hesitation phenomena and grammatical encoding. Language and Speech 8.148-149.

Butters, Ronald R. 1980. Go 'say'. American Speech 55.304-307.

Bryant, Margaret M. (ed.). 1962. Current American usage. Funk and Wagnalls: New York.

Chafe, Wallace L. (ed.). 1980. The pear stories: cognitive, cultural and linguistic aspects of narrative production. Ablex: Norwood, New Jersey.

Clark, Herbert H. and Wade French. 1981. Telephone 'goodbyes'. Language in Society 10.1-19.

Copperud, Roy H. 1972. A dictionary of contemporary and colloquial usage. Avenel Books: New York.

---- 1980. American usage and style. Van Nostrand Reinhold: New York.

Coulmas, Florian (ed.) 1981. Conversational routine. Mouton: The Hague.

Crystal, David and Derek Davy. 1975. Advanced conversational English. Longman: London.

DuBois, J. W. 1974. Syntax in mid-sentence. Berkeley studies in syntax and semantics V.1:III(1-25). Institute of Human Learning. Department of Linguistics, Univeristy of California, Berkeley. 
Duncan, Starkey, Jr. and Donald W. Fiske. 1977. Face-to-face interaction. Lawrence Erlbaum Associates: Hillsdale, New Jersey.

Follett, Wilson. 1966. Modern American usage: a guide. Hill and Wang: New York.

Freeland, L. S. 1951. Language of the Sierra Miwok. Suppl. to International Journal of American Lingusitics 17.1. Indiana University Publications in Anthropology and Linguistics. Memoir \#6 of I.J.A.L.

---- and Sylvia M. Broadbent. 1960. Central Sierra Miwok dictionary with texts. University of California Publlications in Linguistics V.23. University of California Press: Berkeley.

Fries, Charles Carpenter. 1952. The structure of English. Harcourt Brace and World: New York/Burlingame.

Garfinkel, Harold. 1964. Studies of the routine grounds of everyday activities. Social Problems 11.3. (Reprinted in Sudnow).

Goffman, Erving. 1976. Replies and responses. Language in Society 257-313.
1978. Response cries. Lg. 54.4.787-815.

Goldberg, Julia A. 1976. The syntax, semantics, pragmatics and sociolinguistics of some conventionalized parenthetical clauses in English: 'you know' and 'I mean'. Unpublished diploma dissertation, Department of Linguistics, Cambridge University (England).

---- 1980. Discourse particles: an analysis of the role of 'y'know', 'I mean', 'well', and 'actually' in conversation. Ph.D. dissertation, Cambridge University (England).

---- 1981. Track that topic with 'y'know'! Paper presented to the 1981 Summer Conference on Conversational Interaction and Discourse Processes. University of Nebraska, Lincoln.

---- 1982. Hey, y'know, have I got a topic for you. Unpublished paper.

Goodwin, C. 1975. The interactive construction of the sentence within the turn at talk in natural conversation. Everyday language: studies in ethnomethodology, G. Psathas (ed.) Irvington: New York. Distributed by Halstead Press (division of John Wiley \& Sons: New York/London.

Greenbaum, Sidney. 1970. Verb-intensifier collocations in English: an experimental approach. Mouton: The Hague.

----, Sidney and Randolph Quirk. 1970. Elicitation experiments in English: Linguistic studies in use and attitude. Longman: London.

Grice, H. P. 1967. William James Lectures. Published in part as 'Logic and Conversation' in Syntax and Semantics 3 (Speech acts), P. Cole and J. L. Morgan (eds.), 1977, 41-58. Seminar Press: New York. 
Grosjean,Francois, Lysiane Grosjean,and Harlan Lane. 1979. The patterns of silence: performance structures in sentence production. Cognitive Psychology 11.58-81.

Hines, Carole P. 1977. "We11,...". The Fourth Lacus Forum, Michel Paradis (ed.), 308-318. Hornbeam Press: Columbia, South Carolina.

House, Juliane and Gabriele Kasper. 1981. Politeness markers in English and German. In Coulmas.

Jackendoff, Ray. 1972. Semantic interpretation in generative grammar. M.I.T. Press: Cambridge, Massachusetts.

James, Deborah. 1972. Some aspects of the syntax and semantics of interjections. Papers from the Eighth Regional Meeting of the Chicago Linguistic Society, P. Peranteau et al. (eds.).

---- 1973. Another look at, say, some grammatical constraints on, oh, interjections and hesitations. Papers from the Ninth Regiona1 Meeting of the Chicago Linguistic Society, C. Corum et al. (eds.).

---- 1974. The syntax and semantics of some English interjections. University of Michigan dissertation. University of Michigan Papers in Linguistics 1.3 .

---- 1978. The use of 'oh', 'ah', 'say', and 'well' in relation to a number of grammatical phenomena. Papers in Linguistics 11/3-4. 517-535.

Jefferson, Gail. 1972. Side sequences. In Sudnow.

---- 1973. A case of precision timing in ordinary conversation. Semiotica 9.1.47-96.

---- 1978. Sequential aspects of storytelling in conversation. In Schenkien.

Jespersen, Otto. 1923. Language: its nature, development and origin. Allen and Unwin: London.

Joseph, Brian D. 1982. Hittite iwar, wa(r), and Sanskrit iva. Zeitschrift fUr vergleichende Sprachforschung 96.

---- and Lawrence Schourup. 1982. More on (i)wa(r). To appear in Zeitschrift fur vergleichende Sprachforschung 96.

Keller, Eric. 1981. Gambits: conversational strategy signals. In Coulmas.

Kempson, R. M. 1980. Ambiguity and word meaning. Studies in English 1inguistics, S. Greenbaum, G. Leech and J. Svartvik (eds.), 7-16. Longman: London.

----- and Annabel Cormack. 1981. Ambiguity and quantification. Linguistics and Philosophy 4.2.259-310.

Knowles, John. 1980. The tag as a parenthetical. Studies in Language $4 \cdot 3 \cdot 379-409$. 
Labov, William and David Fanschel. 1977. Therapeutic discourse: psychotherapy as conversation. Free Press: New York.

Lakoff, George. 1972. Hedges: a study in meaning criteria and the logic of fuzzy concepts. Papers from the Eighth Regional Meeting of the Chicago Linguistic Society, P. Peranteau et al. (eds.).

Lakoff, Robin T. 1973. Questionable answers and answerable questions. Papers in Honour of Henry and Renée Kahane, B. Kachru (ed.). University of Illinois Press: Urbana. 453-467.

---- 1974. Linguistic theory and the real world. Berkeley Studies in Syntax and Semantics, V. 1, Department of Linguistics and Institute of Human Learning, University of California, Berkeley.

Landy, Eugene E. 1971. The underground dictionary. Simon and Schuster: New York.

Lanyon-Orgill, Peter A. 1960. A grammar of the Raluana language. Published by the author: 1701 Beach Drive, Victoria B.C., Canada.

Laver, John. 1981. Linguistic routines and politeness in greeting and parting. In Coulmas.

Literary Digest. 1937. 1.1 or 1.24 (December 11). No. 22.8-9. Like disliked: of the President's abuse of 'like' and of other presidents' difficulties with formal diction.

Lomas, Charles W. and Ralph Richardson. 1956. Speech: idea and delivery. Houghton Mifflin: Boston.

MacDonnel1, A. 1971. A Vedic grammar for students. Oxford University Press: Bombay.

Major, Clarence. 1970. Dictionary of Afro-American slang. International Publishers: New York.

Malinowski, B. 1946. The problem of meaning in primitive languages. Supplement I to Meaning of meaning, C. K. Ogden and I. A. Richards (eds.). Routledge \& Keegan Paul: London.

Matisoff, James A. 1973. The grammar of Lahu. University of California Publications in Linguistics 75. University of California Press: Berkeley.

Murray, Dinah. 1979. Well. Linguistic Inquiry 10.727-732.

Newman, Edwin. 1974. Strictly speaking: will America be the death of English? Bobbs-Merrill: Indianapolis.

Östman, Jan-0la. 1981. You know: a discourse functional study. John Benjamins: Amsterdam.

Oxford English Dictionary. 1933. Clarendon Press: Oxford, England.

Partridge, Eric. 1970. A dictionary of slang and unconventional usage. Macmillan: New York.

Powell, Mava Jo. 1981. The notion of literal meaning in speech act theory. Nottingham Linguistic Circular 10.1.1-24. 
Quirk, Randolph and Jan Svartvik. 1966. Investigating linguistic acceptability. Mouton: The Hague.

Rochester, S. R. 1973. The significance of pauses in spontaneous speech. Journal of Psycholinguistic Research 2.51-81.

Ross, John R 1973. Slifting. The formal analysis of natural languages, M. Gross, M. Halle and M. P. Schutzenberger (eds.) Mouton: The Hague.

Rotenberg, Joel. 1978. The syntax of phonology. Ph.D. dissertation, M.I.T., Linguistics.

Sacks, Harvey, Emanuel A. Schegloff and Gall Jefferson. 1974. A simplest systematics for the organization of turn taking for conversation. Lg. 50.4.696-735.

Sadock, Jerrold M. 1969. Hypersentences. Papers in Linguistics 1.2.283-370.

Schegloff, Emanuel A. 1978. The relevance of repair to syntax-forconversation. Ms. Department of Sociology, University of California at Los Angeles (cit. by Goldberg 1980).

1981. Discourse and conversation: 'uh huh' and other things that come between sentences. Paper given at Georgetown University Round Table on Languages and Linguistics, 3/20/81. and Harvey Sacks. 1973. Opening up closings. Semiotica 8.289327.

-_--, Gall Jefferson and Harvey Sacks. 1977. The preference for self-correction in the organization of repair in conversation. Lg. 53.2.361-382.

Schenkein, Jim (ed.). 1978. Studies in the organization of conversational interaction. Academic Press: New York.

Schiffrin, Deborah. 1981a. Tense variation in Narrative. Lg. 57.4562 .

---- 1981b. Accountability in discourse analysis: the case of 'now'. Paper read at New Ways of Analyzing Variation in English X, 10/ 24/81, Philadelphia, Pennsylvania.

Schourup, Lawrence. 1981. The basis of articulation. Ohio State University Working Papers in Linguistics 25.1-13.

---- 1982. Quoting with go 'say'. American Speech 57.2.148-149.

Sharrock, W. W. and R. Turner. 1978. On a conversational environment for equivocality. In Schenkein.

Shimanoff, S. and J. Brunak. 1977. Repair in planned and unplanned discourse. Discourse across time and space, O. Keenan and T. L. Bennett (eds.) Southern California Occasional Papers in Linguistics $\# 5$, May 1977. Department of Linguistics, University of Southern California, Los Angeles. 
Sudnow, David (ed.). 1972. Studies in social interaction. Free Press: New York.

Svartvik, Jan. 1980. 'We1l' in conversation. Studies in English for Randolph Quirk, Sidney Greebaum et al. (eds.). Longman: London.

Tannen, Deborah. 1979. Toward a theory of conversational style: the machine-gun question. Paper read at the L.S.A. Annual Meeting, 12/27/79, Los Angeles, California.

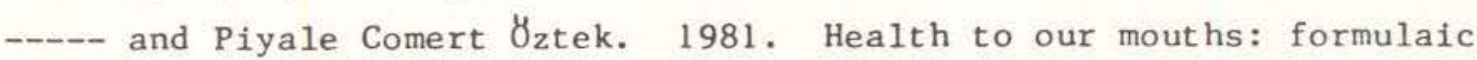
expressions in Turkish and Greek. In Coulmas.

Urdang, Laurence. 1979. Replies. American Speech 54.77-79.

Urmson, J. D. 1963. Parenthetical verbs. Philosophy and ordinary language, C. E. Caton (ed.). University of Illinois Press: Urbana.

Webster's Third New International Dictionary. 1966. G. and C. Merriam Co.: Springfield, Massachusetts.

Wentworth, Harold and Stuart Berg Flexner. 1960. A dictionary of American slang. Thomas Y. Crowe11: New York.

White, William. 1955. Wayne University slang. American Speech 30.4. 301-305.

Whitman, C. Dale. 1974. 'Like' as a conjunction. American Speech 49. $1 / 2.156-158$.

Wood, Frederick T. and Robert J. Hill. 1979. Dictionary of English Colloquial idioms. A. Wheaton: Exeter, G.B.

Woolford, E. 1979. The developing complementizer system of Tok Pisin: syntactic change in progress. The genesis of language, K. Hill (ed.) (The First Michigan Colloquium). Karoma: Ann Arbor.

Wright, Thomas. 1857. Dictionary of obsolete and provincial English. Henry G. Bohn: London. (Reprinted 1967: Gale Research Co., Detroit).

Zwicky, Arnold M. and Jerrold Sadock. 1973. Ambiguity tests and how to fail them. Ohio State University Working Papers in Linguistics 16. 1-36. 